\begin{abstract}
UNIVERSIDADE DE SÃO PAULO
FACULDADE DE ECONOMIA, ADMINISTRAÇÃO E CONTABILIDADE DEPARTAMENTO DE ADMINISTRAÇÃO PROGRAMA DE PÓS-GRADUAÇÃO EM ADMINISTRAÇÃO
\end{abstract}

BATALHA TECNOLÓGICA DO VEÍCULO ELÉTRICO: UMA ANÁLISE DA CORRIDA AUTOMOBILÍSTICA DA GM PELO PROJETO DOMINANTE

\author{
Aluna: Cristina Lau Chu \\ Orientador: Prof. Dr. Abraham Sin Oih Yu
}

SÃO PAULO

2013 
Prof. Dr. João Grandino Rodas

Reitor da Universidade de São Paulo

Prof. Dr. Reinaldo Guerreiro

Diretor da Faculdade de Economia, Administração e Contabilidade

Prof. Dr. Adalberto Américo Fishmann

Chefe do Departamento de Administração

Prof. Lindolfo de Galvão de Albuquerque

Coordenador do Programa de Pós-Graduação em Administração 
CRISTINA LAU CHU

\section{BATALHA TECNOLÓGICA DO VEÍCULO ELÉTRICO: UMA ANÁLISE DA CORRIDA AUTOMOBILÍSTICA DA GM PELO PROJETO DOMINANTE}

Dissertação apresentada ao Departamento da Faculdade de Economia, Administração e Contabilidade da Universidade de São Paulo como requisito para a obtenção do título de Mestre em Ciências

Orientador: Prof. Dr. Abraham Sin Oih Yu

Versão Revisada

SÃO PAULO

2013 
FICHA CATALOGRÁFICA

Elaborada pela Seção de Processamento Técnico do SBD/FEA/USP

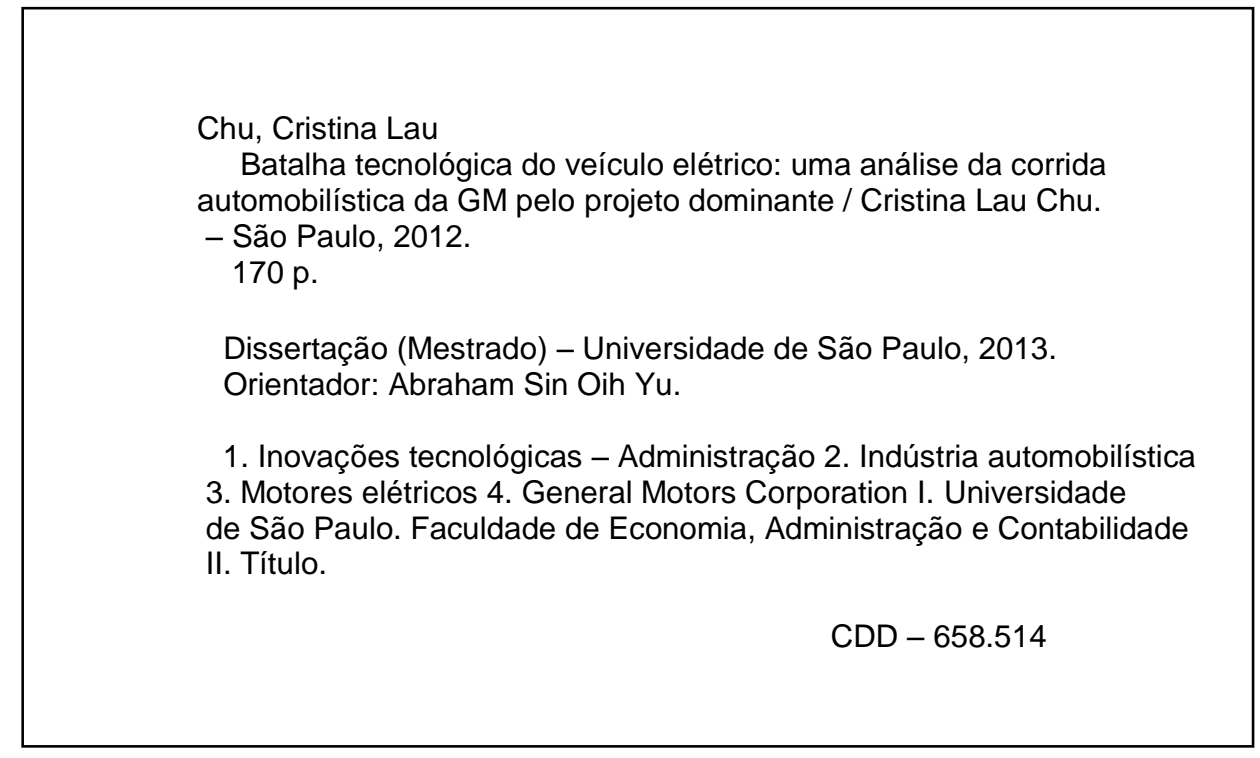


Ao meu pai, em memória; e ao apoio e paciência incondicionais dos meus irmãos e da minha mãe. 


\section{AGRADECIMENTO}

Gostaria de expressar a minha gratidão ao Professor Abraham Yu que me ofereceu a oportunidade de realizar esse estudo através da sua orientação, da sua sabedoria e do seu

exemplo como pessoa. À minha família e aos meus amigos, em especial o William, o Tony e o Renato, agradeço a incomensurável compreensão, paciência e companheirismo, que foram fundamentais ao longo desse estudo. ̀̀ minha mãe, agradeço o carinho imprescindível, que incentivou a progredir continuamente. Ao meu pai, em memória, expresso a minha eterna admiração. 


\section{RESUMO}

A presente pesquisa viabilizou, possivelmente, a expansão do arcabouço teórico desenvolvido por Suarez (2004) e Lynn et al. (1996), seguindo a mesma direção dos resultados obtidos na pesquisa longitudinal desenvolvida por Yu et al. (2011).

Desenvolvemos um estudo descritivo de modo a analisar um período de 42 anos com o objetivo de entender os fatores que influenciaram a trajetória do desenvolvimento da tecnologia do veículo elétrico na GM de modo que utilizamos o arcabouço teórico desenvolvido por Suarez (2004) como norteador das observações empíricas. Assim, construímos o estudo de caso da GM através da coleta de dados secundários da tecnologia de baterias da fase um (construção de P\&D) e da tecnologia do veículo elétrico das fases dois (protótipos) e três (lançamento comercial) da estrutura conceitual do Suarez (2004). As observações dessas fases viabilizaram os seguintes resultados: a possível expansão do arcabouço conceitual do Suarez (2004) em relação ao nível da firma (sondagem e aprendizagem tecnológica, sondagem e aprendizagem mercadológica) e ao nível do ambiente (características do campo tecnológico, política de apoio ao $\mathrm{P} \& \mathrm{D}$, pressão social); e a possível ampliação da vertente teórica de sondagem e aprendizagem mercadológica desenvolvida por Lynn et al. (1996) no sentido de constatarmos a sondagem e aprendizagem tecnológica em um momento anterior a sondagem e aprendizagem mercadológica.

$\mathrm{Na}$ década passada, iniciou-se um processo de efervescência de novos entrantes na indústria do veículo elétrico. Nesse período, a Toyota lançou comercialmente o Prius e está com dificuldade de inserção mercadológica da tecnologia. E, nesta década, duas das principais montadoras mundiais (GM e Nissan) lançaram comercialmente a tecnologia com intenção de produção em larga escala. Esse contexto evidencia a relevância acadêmica do entendimento dos fatores internos e externos que influenciam no surgimento do projeto dominante, indo ao encontro da trajetória de pesquisa iniciada por Abernathy e Utterback (1978). Dessa forma, as contribuições teóricas obtidas nessa pesquisa podem apoiar o processo de tomada de decisão no contexto de incentivo a essa tecnologia tanto da perspectiva da firma quanto da perspectiva do governo. 


\begin{abstract}
In alignment with the results obtained in the longitudinal research conducted by Yu et al. (2011), the present study possibly enabled the expansion of the theoretical framework developed by Suarez (2004) and Lynn et al. (1996).

A descriptive study was developed so as to analyse a 42 year period with views to understanding the factors which influenced the course of development of electric vehicle technology at GM. Thus, to guide empirical observations, the theoretical framework developed by Suarez (2004) was employed. To build the study case, we collected secondary data of battery technology in phase one (R\&D build up) and electric vehicle technology in phase two (prototypes) and three (market creation) of the conceptual framework developed by Suarez (2004). Findings observed in these phases gave rise to the following results: the possible expansion of Suarez's (2004) conceptual framework at corporate level (technological probe and learn, market probe and learn) and at environment level (characteristics of technological field, R\&D policy, social pressure); and the possible extension of the theoretical market probe and learn line of thought developed by Lynn et al. (1996) in as much as the identification of the occurrence of technological probe and learn, at a moment preceding that of market probe and learn, is concerned.

Over the last decade, a new entrant commotion process sprung within the electric vehicle industry. On that period, Toyota launched Prius and is struggling in realizing the interface between the technology and the market successfully. On the current decade, two of the top world manufacturers (GM and Nissan) launched their first electrical vehicles for mass production purposes. This context indicates the academic relevance in understand the internal and external factors which influence the emergence of the dominant design, developing the theorectical trajectory iniciated by Abernathy and Utterback (1978.) To this effect, the theoretical results obtained in this study may support decision processes in as much as incentives are concerned, both from a corporate and government perspective.
\end{abstract}




\section{SUMÁRIO}

LISTA DE ABREVIATURA E SIGLAS ...................................................................... 12

LISTA DE QUADROS ......................................................................................................13

LISTA DE ILUSTRAÇÕES ......................................................................................................14

1 INTRODUÇÃ̃ _....................................................................................................................... 15

1.1 Introdução ………………………………………………………………....15

1.2 Justificativas acadêmicas para esta pesquisa ………………………………….... 16

$1.3 \quad$ Justificativas práticas para esta pesquisa ……………………………………..... 19

1.4 Descrição da tecnologia do veículo elétrico ........................................................ 20

1.5 Questão de pesquisa......................................................................................... 23

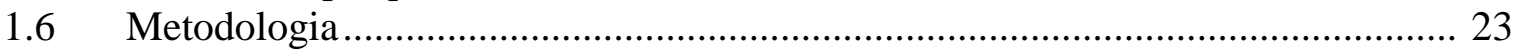

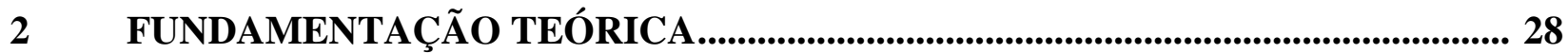

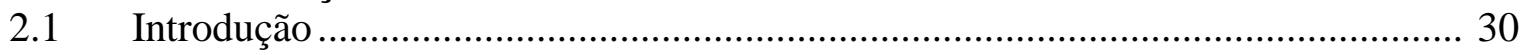

2.2 Efervescência tecnológica ................................................................................ 31

2.3 Análises de marketing vs sondagem e aprendizagem mercadológica .................... 42

$2.4 \quad$ Perspectiva Multi-Nível (PMN) ........................................................................ 47

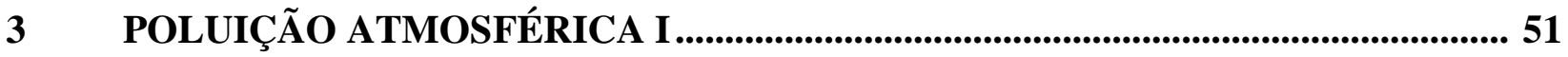

3.1 Introdução …………………………………………………………….... 51

$3.2 \quad$ Protótipos de veículo elétrico .............................................................................. 52

3.2.1 Electrovair I e II .......................................................................... 52

3.2.2 Stir-Lec I, Military 6x6 e Opel Kadette ……………………………....... 53

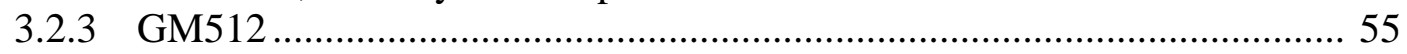

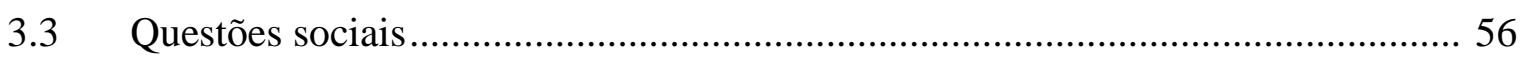

3.3.1 Poluição atmosférica.............................................................................. 56

3.3.2 Segurança dos veículos ........................................................................ 60

3.3.3 Sindicato dos trabalhadores automotivos .................................................. 61

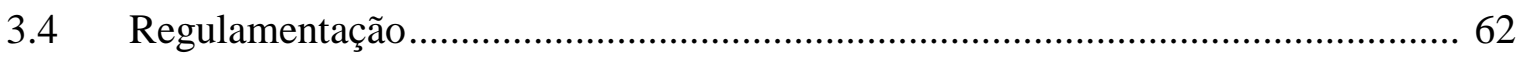

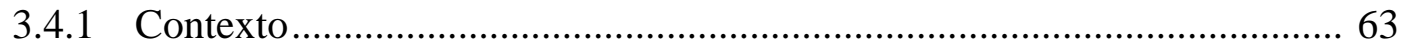

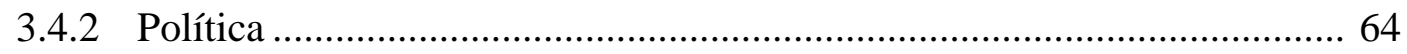

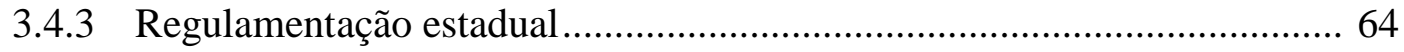

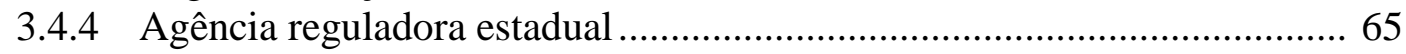

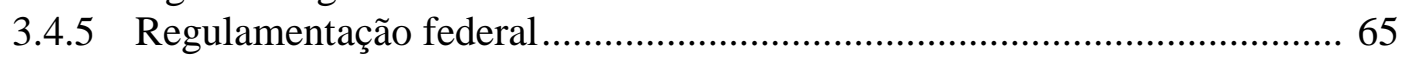

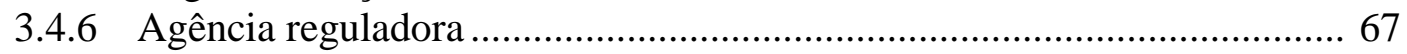

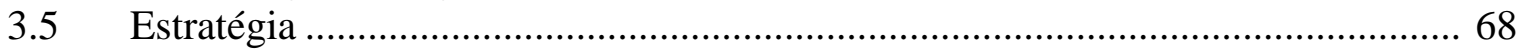

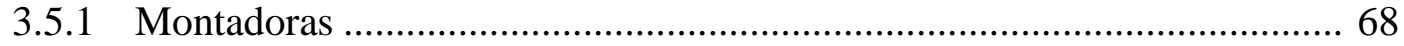

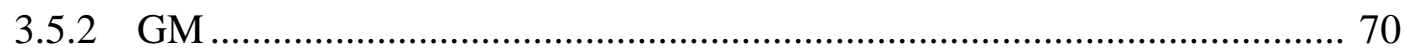

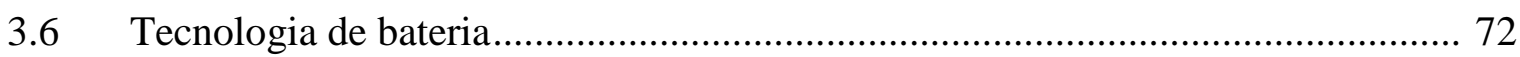

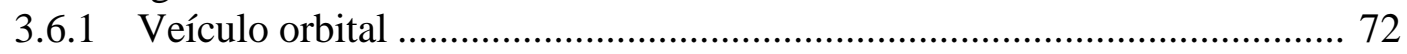

3.6.2 Míssil balístico ................................................................................. 73

3.6.3 Veículo elétrico terrestre........................................................................ 74 


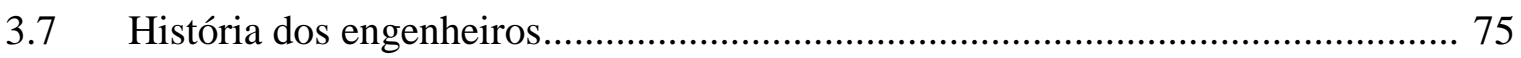

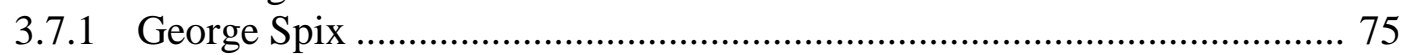

3.7.2 John Joseph Lander ........................................................................ 75

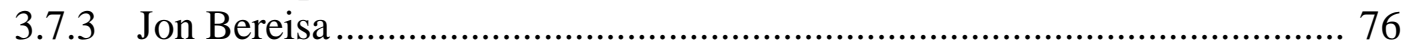

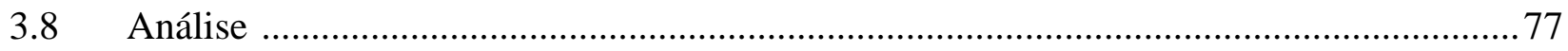

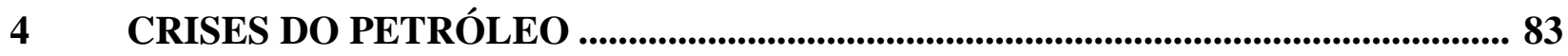

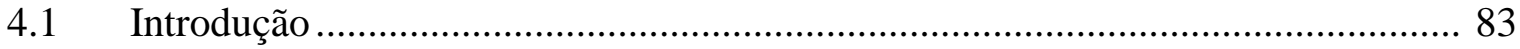

4.2 Protótipos de veículo elétrico ………………………......................................... 84

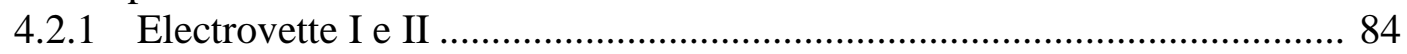

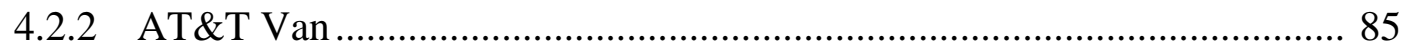

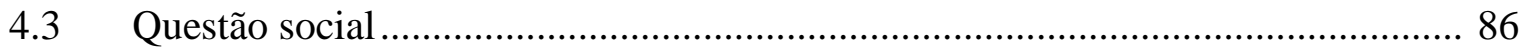

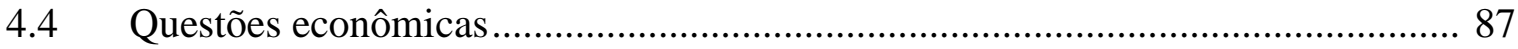

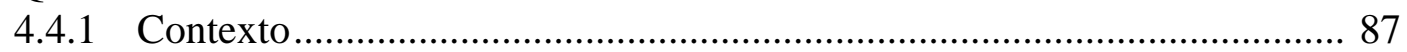

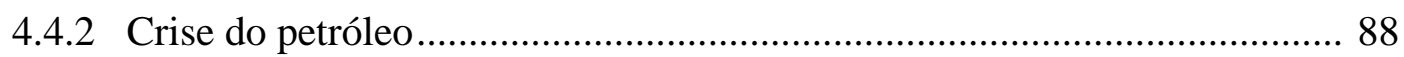

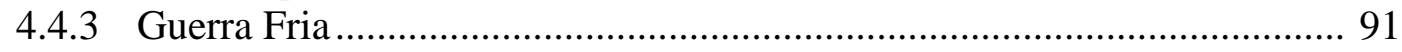

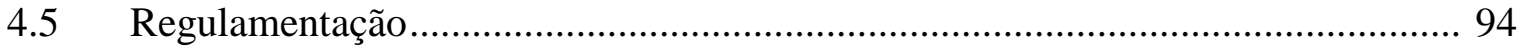

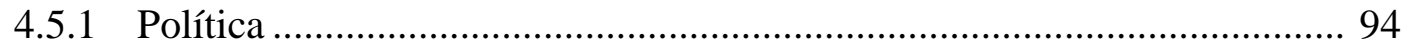

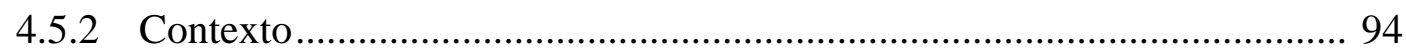

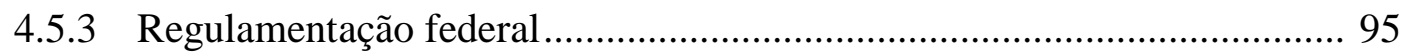

4.5.4 Agência reguladora ............................................................................. 96

4.6 Comportamento do consumidor …………………..................................... 98

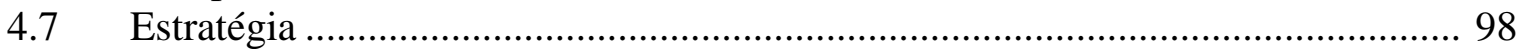

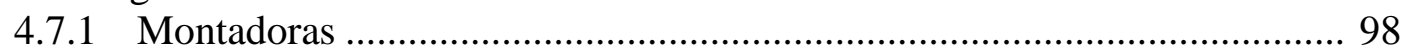

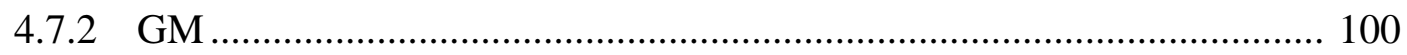

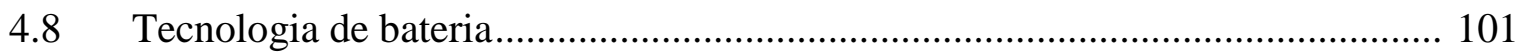

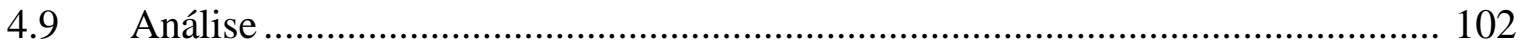

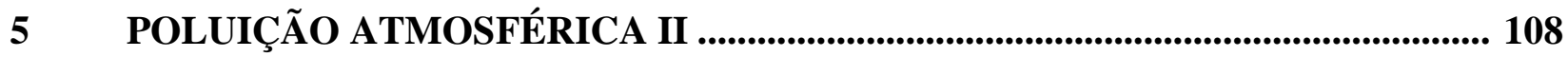

$5.1 \quad$ Introdução ................................................................................................... 108

5.2 Protótipos de veículo elétrico ……………………………………………........ 109

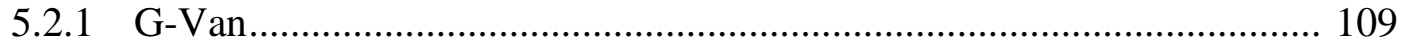

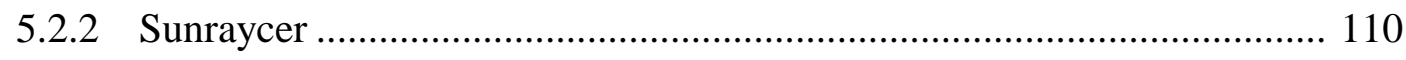

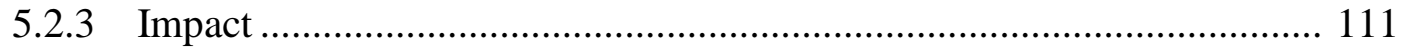

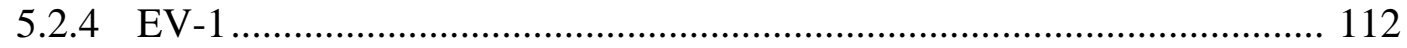

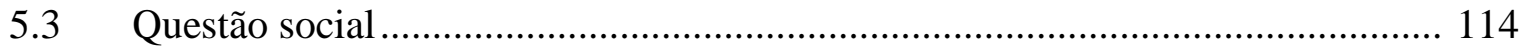

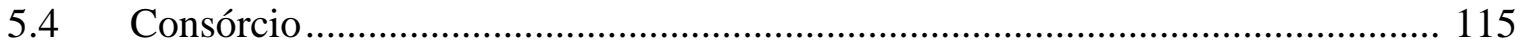

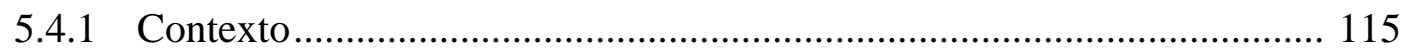

5.4.2 United States Advanced Battery Consortium (USABC) ......................... 117

5.4.3 Advanced Lead-Acid Battery Consortium (ALABC) ............................... 118

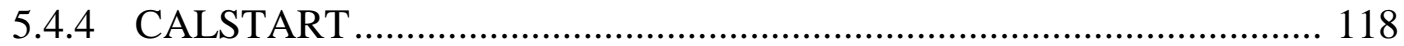

5.4.5 Partnership for a New Generation of Vehicles (PNGV).......................... 119

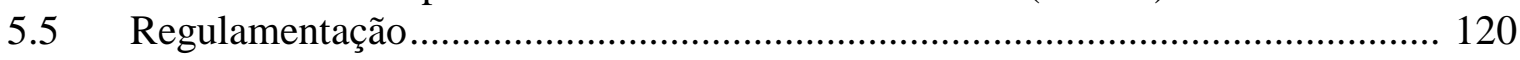

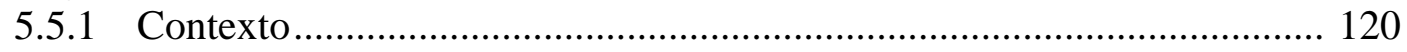

5.5.2 Regulamentação estadual ZEV Mandate .............................................. 121

5.5.3 Regulamentação federal .................................................................. 122

5.5.4 Energy Policy Act Public Law 102-486 ......................................................... 122 
5.5.5 Regulamentação federal Clean Air Act .................................................... 123

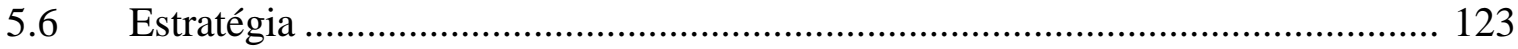

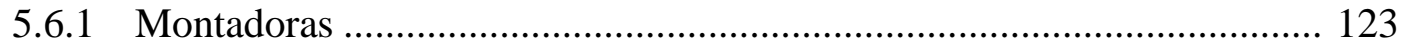

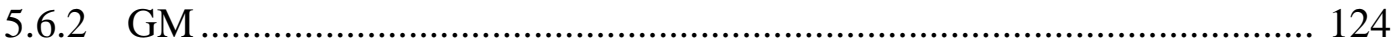

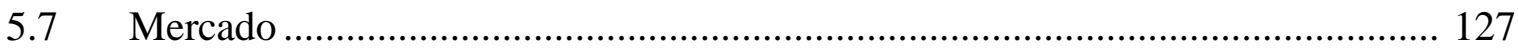

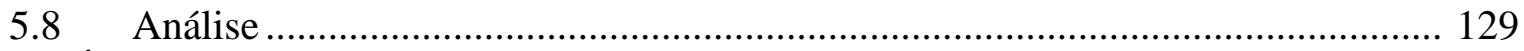

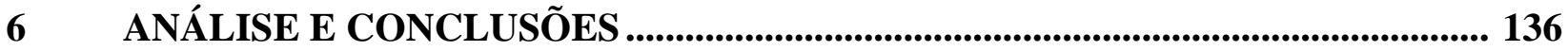

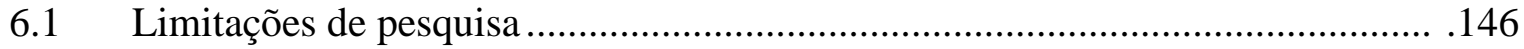

6.2 Sugestões de pesquisas futuras ........................................................................... 146

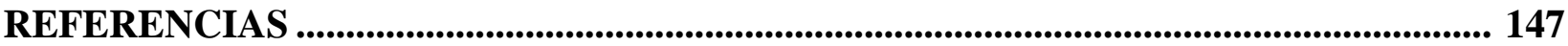




\section{LISTA DE ABREVIATURA E SIGLAS}

AC: Alternative current

ALABC: Advanced Lead-Acid Battery Consortium

DC: Direct current

DOE: Department of Energy

EPRI: Electric Power Research Institute

MCI: Motor de Combustão Interna

P\&D: Pesquisa e Desenvolvimento

PNGV: Partnership for a New Generation of Vehicles

USABC: United States Advanced Battery Consortium

VE: Veículo Elétrico

VEP: Veículo Elétrico Puro

VEH: Veículo Elétrico Híbrido

VCC: Veículo à Célula de Combustível

WSC: World Solar Challenge 


\section{LISTA DE QUADROS}

Quadro 1 - Fatores-chave de sucesso no processo de dominância tecnológica............................42

Quadro 2 - Protótipos da GM entre 1964 e 1969 ......................................................................56

Quadro 3 - Análise das políticas públicas do driver poluição atmosférica ...............................79

Quadro 4 - Protótipos da GM entre 1976 e 1979 ................................................................. 86

Quadro 5 - Análise das políticas públicas do driver das crises do petróleo .............................. 105

Quadro 6 - Protótipos e lançamento comercial da GM entre 1987 e 1996 ............................... 114

Quadro 7 - Análise das políticas públicas do driver da poluiçãa atmosférica II .......................133

Quadro 8 - Transferência de conhecimento entre os engenheiros (1964-1996) ....................... 143

Quadro 9 - Fatores de dominância observados na batalha tecnológica do veículo elétrico na GM (1994-1996) .......................................................................... 145 


\section{LISTA DE ILUSTRAÇÕES}

Figura 1 - Sistema de propulsão de combustão interna e elétrica ..............................................22

Figura 2 - Fontes energéticas em relação aos tipos de veículos elétricos..................................23

Figura 3- Metodologia utilizada para o desenvolvimento do estudo de caso GM .....................26

Figura 4 - Taxa de inovação de produto ............................................................................... 41

Figura 5 - Projeto dominante e número de firmas na indústria automobilística dos

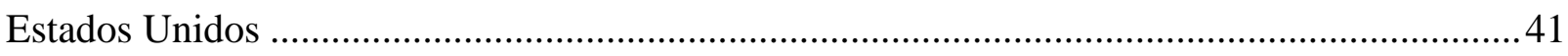

Figura 6 - Cinco fases no processo de dominância tecnológica ...............................................41

Figura 7 - Dinâmica da PMN em transições tecnológicas ......................................................50

Figura 8 - Cinco fases no processo de dominância tecnológica ...............................................50

Figura 9 - Integração da sondagem e aprendizagem nas batalhas tecnológicas ......................... 141 


\section{INTRODUÇÃO}

\subsection{Introdução}

Na década de 70, Utterback e Abernathy iniciaram a trajetória de pesquisa que esta dissertação optou seguir. Essa vertente teórica utiliza o pressuposto que o processo de transição tecnológica é o resultado de ações que são influenciadas por fatores específicos que possuem uma relevância ímpar em determinadas fases do processo (SUAREZ, 2004). Nesse sentido, ela sugere que agentes da sociedade e da organização atuam de forma conjunta para estabelecer o surgimento do projeto dominante (UTTERBACK, 1996).

Desenvolvemos o aprofundamento do estudo desenvolvido por Yu et al. (2011) seguindo a análise longitudinal que verificou as fases iniciais da batalha tecnológica. O nosso objetivo está no entendimento do processo de evolução da batalha tecnológica do veículo elétrico sob a perspectiva da montadora veterana General Motors (GM). Assim, a contribuição teórica está no estudo empírico do arcabouço conceitual de análise do surgimento do projeto dominante desenvolvido por Suarez (2004), que incorpora a verificação do processo no momento anterior a sua primeira inserção mercadológica. Ao observar os possíveis fatores inexistentes na estrutura original, viabilizamos a realização da expansão da literatura de transições tecnológicas. Nesse sentido, integramos, possivelmente, a estrutura teórica de Suarez (2004) e a literatura de sondagem e aprendizagem mercadológica desenvolvida por Lynn et al. (1996) na mesma direção do artigo publicado por Yu et al., em 2011.

Em relação às contribuições práticas, o entendimento do surgimento do veículo elétrico (VE) na GM pode apoiar o processo de tomada da decisão dos envolvidos no processo de incentivo a desenvolvimento de tecnologia. O desenvolvimento do VE pode ser uma alternativa de substituição da utilização de combustíveis fósseis e uma tecnologia complementar ao combustível renovável produzido em larga escala no país: o etanol. 


\subsection{Justificativas acadêmicas para esta pesquisa}

O interesse das fabricantes pelo veículo elétrico (VE) e os desafios para a sua difusão tem gerado muitas pesquisas sobre o VE na perspectiva da dinâmica e da gestão da inovação. Nesse sentido, uma das linhas de pesquisa sobre a dinâmica da inovação surgiu com o estudo sobre as inovações em 120 empresas de cinco indústrias americanas (UTTERBACK, ABERNATHY, 1975). Todas as cinco indústrias tiveram o mesmo padrão de inovação: no início do ciclo de vida da indústria, as inovações são mais em produto. Surge então um projeto dominante do produto e, após deste, na segunda etapa, as inovações de processo são mais dominantes. $\mathrm{O}$ entendimento da causa das variações sistemáticas no processo de inovação à medida que a indústria evolui e se modifica incentivou o desenvolvimento do artigo de Utterback e Abernathy (1975) que instituiu o conceito do projeto dominante (SUAREZ, 2004). Entretanto, este modelo de Utterback e Abernathy é construído a partir de inovações de sucesso no mercado. Inovações não sucedidas e atividades de P\&D que não redundaram em introdução de mercado não são analisadas neste modelo.

Nesse período, Abernathy e Utterback estavam tentando entender em que contextos o foco nas inovações incrementais maximizavam os ganhos de produtividade e em quais circunstâncias esse foco causava crise potencial na indústria. E, de maneira complementar, em que contextos as inovações de produto seriam mais adequadas para direcionar o processo de mudança. Dessa forma, em 1978, Abernathy e Utterback publicaram o artigo que realizou a interface entre os padrões de inovação e a estratégia competitiva, as competências de produção e as características organizacionais. Assim, os autores verificaram que a capacidade da unidade produtiva e as formas de inovação dependem significativamente do estágio de evolução da indústria.

De modo intrínseco a essas observações, os autores indicaram a relevância da fase transitória do foco das inovações de produto para as inovações em processo devido a sua relação com a questão da elevação da produtividade e capacidade de desenvolvimento de novos produtos da firma. Abernathy e Utterback comentam que muitos exemplos de inovações de insucesso indicam uma característica compartilhada: certas condições necessárias para apoiar o desenvolvimento do avanço tecnológico almejado não estavam presentes. Nesse sentido, o arcabouço conceitual desenvolvido pelos autores, no artigo publicado em 1978, ofereceu a descrição das condições 
necessárias que normalmente apoiam os avanços tecnológicos em cada estágio de desenvolvimento. Dessa forma, a partir desse artigo seminal, surgiu a trajetória de pesquisa que busca identificar os fatores influenciadores do processo do surgimento do projeto dominante.

Em 2004, Suarez publicou a pesquisa que tentou unificar as pesquisas empíricas e conceituais desenvolvidas a partir do artigo desenvolvido por Abernathy e Utterback, em 1978, de forma a integrar as ideias e conclusões dos fatores influenciadores no resultado final da batalha tecnológica em um arcabouço teórico analítico que incorporou a observação do processo no momento anterior a primeira inserção mercadológica do artefato tecnológico. Suarez (2004) desenvolveu um arcabouço teórico, a partir de uma revisão de literatura, procurando complementar o modelo de Utterback e Abernathy (1975). Ele incluiu mais duas fases: a fase de P\&D e a fase de viabilidade técnica. Nessa direção, a pesquisa desenvolvida por Suarez se contrastou das pesquisas desenvolvidas anteriormente (ABERNATHY, UTTERBACK, 1978; SUAREZ, UTTERBACK, 1995) que verificaram o processo após o primeiro contato do produto com o mercado.

O arcabouço do Suarez é conceitual e é baseado em muitos estudos de casos no sentido de analisar a evolução tecnológica do ponto de vista do setor e não do ponto de vista de uma empresa. Existe então uma demanda por estudos empíricos de verificação do arcabouço do Suarez. Assim, a utilização dessa estrutura conceitual como norteadora da observação da batalha tecnológica do veículo elétrico sob a perspectiva da GM pode viabilizar a validação teórica no escopo da firma. Sob outra perspectiva, a estrutura teórica de Suarez (2004) possibilita a verificação do surgimento do projeto dominante nas fases anteriores ao estabelecimento mercadológico da tecnologia de forma a ir ao encontro do período estudado nessa pesquisa.

Em 2006, Murmann e Frenken publicaram o artigo que objetivou integrar as diversas pesquisas empíricas relacionadas ao processo de surgimento do projeto dominante e ofereceu uma estrutura de análise no sentido de viabilizar o estabelecimento da interface entre as inovações tecnológicas e a mudança industrial (estrutura de mercado) de forma a ampliar o entendimento da forma que a mudança tecnológica se relaciona com a modificação na estrutura de mercado. Assim, essa estrutura conceitual objetivou explicar a razão do desenvolvimento hierárquico dos ciclos 
tecnológicos e da multiplicidade de mecanismos que contribuem para o surgimento do projeto dominante. Dessa forma, esse arcabouço teórico proporcionou a verificação do processo do surgimento do projeto dominante em uma granularidade que possibilita a análise da batalha tecnológica em diferentes escopos de forma a ampliar a compreensão causal do fenômeno de forma a sincronizar com a intenção da pesquisa de Utterback e Abernathy, publicada em 1975.

O surgimento do projeto dominante está relacionado ao momento de transição da inovação radical para a inovação incremental do produto que é acompanhado pelo aumento da competição por preço e ênfase na inovação de processo. E, no momento anterior a essa fase transitória, as inovações se caracterizam tanto pela incerteza mercadológica quanto pela incerteza tecnológica (ABERNATHY, UTTERBACK; 1978). Nesse sentido, surge uma questão de alta relevância em termos de ser considerado o fator decisivo entre as inovações de sucesso e de fracasso nas firmas: a compreensão das necessidades de mercado desde o início do processo da inovação (MURMANN, FRENKEN; 2006).

Como o consumidor não possui conhecimento prévio em relação aos benefícios que a nova tecnologia pode oferecer a sua utilização como fonte de informação no processo de redução de incertezas é pouco recomendado (VERYZER, 1998). Nesse sentido, em 1996, Lynn et al. publicaram a pesquisa que oferece uma abordagem metodológica visando o desenvolvimento do entendimento de mercado no contexto de desenvolvimento de inovações radicais na perspectiva das empresas e não na perspectiva da indústria.

O desempenho desapontador das firmas americanas durante a década de 80 nos mercados globais e de tecnologia intensiva (consumo eletrônicos, automação industrial, memórias de semicondutores, etc.) foi atribuído ao fracasso em melhorar continuamente e incrementalmente seus produtos e processos. Mas, ao desenvolver inovações radicais, verificou-se que a utilização da abordagem de marketing para entender esses mercados estava pouco aderente ao contexto. Dessa forma, no artigo publicado em 1996, Lynn et al. estudaram o processo de sondagem e aprendizagem das empresas na comercialização de uma inovação radical de sucesso. Nessa pesquisa, os autores esclareceram as diferenças entre as abordagens de pesquisas de marketing e a sondagem e aprendizagem mercadológica, indicando as suas relações com as inovações 
incrementais e radicais. Dessa forma, essa abordagem metodológica se difere da estrutura teórica de Suarez em relação a granulidade de pesquisa,. Mas, sob outra perspectiva, a observação do período anterior ao estabelecimento do projeto dominante é um ponto de intersecção entre as estruturas conceituais. Deste modo, a presente pesquisa busca entender o processo de sondagem e aprendizagem tecnológica antes de iniciar a fase de comercialização (etapas I e II do Suarez) de uma empresa (GM) em relação ao desenvolvimento da tecnologia de VE.

Através da construção do estudo de caso do desenvolvimento do veículo elétrico na GM utilizando a metodologia de construção teórica indutiva fundamentada em dados, esse estudo longitudinal encontrou uma sincronicidade entre as vertentes teóricas abordadas por Suarez (2004) e Lynn et al. (1996).

\subsection{Justificativas práticas para esta pesquisa}

O contexto prático está alicerçado no interesse recente pelos carros elétricos que é demonstrado pelos lançamentos do Volt pela GM e da Leaf pela Nissan. Esses não são carros conceitos, mas são carros projetados para serem produzidos em grandes volumes por duas das maiores fabricantes de automóveis do mundo. Um levantamento recente mostra que o número de fabricantes de veículos elétricos (desde triciclos até carro de passeio) no mundo cresce desde o início de 1990 de modo que em 2010 havia mais de 40 novas entrantes nesse segmento (YU et al., 2011).

Esses lançamentos são motivados pela oportunidade aberta por ameaças de mudanças climáticas e de escassez de petróleo num futuro próximo. Em razão da representatividade de dois terços da produção total da energia elétrica global estar vinculada a combustíveis fósseis (DRESSELHAUS, THOMAS, 2001) de forma que dois terços da demanda energética dos EUA se referem ao setor de transportes, que possui $97 \%$ da sua composição de consumo energética em petróleo (BULL, 2001), o desenvolvimento da tecnologia do veículo elétrico está sendo considerado como uma alternativa para modificar a composição dessa representatividade (DRESSELHAUS, THOMAS, 2001). 
Mas, apesar do interesse pelos veículos elétricos híbridos, o sucesso, em termos de participação de mercado de automóveis não é garantido. Um exemplo é o carro híbrido cujo primeiro lançamento foi o Prius da Toyota, lançado em 1996, e em 2006 (dez anos depois) a participação de VEH na venda de carros é menos de 5\% nos EUA (CHANARON, TESKE; 2007). Uma das barreiras é o alto custo de VEH mesmo com subsídios governamentais. Outros tipos de VEH enfrentam outras barreiras, por exemplo, o Veículo Elétrico Puro (VEP) ainda tem problema de alcance (raio de ação) limitado com uma carga de bateria.

A dificuldade de estabelecimento do sucesso comercial do veículo elétrico híbrido e puro no período atual gera um contexto compatível com a intenção de pesquisa do modelo conceitual desenvolvido por Utterback e Abernathy, em 1975. De modo que o entendimento dos fatores que proporcionam as variações sistemáticas do projeto dominante vai ao encontro da intenção dessa pesquisa descritiva que busca compreender os fatores que influenciaram a batalha tecnológica do VE na GM.

\subsection{Descrição da tecnologia do veículo elétrico}

O sistema de propulsão do veículo pode ser composto por diversas tecnologias como, por exemplo, o motor a vapor, elétrico ou a combustão interna (HOYER, 2008). Nessa direção, a presente pesquisa abordará a tecnologia do veículo elétrico em relação a tecnologia de combustão interna devido a questão da relevância dessas duas tecnologias no período atual (CHAN, 2002). Uma forma de diferenciá-las é em relação à transformação energética do sistema. O motor elétrico utiliza a energia magnética para transformar a energia elétrica em energia mecânica (que movimenta o veículo) (WESTBROOK, 2001), enquanto que o motor de combustão interna utiliza a energia química na conversão energética (CEEETA, 2011).

O veículo elétrico pode utilizar exclusivamente o motor elétrico ou pode incorporar o motor de combustão interna no seu sistema de propulsão (CHAN, 2002), conforme ilustrado na figura 1. A sua classificação está relacionada à composição do seu sistema de propulsão, sendo que os veículos elétricos puros (VEP) utilizam exclusivamente o motor elétrico; os veículos elétricos híbridos (VEH) possuem o motor elétrico e o de combustão interna e os veículos à célula de 
combustível (VCC) possuem uma célula de combustível que utiliza a conversão eletroquímica dos combustíveis para geração de energia elétrica (CHAN, 2002). Nessa categoria o fornecimento da eletricidade ocorre de forma contínua de forma que, em aplicações de propulsão automotiva, é recomendável a utilização conjunta de um sistema de baterias ou de capacitores eletroquímicos (WINTER, BRODD, 2004).

\section{Figura 1 - Sistema de propulsão de combustão interna e elétrica}

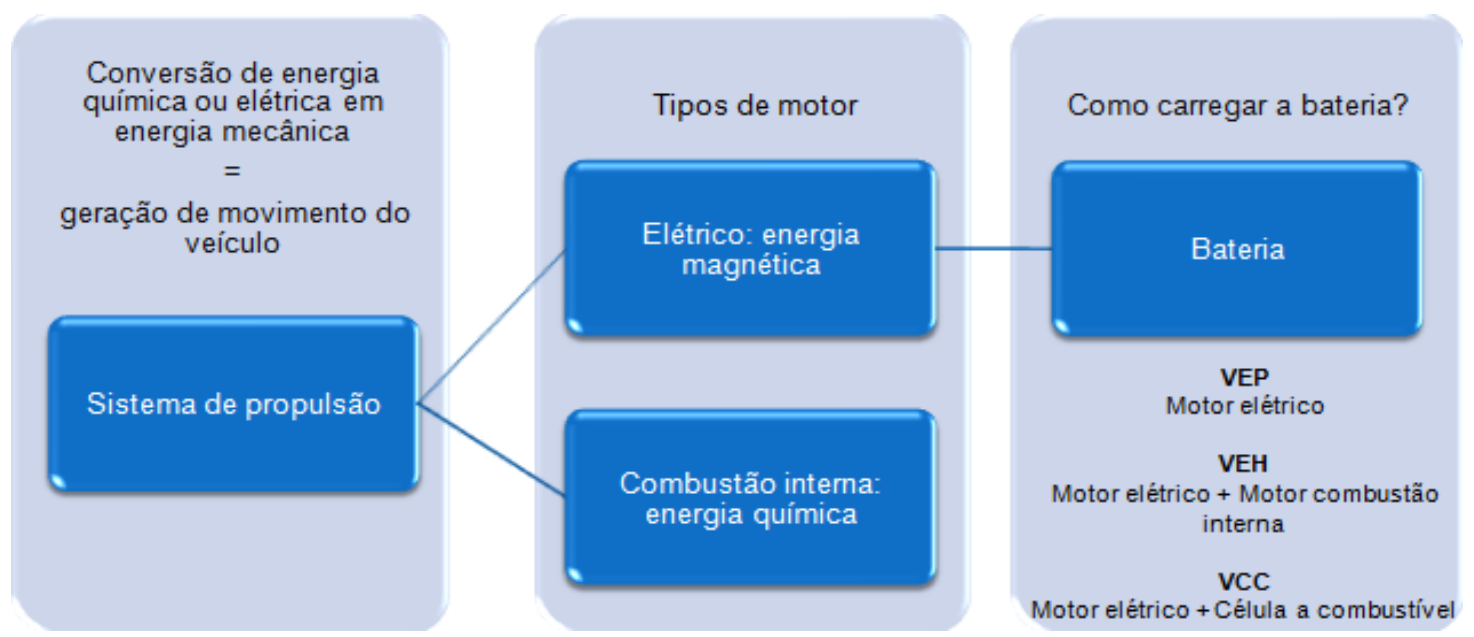

Fonte: elaboração da autora

O desenvolvimento dos VEP, VEH e VCC estão em distintas fases de evolução. Isso pode envolver desafios singulares e a necessidade de estratégias diferenciadas para cada tecnologia (CHAN, 2002). A tecnologia do VEP pode ser mais adequada para veículos menores para o uso urbano; a tecnologia do VEH se compatibiliza com as preferências dos consumidores, mas o seu custo é o grande desafio a ser solucionado e a tecnologia do VCC possui um potencial de longo prazo porque está em um estágio de desenvolvimento inicial, sendo que o seu custo e a infraestrutura de recarga são os seus principais desafios (CHAN, 2002).

Em relação às fontes energéticas, elas são fundamentalmente caracterizadas como fonte energética primária ou como portadores energéticos. As fontes energéticas primárias podem ser as radiações solares, os combustíveis fósseis ou as quedas hídricas enquanto que os portadores 
energéticos (derivados das fontes energéticas primárias) podem ser a eletricidade, a gasolina e o vapor (RAUGEI et al., 2012).

No contexto das energias renováveis, elas podem ser originadas da luz solar, dos ventos, da corrente hídrica, do calor interno do planeta e da biomassa (energia das plantações, dos resíduos industriais, agrícolas e urbano, etc.). Em relação às energias mnão renováveis, as suas fontes podem ser o gás natural, o carvão, o petróleo. Dessa maneira, esses recursos podem ser utilizados para a geração de eletricidade para todos os setores econômicos, para a produção de combustíveis para o setor de transporte e de energia térmica para o uso urbano e processos industriais (BULL, 2001).

O desenvolvimento do veículo elétrico está contextualizado como uma alternativa de viabilização do uso das energias renováveis geradas em fontes intermitentes (solar, eólica) de forma a estabilizar o fluxo de fornecimento energético na matriz energética (KEMPTON, TOMIC, 2005). Nesse sentido, a fonte energética do veículo elétrico pode ser originada de fontes renováveis (hídrica, biomassa, fotovoltaica, eólica, hidrogênio, etanol, etc.) (ORHAN et al., 2012; GERSSEN-GONDELACH, FAAIJ, 2012; TARTAKOVSKY et al., 2011; SARAVANAN et al., 2012) e de fontes não renováveis (petróleo, gás natural, etc.) (RAUGEI et al., 2012; TARTAKOVSKY et al., 2011)

Conforme a figura 2, as diferentes tecnologias possuem alternativas de abastecimento se harmonizam com o seu sistema de propulsão. O VEP se beneficia exclusivamente da rede elétrica para carregar o sistema de propulsão, o VEH utiliza o combustível e a eletricidade para alimentar o veículo e o VCC utiliza exclusivamente o combustível como fonte energética (CHAN, 2002). 
Figura 2 - Fontes energéticas em relação aos tipos de veículos elétricos

\begin{tabular}{|c|c|}
\hline $\begin{array}{c}\text { VEP } \\
\text { Energia elétrica }\end{array}$ & $\begin{array}{l}\text { •Renováveis } \\
\text { •Hídrica, eólica, fotovoltaica, biomassa } \\
\text { • Não renováveis } \\
\text { •Petróleo, gás natural }\end{array}$ \\
\hline $\begin{array}{l}\text { VEH } \\
\text { Energia elétrica }+ \\
\text { Combustível }\end{array}$ & $\begin{array}{l}\text { •Renováveis } \\
\text { • Hidrica, eólica, fotovoltaica, biomassa, etanol } \\
\bullet \text { Não renováveis } \\
\text { •Petróleo, gás natural, gasolina }\end{array}$ \\
\hline $\begin{array}{c}\text { VCC } \\
\text { Combustível }\end{array}$ & $\begin{array}{l}\text { •Renováveis } \\
\text { - Hidrogênio, etanol } \\
\text { • Não renováveis } \\
\text { • Gasolina }\end{array}$ \\
\hline
\end{tabular}

Fonte: elaboração da autora

\subsection{Questão da pesquisa}

Dessa forma, o entendimento do processo de evolução da tecnologia do veículo elétrico pode apoiar a expansão teórica da linha de pesquisa iniciada por Utterback e Abernathy de forma a buscar a compreensão dos fatores que viabilizam o surgimento do projeto dominante com o objetivo de oferecer o apoio necessário para o avanço tecnológico da indústria. Assim, a questão de pesquisa norteadora dessa dissertação é:

\section{Quais são as ações em tecnologia que a General Motors realizou em relação à batalha tecnológica do veículo elétrico?}

\subsection{Metodologia}

Para se entender o fenômeno da batalha tecnológica do veículo elétrico, alicerçado nessa questão de pesquisa, será feita uma pesquisa qualitativa exploratória indutiva de construção teórica fundamentada em dados. E a vertente a ser seguida nesse estudo é o da construção de contribuição teórica através de estudos de casos, utilizando o modelo desenvolvido pela Eisenhardt (1989). 
Desenvolveremos uma pesquisa longitudinal indutiva conduzida através da estratégia de pesquisa de rastreamento de processo utilizada por George e Bennett (2005).

Serão coletados dados secundários para a construção do estudo de caso. E, ao longo dessa etapa, será feita a comparação dos dados empíricos com os indicadores conceituais para viabilizar a codificação e abstração da pesquisa, bem como, quando possível, verificar eventuais relações causais no processo da batalha tecnológica.

Essa estratégia de pesquisa foi baseada na metodologia de estudo de caso histórico utilizado por George e Bennet (2005), que utiliza a abordagem de rastreamento de processo através do estudo de caso histórico. O objetivo desse enfoque se encontra no entendimento profundo do caso para se embasar com maior consistência as relações causais encontradas na pesquisa.

A justificativa para se optar pelo estudo de caso histórico utilizado por George e Bennet (2005) em relação à abordagem utilizada por Robert Yin (2001) é devido a vantagem do estudo de caso histórico se servir de dados secundários para a construção dos casos. Esse é o motivador principal da adoção dessa metodologia porque o acesso aos dados em fontes primárias é um limitador das pesquisas longitudinais de forma geral.

Ao utilizar a abordagem do George e Bennet (2005), viabiliza-se uma opção de estratégia de pesquisa que pode beneficiar o processo de investigação em áreas como a da Administração, que investe em pesquisas empíricas do tipo estudo de caso para desenvolver as suas concepções teóricas. Como por exemplo, o próprio caso da pesquisa longitudinal a ser desenvolvida nessa pesquisa.

Essa investigação é caracterizada pela dependência dos dados de forma constante durante o período a ser estudado. Ao optar pelo método de pesquisa que utilize dados primários, o incentivo para se explorar as investigações longitudinais se torna pouco atrativo. Mas, o estudo longitudinal possui a vantagem de revelar a mudança e a evolução de uma variável consequente (dependente). Outra vantagem seria em relação à possibilidade de verificação de efeitos de longo prazo de crescimento ou mudança de uma variável consequente particular. Assim, o maior 
destaque dos estudos longitudinais está na abordagem de questões de pesquisa que seriam impossíveis de abordar em pesquisas transversais (LAVRAKAS, 2008).

Nesse sentido, ao utilizar o método de rastreamento de processo, gerou-se uma segurança maior para se investir nesse tipo de pesquisa porque os dados secundários são de acesso público. Assim, evita-se ou diminui-se a probabilidade de descontinuidade de fornecimento de dados ao longo do processo. Essa possibilidade de estratégia de pesquisa viabiliza o embasamento das contribuições teóricas de forma consistente no sentido de tornar o processo de coleta de dados menos instável e com a possibilidade de verificação de relações causais que não estão contidas na natureza dos estudos transversais devido a sua natureza metodológica.

Dessa forma, a pesquisa abordará a montadora veterana GM com o objetivo de verificar historicamente a evolução da trajetória tecnológica do VE, viabilizando, possivelmente, a realização de inferências causais entre as variáveis de controle.

Foi desenvolvido um estudo longitudinal das ações da GM em relação ao veículo elétrico entre 1964 e 1996. O estudo abordou os eventos iniciais, os eventos colaborativos ou opositores, as ações do governo, o mercado de carros, o campo tecnológico, a estratégia e as ações em tecnologia de veículos elétricos da GM. Para realizar a pesquisa, segmentamos, respectivamente, três períodos: poluição atmosférica I, crises do petróleo e poluição atmosférica II. Eles foram selecionados devido a sua relevante influência como direcionador do desenvolvimento da tecnologia do veículo elétrico. Dessa forma, finalizamos a linha do tempo na análise do EV-1 devido a sua representatividade como lançamento comercial, demarcando a fase três (criação de mercado) do arcabouço teórico do Suarez (2004).

Utilizamos dados secundários tais como artigos técnicos, agências governamentais e livros para obtenção do material empírico utilizado na construção dos casos. Essas fontes forneceram informações sobre os objetivos dos protótipos, as lições aprendidas, a transferência de conhecimento, a relação entre os modelos protótipos e lançamentos comerciais, por exemplo. 
Através dessas fontes, foi construída a linha do tempo da evolução da tecnologia na GM e contextualizaram-se os pontos de ação identificados (baterias, protótipos e lançamento comercial). O foco da busca foi nas fases um, dois e três do arcabouço teórico de análise do Suarez (2004) que representam, respectivamente, a realização de P\&D, o desenvolvimento de protótipos e lançamentos comerciais.

Assim, obtivemos os dados da fase um (desenvolvimento de P\&D) da cadeia de baterias e das fases dois (desenvolvimento de protótipos) e três (lançamentos comerciais) dos desenvolvimentos tecnológicos de veículos elétricos da GM.

Figura 3 - Metodologia utilizada para o desenvolvimento do estudo de caso GM.

\begin{tabular}{|c|c|c|c|}
\hline $\begin{array}{c}\text { Classificação do } \\
\text { estudo }\end{array}$ & Fontes & Observações & Processo \\
\hline $\begin{array}{l}\text { Estudo longitudinal } \\
\text { (quatro décadas) }\end{array}$ & $\begin{array}{l}\text { Artigos técnicos } \\
\text { Notícias na mídia } \\
\text { Agências } \\
\text { governamentais } \\
\text { Livros }\end{array}$ & $\begin{array}{c}\text { Lições aprendidas } \\
\text { Protótipos } \\
\text { Lançamentos comerciais } \\
\text { Transferência de } \\
\text { conhecimento } \\
\text { Regulamentações }\end{array}$ & $\begin{array}{l}\text { Linha do tempo das } \\
\text { fases I, II e III da } \\
\text { estrutura conceitual } \\
\text { do Suarez (2004) }\end{array}$ \\
\hline
\end{tabular}

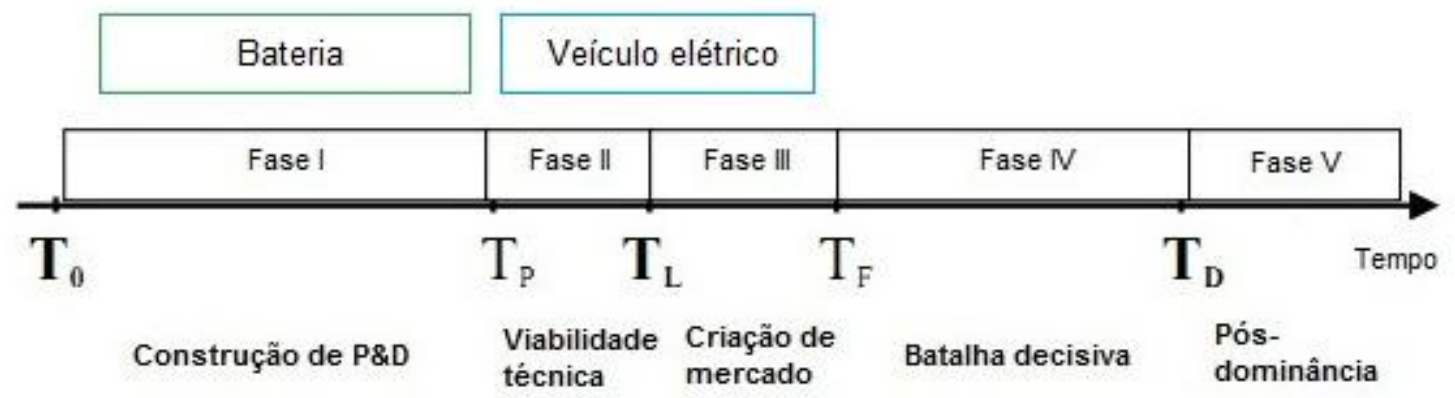

Fonte: adaptado de Suarez (2004)

Dessa forma, no capítulo dois desenvolveremos a fundamentação teórica relevante para alicerçar as observações empíricas da pesquisa. Nos capítulos seguintes, apresentaremos os desenvolvimentos tecnológicos da GM em relação à tecnologia do veículo elétrico. No capítulo 3, apresentaremos os primeiros protótipos da GM que foram direcionados pela questão da poluição atmosférica. No capítulo 4, descreveremos os protótipos que foram desenvolvidos no período 
direcionado pela questão da crise do petróleo. No próximo capítulo, apresentaremos os protótipos e o primeiro lançamento comercial da GM que foram direcionados pelo retorno da questão da poluição atmosférica.

Através das confrontações entre os dados teóricos e empíricos apresentados nos capítulos anteriores, no capítulo 6, verificaremos as conclusões obtidas. Nesse capítulo também apresentaremos as delimitações da pesquisa bem como ofereceremos as sugestões de pesquisas futuras. 


\section{FUNDAMENTAÇÃO TEÓRICA}

A inovação tecnológica contribui de forma relevante para o crescimento e mudança na sociedade (HILL, UTTERBACK, 1983). Ao considerar os modelos macroeconômicos de crescimento em que o avanço técnico é a força motriz e que as estruturas tecnológicas e industriais co-evoluem, os resultados desses processos estão em fenômenos agregados como, por exemplo, o crescimento produtivo e rendas per capita, padrões de difusão da inovação relativamente regulares, flutuações constantes nas taxas de crescimento das rendas (DOSI, NELSON; 1994).

Mas os modelos macroeconômicos ou propostas de incentivo fiscal para a realização de $\mathrm{P} \& \mathrm{D}$ não são adequados para prescrever políticas econômicas de incentivo a inovação no nível das firmas. E a microeconômica tradicional é baseada no pressuposto de condições de equilíbrio e na maximização dos lucros. Para entender os aspectos da geração da inovação, a formulação da maximização de lucros está fragilmente relacionada com as questões de custo e viabilização da inovação. Dessa forma, Nelson e Winter (1977) sugeriram que uma abordagem processual, visando reprojetar as instituições ao invés de focar em alocações de recursos, seria uma perspectiva mais adequada para influenciar determinados setores econômicos.

Para entender as anomalias encontradas na teoria microeconômica tradicional, que pressupõe a racionalidade perfeita dos agentes (DOSI, NELSON, 1994), surgiram quatro vertentes teóricas (Organização Industrial Moderna, Nova Economia Institucional, Teoria Econômica Organizacional e Teoria Econômica Evolucionária) que compartilham as premissas de que a firma não é considerada como uma função de produção ou uma construção técnica, mas é considerada como uma estrutura de governança ou uma construção organizacional onde a estrutura interna possui objetivo e efeito econômico; a percepção da passividade de comportamento em relação a estrutura do setor especificada pela conduta e desempenho das firmas se substituí pela percepção do comportamento de forma mais ativa; e o ambiente e o arranjo institucional na atividade econômica são relevantes (SLANGEN, LOUCKS, SLANGEN; 2008). 
$\mathrm{Na}$ vertente da Teoria Econômica Evolucionária (TEE) encontra-se o pressuposto da individualidade dos agentes econômicos de forma que essa percepção se contrasta com a crença das outras vertentes teóricas que pressupõem a homogeneidade dos agentes, considerando a firma como a caixa-preta. Na TEE, a heterogeneidade (variação) dos agentes deve ser considerada e ela está relacionada a questão da racionalidade limitada (SLANGEN, LOUCKS, SLANGEN; 2008).

Sob a perspectiva evolucionária, a unidade de análise pode ser representada pelo espaço tecnológico e pelo espaço comportamental ou formas organizacionais de forma que a interface entre as características do espaço tecnológico e as dinâmicas de mercado é realizada pelas características organizacionais e comportamentais (rotinas organizacionais e competências) das firmas (DOSI, NELSON, 1994). Nesse sentido, a inovação é percebida como uma sequência de atividades que envolvem a aquisição, a transferência e a utilização da informação, sendo que o seu foco principal está nos traços individuais das personalidades, na origem das ideias inovadoras e na forma que as práticas administrativas e a estrutura da organização influenciam o seu desenvolvimento. $\mathrm{O}$ alicerce da firma se encontra no conjunto dos seus recursos materiais, nas habilidades e relações humanas e nos seus conhecimentos relevantes. Essas são as competências ou ingredientes competitivos nos quais a firma constrói as características dos produtos que oferecem ao mercado (ABERNATHY, CLARK; 1985).

No modelo formal microeconômico de crescimento evolucionário desenvolvido por Nelson e Winter (1982), os atores centrais são as firmas que, por um lado, são percebidos como entidades mais ou menos lucrativas. Mas que por outro lado podem ser percebidas como portadores de tecnologias, consideradas como a materialização das ações e da forma que elas são conduzidas determinadas pelas práticas ou competências da firma. $\mathrm{Na}$ prática, todos os modelos desenvolvidos por Nelson e Winter assumem que a pesquisa é o gatilho para a descoberta de novas técnicas de produção ou para a melhoria das técnicas existentes. Alguns autores consideram a pesquisa como P\&D enquanto outros autores a denominam como aprendizagem. Nesses processos de pesquisa se encontram a fonte das diferenças de lucratividade das firmas (DOSI, NELSON; 1994). Dessa forma, a teoria evolucionária sugere que as firmas lucrativas irão crescer e as firmas não lucrativas irão se contrair, conduzindo as características operacionais da firma mais lucrativa ao crescimento econômico da indústria (NELSON, WINTER; 1982). 


\subsection{Introdução}

Estamos tentando entender o surgimento do projeto dominante do veículo elétrico na GM ao longo do período de 1964 e 1996. Dessa forma, esse estudo longitudinal busca analisar a batalha tecnológica no período anterior a sua inserção mercadológica.

Nesse sentido, a seção 2.2 aborda a vertente teórica do ciclo de vida do produto desenvolvido por Abernathy e Utterback (1975) e o arcabouço teórico do surgimento do projeto dominante desenvolvido por Utterback (1996), que abordaram a questão do surgimento do projeto dominante após a sua primeira inserção mercadológica para contextualizar o desenvolvimento da fundamentação teórica da estrutura conceitual das batalhas tecnológicas desenvolvido por Suarez (2004). Essa vertente conceitual permite a análise do processo de efervescência tecnológica no momento anterior a sua primeira inserção mercadológica, indo ao encontro do objetivo empírico da pesquisa.

Na seção 2.3, continuaremos o desenvolvimento da fundamentação teórica com a abordagem da vertente conceitual da sondagem e aprendizagem tecnológica e mercadológica versus a análise de marketing devido à questão da relevância do entendimento do mercado desde o período inicial do processo. Essa é uma questão considerada fundamental para o sucesso das inovações radicais e a utilização do cliente como fonte de informação no contexto de alta incerteza tecnológica e mercadológica caracterizada na fase de efervescência tecnológica é uma questão a ser contornada. Por isso, abordamos as metodologias de coleta de informações de análise de marketing versus sondagem e aprendizagem tecnológica e mercadológica para evidenciar as diferenças dessas abordagens e desenvolver o entendimento da compatibilização da metodologia de coleta de informações de mercado com o tipo de inovação que está se buscando entender.

Na seção 2.4, finalizaremos o capítulo no desenvolvimento da fundamentação teórica da estrutura teórica da perspectiva multi-nível (PMN), desenvolvida por Geels (2002), devido a questão da sua abordagem integrativa do processo de efervescência tecnológica em diferentes níveis, complementando a fundamentação teórica da efervescência tecnológica da seção 2.2 que aborda o processo em diferentes fases. Essa fundamentação teórica aborda a questão cognitiva dos 
atores, oferecendo uma estrutura de análise complementar ao arcabouço conceitual desenvolvido por Suarez (2004). Na PMN, a granulidade de análise se encontra na questão cognitiva dos agentes enquanto que o arcabouço conceitual das batalhas tecnológicas utiliza a perspectiva da indústria.

\subsection{Efervescência tecnolológica}

Ao longo de um período econômico, uma significativa parte do seu crescimento econômico é representada pela inovação e pelo crescimento produtivo das indústrias que produzem os bens que incorporam os paradigmas tecnológicos. O paradigma contém os padrões específicos de resolução de problemas econômico-tecnológicos relevantes e frequentemente está relacionado ao surgimento do projeto dominante (DOSI, NELSON; 2009).

Existe uma vertente que acredita que o surgimento do projeto dominante é o resultado de eventos de chance e que não pode ser previsto. Outra vertente possui um posicionamento determinístico e que, portanto, algo inerente a tecnologia determina o resultado do surgimento do projeto dominante. Uma terceira vertente sugere que fatores sociais e organizacionais funcionam de forma conjunta para determinar o surgimento do projeto dominante (UTTERBACK, 1996).

Essas diferenças de crenças estão, possivelmente, relacionadas com o entendimento do surgimento do projeto dominante como uma causa ou consequência da evolução industrial.

O surgimento do projeto dominante modifica os padrões de competição na indústria (SUAREZ,

UTTERBACK, 1995). É a síntese das inovações tecnológicas individuais lançadas independentemente nos produtos anteriores. O seu efeito força a padronização para que seja viável realizar as economias de escala. Dessa forma, a base competitiva se modifica para o foco em custos e em desempenho do produto (ABERNATHY, UTTERBACK, 1978).

Outro efeito, relacionado ao surgimento do projeto dominante, é observado nas inovações em processo. Elas possuem um desenvolvimento relativamente baixo se as inovações em produto não estiverem satisfatoriamente maduras para se obter um volume de vendas suficiente para a sua 
evolução e, pelo menos, alguns itens estáveis no projeto do produto (UTTERBACK, ABERNATHY, 1975). Nesse contexto, o projeto dominante está vinculado ao estabelecimento da mudança de foco das inovações em produto para as inovações em processo (ABERNATHY, UTTERBACK, 1978). A lógica da inovação de processo que organiza e coordena a produção é derivada da importância da escala, velocidade e custo ao longo da evolução industrial (CLARK, 1985).

O projeto dominante não é representado pelas descontinuidades tecnológicas, caracterizado pelas inovações de ruptura. Essas inovações expandem as fronteiras do preço versus desempenho e iniciam o ciclo tecnológico e o processo de fermentação tecnológica. Mas raramente se tornam o projeto dominante porque essa não é a única dimensão a ser considerada no contexto. $\mathrm{O}$ surgimento projeto dominante é o resultado de dinâmicas sociais e políticas que possuem influências assimétricas no processo. Essa é a razão pela qual não se pode verificar previamente a sua manifestação (ANDERSON, TUSHMAN, 1990), sendo considerada como efeito da evolução industrial.

Outra forma de perceber o surgimento do projeto dominante seria em relação ao entendimento do fenômeno com a possibilidade antecipação porque ele seria a causa da evolução industrial (MURMANN, FRENKEN, 2006). Abernathy \& Utterback (1978) concluíram que as modificações no padrão inovativo; no processo de produção; na escala e, de alguma forma, na capacidade produtiva ocorrem todas juntas de forma consistente e previsível.

Utterback (1996) sugere que o pico da curva da população total de firmas no seu processo de competição pelo projeto dominante irá ocorrer um ou dois anos antes do seu surgimento. Em um período anterior ao surgimento do projeto dominante, Utterback (1996) sugere que possa ocorrer a formação de uma onda de novos entrantes com grande variação e experimentação de versões do produto. Ao ocorrer o surgimento do projeto dominante, Utterback (1996) sugere que se verifique uma onda de saídas de firmas competidoras e a consolidação geral da indústria. 
Segundo George White (1978) apud Abernathy \& Utterback (1978), os projetos dominantes podem ser reconhecidos nos estágios iniciais de desenvolvimento. A sua análise sugere que os projetos dominantes têm uma probabilidade maior de conter um ou mais dos seguintes pontos:

- Tecnologias que exaltam restrições técnicas fundamentais, limitando as tecnologias anteriores enquanto não impõe novas restrições relevantes;

- Projetos que elevam o valor de inovações potenciais em outros elementos do produto ou do processo;

- Produtos que asseguram a expansão para novos mercados.

Para entender como identificar o projeto dominante, é necessário compreender a sua natureza, o contexto que viabiliza o seu surgimento e os incentivos que se compatibilizam com a sua necessidade para permitir a sua evolução na trajetória tecnológica.

As unidades em diferentes estágios de evolução respondem a diferentes estímulos e oferecerão diferentes tipos de inovação (ABERNATHY, UTTERBACK, 1978). Nesse sentindo, a estrutura teórica desenvolvida por Suarez (2004) pode ser classificada como a vertente conceitual que considera o surgimento do projeto como a causa da evolução industrial.

$\mathrm{O}$ projeto dominante freqüentemente emerge para responder às oportunidades de economia de escala ou para obter vantagens do ambiente externo (DAVID, 1985; ARTHUR, 1988 apud HENDERSON, CLARK, 1990). Esse contexto e a forma de captar esses favorecimentos são influenciados pela hierarquia de projeto de organização.

As decisões dos desenvolvedores de produtos (ou processos) e as escolhas dos consumidores seguem uma lógica de resolução de problemas no contexto e na formação de conceitos que impõe uma estrutura hierárquica na evolução tecnológica (CLARK, 1985).

As diversas opções tecnológicas e o pouco entendimento da necessidade dos consumidores, ou a falta da conexão entre a tecnologia e o mercado, conduzem as escolhas dos consumidores e a inovação a serem caracterizadas pela pesquisa, pelo extensivo processamento de informação e 
pela aprendizagem. O padrão de inovação que emerge desse processo, os tipos de mudanças introduzidas, o alinhamento de tempo das modificações, etc., dependerá em parte do padrão da incerteza e da forma que ocorrer esse entendimento. As incertezas contidas no campo tecnológico e no campo mercadológico se tornam o determinante do padrão dessa estrutura hierárquica (CLARK, 1985).

Nas fases iniciais do desenvolvimento tecnológico, antes do surgimento do projeto dominante, as organizações estão competindo para projetar experimentos de sucesso com diversas tecnologias diferentes. O sucesso de mercado é o resultado da síntese de inúmeras tecnologias de pouco conhecimento prévio. Isso gera uma necessidade de desenvolver esse conhecimento, tanto em relação aos componentes quanto em relação às suas possibilidades de integração. Através da emergência do projeto dominante, que sinaliza a aceitação generalizada de uma única arquitetura, as firmas cessam os investimentos em aprendizagem de novas configurações alternativas do conjunto estabelecido de componentes. Novos conhecimentos sobre componentes se tornam mais valiosos para a firma em relação a novos conhecimentos de arquitetura porque a competição entre os projetos se volta para o aperfeiçoamento em certos componentes (HENDERSON, CLARK, 1990).

$\mathrm{O}$ projeto dominante centraliza as necessidades de várias classes de consumidores em um produto. Ele pode não englobar as necessidades de alguma classe específica de forma customizada ou incorporar os desempenhos tecnológicos mais avançados. Mas o projeto dominante representa o ponto de transição na vida da indústria (SUAREZ, UTTERBACK, 1995).

A dinâmica da inovação de produto do projeto dominante pode ser descrita no primeiro e no segundo estágio de desenvolvimento do ciclo de vida de produto e de processo da unidade produtiva (UTTERBACK, ABERNATHY; 1975; ABERNATHY, UTTERBACK, 1978).

No estágio 1 do desenvolvimento do ciclo de vida de produto e de processo, os processos estão em um momento "orgânico" onde as respostas à mudança são rápidas, mas pouco eficientes. É chamado de não coordenado e a sua composição majoritária é formada por operações sem 
padronização e manuais e que podem se concentrar em um equipamento de abrangência genérica (UTTERBACK, ABERNATHY; 1975).

Em relação aos produtos, o enfoque se encontra no desempenho funcional do produto que está inserido em um contexto de alto grau de incerteza sobre o mercado. As inovações tendem a ser estimuladas pelo mercado, que fornece os parâmetros relevantes a serem desenvolvidos no produto. As fontes de informação tendem a ser múltiplas e abrangentes para a criação de entendimento do mercado. Essa etapa é chamada de maximização de desempenho técnico e, provavelmente, a indústria é formada por poucas empresas que são ou novas entrantes de pequeno porte ou veteranas que desejam entrar em um mercado completamente novo utilizando o seu potencial tecnológico existente. Nesse período ocorre o pico das inovações de produtos originais (UTTERBACK, ABERNATHY; 1975).

Esse período é considerado o padrão fluído do processo de inovação, verificando-se o predomínio das inovações radicais (ABERNATHY, UTTERBACK; 1978).

No arcabouço teórico desenvolvido por Suarez (2004), esse período pode ser representado pela fase III e IV.

A fase III (criação de mercado) é caracterizada pelo lançamento comercial do produto que, pela primeira vez, relaciona diretamente a tecnologia desenvolvida nos laboratórios aos consumidores. O primeiro produto a ser comercializado, geralmente, possui um valor de aquisição relativamente alto para o mercado de massa, dessa forma, são os aficcionados por tecnologias que possuem uma representatividade relevante nessa fase (SUAREZ, 2004).

Essa é a última chamada para as firmas remanescentes acelerarem os seus esforços em P\&D para evitar serem deixados para trás. Essa etapa estabelece uma modificação irreversível do foco nos fatores tecnológicos para o foco nos fatores de mercado, o que indica que as diferenças tecnológicas entre as alternativas se tornam gradativamente menos relevantes (SUAREZ, 2004). 
No nível da firma, a manobra estratégica possui o maior impacto no resultado final. Ao assegurar a posição de pioneiro, podem-se absorver as vantagens obtidas pela reputação e bloquear o acesso dos novos entrantes a recursos-chave (LIEBERMAN \& MONTGOMERY, 1998 apud SUAREZ, 2004).

Nessa etapa, o preço possui o efeito mais forte porque as firmas não desenvolveram a vantagem da base instalada. As decisões dos consumidores estão mais tendenciosas a serem altamente influenciados pelo preço. De forma similar, provavelmente, o comprador possui uma informação limitada dos benefícios do produto. Nesse contexto, os esforços de marketing podem moldar as expectativas dos consumidores (SUAREZ, 2004).

Nesse estágio, os competidores precisam garantir o suporte das suas trajetórias tecnológicas através de produtos ou serviços complementares. Mesmo que as firmas comecem o cortejo pelo suporte da sua tecnologia na fase anterior, os produtores de bens complementares geralmente aguardam a inserção mercadológica da tecnologia antes de se comprometer a fornecer suporte de forma integral (SUAREZ, 2004).

A fase IV (batalha decisiva) é caracterizada pela clara presença de um candidato preferencial na corrida. Ele possui a chance de vencer a batalha, mas essa vantagem possui o viés do excesso de inércia criado pela posse da maior fatia de mercado. O resultado final dependerá da velocidade dos outros competidores em desenvolver as suas trajetórias e do crescimento do mercado (SUAREZ, 2004).

$\mathrm{Na}$ fase III, inúmeros competidores iniciaram a acumular uma base instalada de consumidores. $\mathrm{Na}$ fase IV, essa base de consumo começa a exercer um efeito relevante nas decisões dos consumidores (SUAREZ, 2004).

No nível da firma, o efeito da força dessa base instalada é determinado pela força dos efeitos de rede e custos de mudança, no nível do ambiente. Os ativos complementares e a credibilidade freqüentemente exercem um papel importante nesse estágio. Os consumidores conservadores 
demonstram que são menos impressionados unicamente pelo desempenho: eles tendem a preferir adquirir os produtos produzidos por veteranas que eles consideram confiáveis (SUAREZ, 2004).

No estágio 2 do ciclo de vida desenvolvimento de produto e de processo da unidade produtiva, com a maturidade da indústria e do desenvolvimento do produto, a competição pelo preço se torna mais intensa. Os sistemas de produção, projetados para aumentar a eficiência, se tornam mecanicistas e rígidos e as tarefas se tornam mais especializadas, sujeitas ao controle operacional mais formal. Em termos de processo, o sistema de produção tende a se tornar sofisticado e fortemente integrado através da automação e do controle de processo. Nesse período, ocorre o pico das inovações de processo originais (UTTERBACK, ABERNATHY, 1975).

Essa etapa é chamada de segmental e alguns dos seus subprocessos podem estar altamente automatizados a uma tecnologia específica enquanto outros podem continuar essencialmente manuais ou centrados em um equipamento de uso genérico. Para ocorrer a evolução do desenvolvimento de processo, o desenvolvimento de produto necessita estar em um estágio de maturidade que garanta certo volume de vendas e que, pelo menos, possua alguns componentes estáveis (UTTERBACK, ABERNATHY; 1975).

No contexto do desenvolvimento de produtos, há uma redução da incerteza de mercado devido à experiência obtida pelos desenvolvedores e usuários do produto. É esperado um grau mais elevado de competição através da diferenciação dado o surgimento da dominância de alguns projetos de produtos. Esse estágio é chamado de maximização das vendas e a redução da incerteza de mercado permite um avanço na aplicação de tecnologias mais avançadas que será fonte de novas inovações. As mudanças fundamentais podem ocorrer com a intenção de substituição de um produto existente ao invés de criar uma aplicação de produto totalmente nova e o impacto econômico pode ser quase imediato (UTTERBACK, ABERNATHY; 1975).

De forma simultânea, começa a se instituir forças que reduzem a taxa de mudança e inovação no produto. A introdução de modificações óbvias dificulta o progresso da melhoria em desempenho dos produtos anteriores. Os usuários desenvolvem lealdade e preferências e ocorre uma maior 
padronização das práticas de marketing, da rede de distribuição, da manutenção, etc. (UTTERBACK, ABERNATHY; 1975).

Esse período é considerado o padrão transitório do processo de inovação, verificando-se o surgimento do projeto dominante (ABERNATHY, UTTERBACK; 1978).

No arcabouço teórico desenvolvido por Suarez (2004), esse período pode corresponder a fase V da batalha tecnológica.

A fase V (pós-dominância) é caracterizada pelo surgimento do projeto dominante. Ele emerge quando, durante a fase IV, um ou ambos os eventos ocorrem (SUAREZ, 2004):

- Existe um claro sinal de que a alternativa que possui a maior competitividade demonstra de forma direta ou indireta o abandono ativo da batalha (SUAREZ, 2004);

- O projeto atingiu uma clara vantagem de mercado em relação aos outros projetos alternativos e as recentes tendências de mercado sugerem de forma unânime que essa vantagem está crescendo (SUAREZ, 2004).

No nível da firma, a base instalada de clientes atua como uma forte barreira contra desafiantes potenciais, particularmente em situações de ambientes que possuem um forte efeito de rede e alto custo de mudança (SUAREZ, 2004).

Dessa forma, no nível do ambiente, os fatores relevantes são os efeitos de rede e custos de mudança (SUAREZ, 2004).

Ao atingir a dominância, o projeto dominante permanece sem desafiadores até que surja a próxima descontinuidade tecnológica e se inicie um novo ciclo; a descontinuidade tecnológica abre a porta para novos entrantes e começa um novo processo de dominância (ANDERSON \& TUSHMAN, 1990 apud SUAREZ, 2004).

As fases I e II da estrutura conceitual desenvolvida por Suarez (2004) abordam o período anterior a sondagem e aprendizagem com o mercado. Dessa forma, elas não possuem uma 
correspondência com o arcabouço teórico de ciclo de vida de produto e processo desenvolvido por Utterback e Abernathy (1975) ou com a estrutura teórica do surgimento do projeto dominante desenvolvida por Utterback (1996), que foram baseadas na relação da firma com o mercado.

A fase I (construção de P\&D) é caracterizada pelo inicio dos investimentos em P\&D aplicados com a finalidade de se desenvolver um novo produto. Essa etapa determina as característicaschave do campo tecnológico. Grandes corporações especialistas em uma determinada tecnologia, novas firmas entrantes e grupos de pesquisa aplicada em universidades ou similares fazem parte desse processo. O nível de competição e colaboração é determinado pela natureza, pelo porte e pelo poder de mercado existente entre as instituições. As diferentes trajetórias tecnológicas estão se desenvolvendo e o foco se encontra na tecnologia e nos recursos humanos que possuem esse talento tecnológico (SUAREZ, 2004).

No nível da firma, os ativos complementares e a credibilidade exercem uma grande influência para atrair bons pesquisadores. Novas entrantes, tipicamente, oferecerão opções de compra de ações para persuadir os talentos existentes a investirem seus esforços na empresa, compensando os benefícios oferecidos pelas veteranas. Atrair talentos técnicos-chave possui alta relevância nessa fase e ainda assim, existe um alto risco tecnológico envolvido (SUAREZ, 2004).

No nível do ambiente, o regime de apropriação exerce uma função importante, de forma que determina se as firmas com inovações relevantes poderão seguir a sua trajetória tecnológica com ou sem imitadores ao longo do percurso (SUAREZ, 2004).

A fase II (desenvolvimento técnico) é caracterizada pelo surgimento do primeiro protótipo do novo produto. Essa é a sinalização de que pelo menos uma trajetória tecnológica foi possível desenvolver a um nível que possa ser viável a sua inserção mercadológica em um futuro próximo. Essa etapa é utilizada, freqüentemente, para a reavaliação dos programas de $\mathrm{P} \& \mathrm{D}$ das firmas concorrentes e verificar a viabilidade de desenvolvimento das suas trajetórias de forma independente (SUAREZ, 2004). 
No nível da firma, a superioridade tecnológica possui o maior impacto no resultado final e, em alguns casos, pode levar ao surgimento precoce da tecnologia vencedora (SUAREZ, 2004).

No nível do ambiente, a regulamentação governamental pode afetar diretamente no resultado da batalha, favorecendo uma tecnologia em particular ou restringir as possibilidades tecnológicas da batalha (SUAREZ, 2004).

Segundo as figuras 4, 5 e 6, pode-se observar o surgimento do projeto dominante entre a teoria do ciclo de vida do produto e processo desenvolvido por Utterback e Abernathy (1975), do surgimento do projeto dominante desenvolvido por Utterback (1996) e da batalha tecnológica desenvolvida por Suarez (2004). 


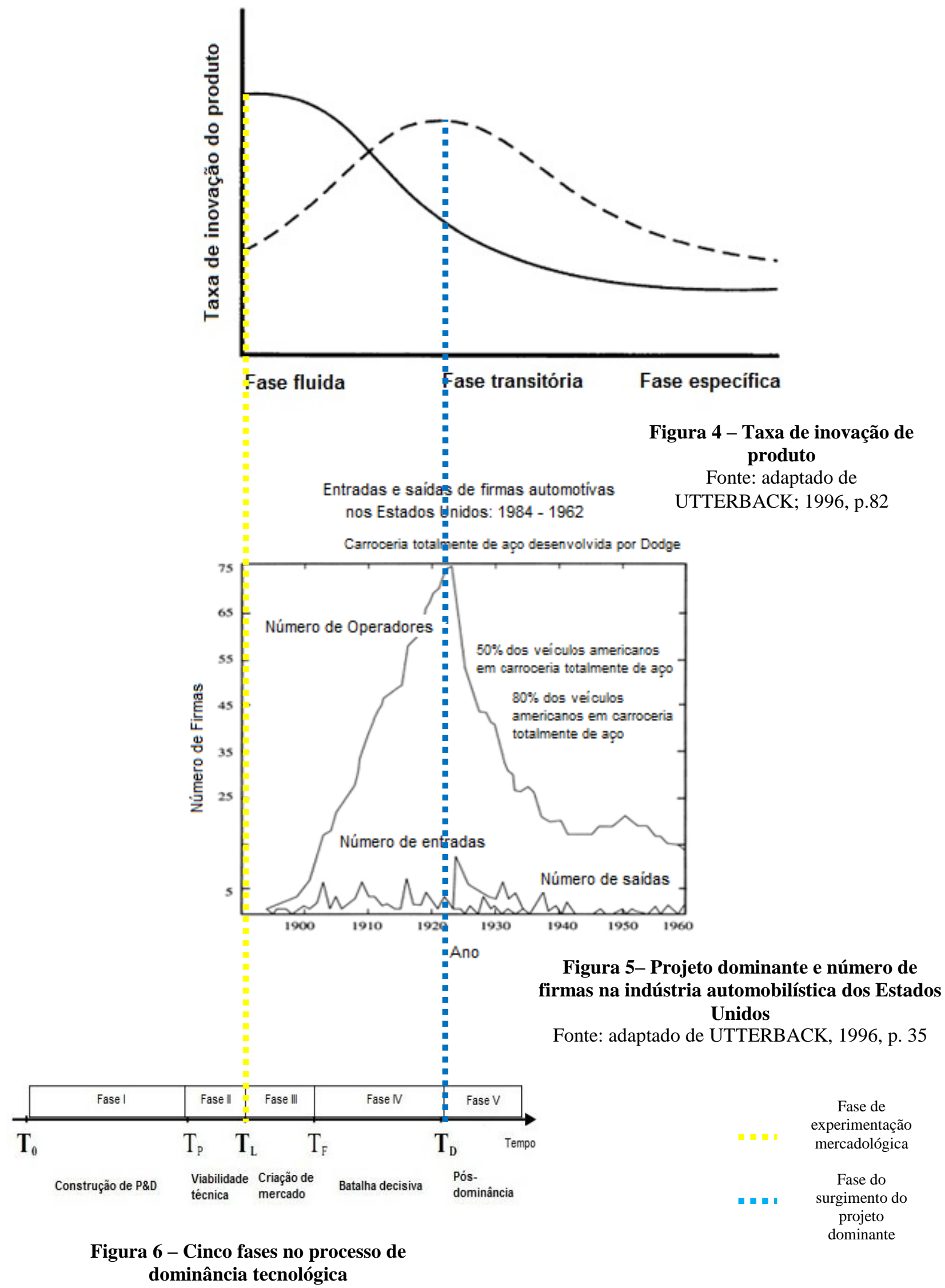

Fonte: adaptado de SUAREZ, 2004, p. 281. 
Quadro 1 - Fatores-chave de sucesso para cada fase do processo de dominância tecnológica

\begin{tabular}{|c|c|c|c|c|c|c|}
\hline $\begin{array}{l}\text { Escopo do } \\
\text { fator }\end{array}$ & $\begin{array}{c}\text { Fator de } \\
\text { dominância }\end{array}$ & Fase I & Fase II & Fase III & Fase IV & Fase V \\
\hline \multirow{4}{*}{ Firma } & $\begin{array}{l}\text { Superioridade } \\
\text { tecnológica }\end{array}$ & & $* * *$ & & & \\
\hline & $\begin{array}{c}\text { Credibilidade/ } \\
\text { ativos } \\
\text { complementares } \\
\end{array}$ & $* * *$ & & & $* * *$ & \\
\hline & Base instalada & & & & $* * *$ & $* * *$ \\
\hline & $\begin{array}{c}\text { Manobra } \\
\text { estratégica }\end{array}$ & & & $* * *$ & & \\
\hline \multirow{4}{*}{ Ambiente } & Regulamentação & & $* * *$ & & & \\
\hline & $\begin{array}{c}\text { Efeitos de rede } \\
\text { e custos de } \\
\text { mudança }\end{array}$ & & & & $* * *$ & $* * *$ \\
\hline & $\begin{array}{c}\text { Regime de } \\
\text { apropriabilidade }\end{array}$ & $* * *$ & & & & \\
\hline & $\begin{array}{c}\text { Características } \\
\text { do campo } \\
\text { tecnológico }\end{array}$ & $* * *$ & & & & \\
\hline
\end{tabular}

Fonte: adaptado de SUAREZ, 2004, p. 283.

\subsection{Análises de marketing versus Sondagem e aprendizagem mercadológica}

Segundo Penrose (1959), a direção da inovação não é randômica. Ela está fundamentada na natureza e no acúmulo de recursos existentes que formarão o tipo e a extensão dos serviços produtivos que a firma poderá gerar (DANNEELS, 2002). Nesse sentido, a trajetória tecnológica irá se desenvolver de acordo com as interações entre a inovação tecnológica e a demanda do mercado, formando o processo de evolução tecnológica (CLARK, 1985). Ao considerar que o fator decisivo para o sucesso das firmas é a extensão da compreensão das necessidades dos clientes desde o início do processo de inovação (MURMANN, FRENKEN, 2006), a sondagem e a aprendizagem pode ser um mecanismo de redução de incertezas coerente com esse contexto.

A fase de retenção tecnológica é caracterizada pelas inovações incrementais. (ANDERSON, TUSHMAN, 1990). Elas viabilizam o acúmulo de competências adquiridas na fase de variação e 
seleção do processo evolucionário da tecnologia seguindo a lógica de que uma variação selecionada com sucesso deve ser preservada e propagada (CAMPBELL, 1969 apud ANDERSON, TUSHMAN, 1990). Mas uma leitura cuidadosa da história industrial recente indica a conclusão de que em mercados globais competitivos de tecnologia intensiva a vantagem é construída e renovada pelas inovações mais descontínuas através da criação de novos negócios e famílias de produtos. As inovações incrementais ou contínuas são essenciais para a manutenção da liderança, mas apenas após o estabelecimento da inovação descontínua (LYNN et al, 1996).

O conceito do projeto dominante parte do pressuposto de que as tecnologias se desenvolvem através de um processo de tentativa e erro que implicam em riscos as firmas envolvidas no processo (MURMANN, FRENKEN; 2006). Nesse sentido, a gestão da inovação descontínua ou radical possui uma série de desafios únicos. É um processo longo (freqüentemente por mais de uma década), de intenso investimento (freqüentemente acima de 100 milhões de dólares) e caracterizado por surpresas desagradáveis e reveses sem garantia de sucesso. E o alto grau de incerteza é o fator mais persistente no processo (LYNN et al., 1996).

Tipicamente, a tecnologia está evoluindo, o mercado é pouco definido e a infraestrutura para entregar a tecnologia ainda em desenvolvimento ao mercado ainda indefinido é inexistente. Ao encontrar essas incertezas, o decisor possui poucos incentivos para maiores investimentos em programas formais de P\&D (ABERNATHY, UTTERBACK, 1978). O contexto se torna mais nebuloso pelas questões de alinhamento de tempos entre o desenvolvimento tecnológico, a emergência do mercado, o desenvolvimento das tecnologias concorrentes e por regulamentações governamentais sobre as quais a firma possui pouco ou nenhum controle. E essas incertezas interagem. A forma que a tecnologia em desenvolvimento terá dependerá da resposta do mercado em desenvolvimento às versões prévias da tecnologia. De maneira paradoxal, a réplica do mercado está relacionada à forma que a tecnologia se apresentar a ele (LYNN et al., 1996). Sem essas incertezas, a evolução tecnológica seria uma questão de seleção trivial do encontro de um projeto conhecido com uma necessidade conhecida (CLARK, 1985).

Inúmeras abordagens convencionais de marketing de novos produtos falham na sua aplicação às inovações descontinuas e a razão dessa ocorrência está na sutileza das incertezas (LYNN, 1993 
apud LYNN et al., 1996). Utilizar o cliente como direcionador de inovação é de pouca utilidade se não está claro quem ele é. Esse mercado nunca experimentou previamente os benefícios da nova tecnologia. E os métodos analíticos de avaliação de novas oportunidades de produto (fluxo de caixa descontado e análises de difusão de mercado) se parecem mais apropriados às inovações incrementais em relação às inovações radicais ou descontínuas (LYNN et al., 1996).

As projeções de desempenho futuro dessas análises se baseiam nas suposições realizadas sobre a grandeza e a taxa de crescimento futuros do mercado, na evolução e no grau de sucesso da tecnologia, no progresso realizado pelos competidores e tecnologias competidoras e no impacto de fatores exógenos como as regulamentações do governo. Todas essas suposições possuem uma alta incerteza no domínio descontínuo (Lynn et al.; 1996).

A forma de criação de entendimento de novos mercados está relacionada ao sucesso das firmas no desenvolvimento das inovações radicais (LYNN et al., 1996). E a abordagem utilizada para esse processo segue a lógica de síntese, contrapondo a lógica de análise das ferramentas tradicionais de marketing.

$\mathrm{Na}$ fase inicial fluida do ciclo de vida de produto e de processo da unidade produtiva, as necessidades de mercado estão pouco definidas e as tecnologias fundamentais foram pouco exploradas. Nesse contexto, existem duas fontes de ambigüidade relevantes para qualquer programa de P\&D: a incerteza tecnológica e a incerteza mercadológica (ABERNATHY, UTTERBACK, 1978).

Baer et al. (1976) aborda sobre a distinção entre as sondagens de campo, utilizadas para testar a tecnologia, e as demonstrações pré-comerciais subsequentes, utilizadas para realizar testes mercadológicos. Os engenheiros realizam essas distinções devido às noções de escala. Por exemplo, nos testes realizados em veículos sem emissão de poluentes, a fase de testes de campo pode envolver cerca de 100 veículos por ano enquanto que a fase de pré-commercialização pode envolver cerca de 1000 veículos por ano (HARBORNE, HENDRY; 2009). 
No processo de desenvolvimento de novos produtos de natureza descontínua, o desenvolvimento de protótipos precede as pesquisas de mercado porque os consumidores nem sempre estão aptos a compreender ou apreciar os produtos descontínuos e as suas possíveis ramificações. Os protótipos que envolvem a inovação descontínua possuem uma característica exploratória, contrastando com os protótipos alfa utilizados nas inovações contínuas (VERYZER, 1998). Dessa forma, eles poderiam corresponder aos testes de campo abordadas por Baer et al., (1976).

Como o consumidor é uma fonte de informação pouco adequada nesse contexto, uma alternativa utilizada em algumas empresas é a realização de inferências por um visionário do produto que possua uma percepção acurada da tecnologia e do mercado. A atenção é alocada na vantagem competitiva técnica que o novo produto irá oferecer em relação aos produtos e tecnologias existentes ao invés de observar os benefícios aos consumidores ou oportunidades comerciais. Dessa forma, esse processo é necessariamente conduzido pela tecnologia (VERYZER, 1998).

Lynn et al. (1996) consideram que o desenvolvimento do entendimento de novos mercados para as inovações descontínuas pode ocorrer através da sondagem e aprendizagem. O lançamento de versões prévias do produto no mercado viabiliza a sondagem da reação do mercado, obtendo informações para viabilizar a aprendizagem que será utilizada para o aperfeiçoamento e desenvolvimento de novas versões de produto. Dessa forma, obtém-se o processo de sondagem e aprendizagem para a criação de entendimento do mercado que ainda não existe para se desenvolver o produto que ainda não conhece as preferências de mercado.

Essa sondagem pode ser feita através de uma série de experimentos, lançando protótipos em diversos segmentos de mercado. O produto inicial não está relacionado ao ápice do desenvolvimento do processo, mas representa o primeiro passo da jornada. E a sua importância está relacionada a geração da aprendizagem que possibilitará o avanço no desenvolvimento dos próximos experimentos de mercado (LYNN et al., 1996). Na literatura da Perspectiva MultiNível desenvolvida por Geels (2002), a sondagem e aprendizagem mercadológica possui relevância significativa no desenvolvimento de nichos de mercado para inovações radicais (SCHOT, GEELS; 2008), podendo ser considerado como a fase de demonstração comercial abordado por Baer et al., (1976). 
Os testes realizados com versões imaturas do produto apenas se justificam se forem utilizados como uma forma de se aprender sobre a tecnologia, sobre o momento e a forma de execução do seu escalonamento, sobre o mercado e os tipos de aplicações e segmentos que possuem maior receptividade aos testes e sobre a influência dos fatores exógenos como as mudanças das regulamentações governamentais e a necessidade das suas aprovações. De alguma forma, os gestores precisam saber distinguir as oportunidades que valem a pena sondar e persistir das que não valem a pena porque esse processo consome uma quantidade relativamente alta de recursos e de tempo para se reduzir as incertezas contidas na trajetória a ser percorrida (LYNN et al., 1996).

A relevância de se utilizar a vertente teórica de sondagem e aprendizagem do Lynn et al. (1996) está na utilização desse mecanismo para a redução de incertezas contidas na trajetória de surgimento do projeto dominante. Dessa forma, essa literatura se compatibiliza com a literatura de batalhas tecnológicas.

A importância dessa estrutura conceitual para a pesquisa está incorporada no mecanismo de redução de incertezas que as organizações utilizam para obter informações do mercado em desenvolvimento com o objetivo de desenvolver a tecnologia que ainda não conhece as características que o mercado valoriza no contexto das inovações radicais.

O contexto estratégico define essa tomada de decisão. Ele exerce a função fundamental de incorporar a persistência no processo de busca pelas oportunidades. Ao encontrar as grandes dificuldades, as desencorajadoras incertezas tecnológicas e mercadológicas e a crescente resistência interna da organização é tentador atribuir a persistência para seguir em frente à visão de indivíduos extraordinários (LYNN et al., 1996).

Mas uma interpretação mais acurada desse percurso permite afirmar que os gestores veteranos persistem porque essas oportunidades convergem de forma estratégica com a organização. Ao observar de forma alheia à organização, podem-se classificar algumas oportunidades como sendo de alto risco. Sob outra perspectiva, se a observação incorporar o contexto estratégico da organização, pode-se considerar o mesmo investimento como sendo coerente com os seus objetivos futuros (LYNN et al., 1996). 
A literatura de inovação aborda a questão da relevância do papel da experimentação das firmas para conduzir novos produtos ao mercado, especialmente nos estágios iniciais de desenvolvimento das inovações radicais. Mas em alguns setores industriais, como o energético, por exemplo, as firmas costumam realizar esse processo de experimentação com o apoio do governo. Os programas de demonstração co-financiadas pelo governo são projetados para suprir essa questão (HARBORNE, HENDRY; 2009).

Os projetos de demonstração podem ser utilizados na redução das incertezas através da aprendizagem sobre direcionadores práticos, institucionais e sociais da tecnologia bem como sobre as barreiras que a nova tecnologia irá encontrar que podem gerar a necessidade de mudanças em instituições e na educação pública e se tornar um ponto focal para se realizar coalizões de ativistas e pioneiros para apoiar a sua adoção (HARBORNE, HENDRY; 2009).

\subsection{Perspectiva Multi-Nível (PMN)}

O processo de transição tecnológica pode ser analisado através do arcabouço conceitual descritivo da Perspectiva Multi-Nivel (PMN) desenvolvido por Geels (2002). Essa vertente teórica analisa o processo de transição tecnológica sob a perspectiva da ocorrência da evolução através de processos de variação, seleção e retenção (GEELS, 2002).

Essa vertente teórica considera que os fatores ambientais determinam as decisões das firmas (NELSON, WINTER; 1974). Nesse sentido, a PMN pode ser classificada como a vertente teórica que percebe o surgimento do projeto dominante como a consequência da evolução industrial.

Anderson \& Tushman (1990) consideram que a fase de variação é motivada pelas descontinuidades tecnológicas que iniciam uma rivalidade acirrada entre os regimes tecnológicos. Dinâmicas sociais, políticas e organizacionais selecionam os padrões industriais ou projetos dominantes entre as diversas alternativas existentes. As variações selecionadas positivamente se desenvolvem através de um longo período de retenção que ocorre através das modificações tecnológicas incrementais, do aumento da interdependência e do desenvolvimento de competências entre os participantes do processo. 
A PMN considera o processo de transição tecnológica como um processo de criação de sentido. Dessa forma, a dinâmica sócio-institucional argumenta que os grupos sociais influenciam as regras legislativas (regulamentações, padrões, leis), normativas (relacionamentos, valores, normas comportamentais) e cognitivas (sistemas de crenças, seleção de inovação, estruturação de problemas, princípios norteadores, busca por heurísticas) de uma forma direta (GEELS, SCHOT; 2007) e que as grandes mudanças legislativas e normativas são precedidas pelas mudanças cognitivas (GEELS, 2006).

Quando novas tecnologias emergem, existe uma flexibilidade interpretativa. Os grupos sociais divergem na estruturação e na interpretação dos problemas de forma a direcioná-las a explorar soluções divergentes, surgindo uma variedade de significados que pode ser eventualmente reduzida através do acordo: um processo de negociação em grupos e construção de coalizões. O acordo significa que uma interpretação eventualmente se torna dominante em uma comunidade e outras deixam de existir. Esse processo envolve a construção de uma estruturação cognitiva compartilhada que comporta elementos como, por exemplo, objetivos, problemas fundamentais, estratégias de solução de problemas (heurísticas), requerimentos a serem contempladas pelas soluções, teorias correntes, conhecimento tácito, procedimento de testes, métodos de projeção e critérios (GEELS, SCHOT; 2007).

O acordo poderia ser o equivalente ao surgimento do projeto dominante no arcabouço conceitual desenvolvido por Utterback e Abernathy (1975), Utterback (1996) e Suarez (2004), sendo considerado o agente referente na estabilização dos processos de aprendizagem.

Assim, a PMN busca entender como ocorre a transição tecnológica através da descrição hierárquica de três níveis: o micro-nível, onde ocorre o estabelecimento de nichos para a geração e desenvolvimento de inovações radicais; o meso-nível, no qual se encontram os regimes sociotécnicos e o macro-nível, onde se encontram os fatores externos que formam a paisagem (GEELS, 2002).

As trajetórias tecnológicas estão situadas na paisagem, sendo formadas por estruturas com tendências profundas. A paisagem sociotécnica é formada por fatores heterogêneos como preços 
do petróleo, crescimento econômico, guerras, emigração, amplas coalizões políticas, valores culturais e normativos, questões ambientais. Nesse nível encontramos a estrutura externa ou o contexto para a interação entre os atores. Nos regimes sociotécnicos se encontram as regras utilizadas para viabilizar e restringir as atividades nas comunidades de forma que atua como um mecanismo de seleção e retenção do processo, sendo considerada uma estrutura profunda. $\mathrm{O}$ contexto da paisagem é mutável, mas é mais lento se comparado ao processo de mudança do regime (GEELS, 2002).

A PMN considera que as transições tecnológicas ocorrem através das interações entre esses três níveis de forma que as inovações do nível micro de nicho constroem uma dinâmica interna através de processos de aprendizagem, melhorias em desempenho/preço e apoio de grupos de alta representatividade (GEELS, SCHOT; 2007). As mudanças no nível macro da paisagem geram pressão no nível meso do regime e a desestabilização do regime gera uma janela de oportunidade para as inovações geradas nos nichos. $\mathrm{O}$ alinhamento desses processos viabiliza as inovações radicais no mercado corrente onde eles competem com o regime existente (GEELS, SCHOT; 2007). 
Fase de experimentação mercadológica

Fase do $\because n-$ surgimento do projeto dominante

\section{Paisagem}

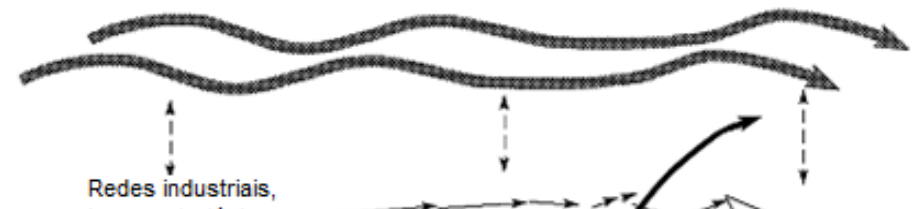
socio-técnico

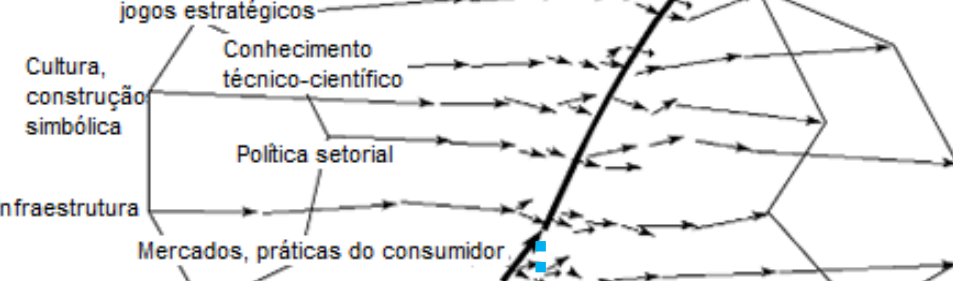

Nichos tecnológicos

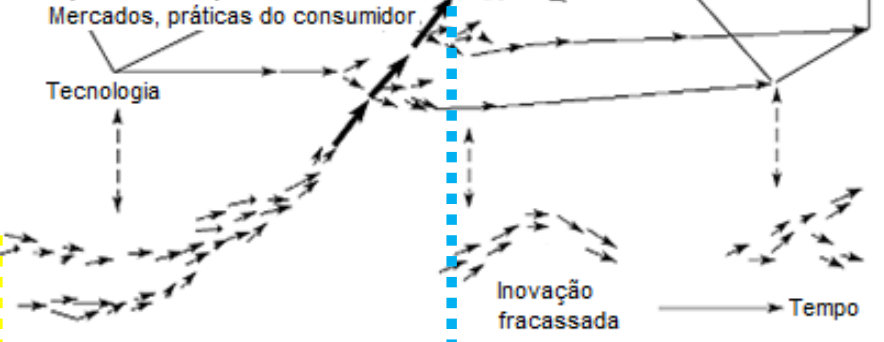

Figura 7 - Dinâmica da PMN em transições tecnológicas FONTE: adaptado de GEELS, 2002, p.1263.

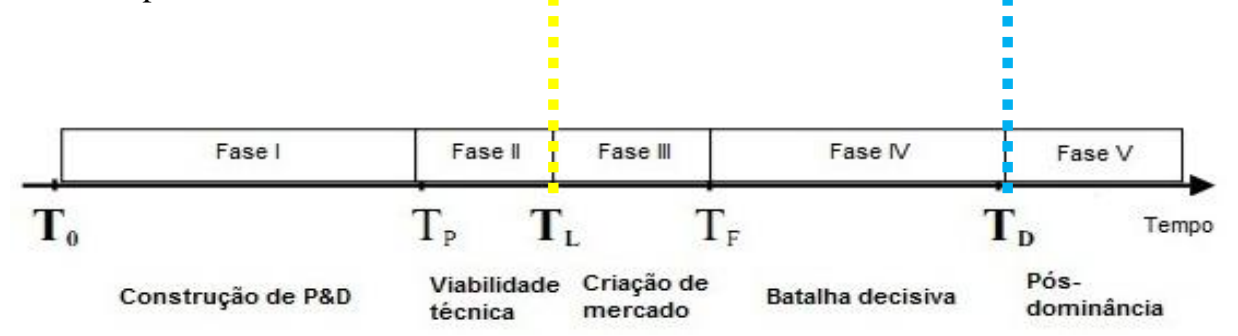

Figura 8 - Cinco fases no processo de dominância tecnológica FONTE: adaptado de SUAREZ, 2004, p. 281.

A relevância desse arcabouço teórico no entendimento do surgimento do projeto dominante está na viabilização da análise sob a perspectiva de multi-nível do processo de desenvolvimento das competências da batalha tecnológica.

No nível-micro, o projeto dominante não está estabelecido, ocorrendo uma efervescência de esforços para todas as direções possíveis, gerando a variação (GEELS, 2002). Nesse sentido, as organizações devem desenvolver diversas competências para influenciar e serem influenciadas no processo de evolução tecnológica. Dado que as inovações descontínuas podem ser imprevisíveis, as firmas devem desenvolver a capacidade de iniciar essas descontinuidades ou reagir de forma ágil (ANDERSON, TUSHMAN; 1990). 


\section{POLUIÇÃO ATMOSFÉRICA I}

\subsection{Introdução}

No capítulo anterior, descrevemos a fundamentação teórica utilizada para a construção do estudo de caso da GM. Nesse capítulo, desenvolveremos um maior entendimento sobre o desenvolvimento da tecnologia de veículos elétricos na GM, analisando os fatores internos (firma) e externos (ambiente) que influenciaram o processo da evolução da tecnologia na firma.

Iniciaremos o capítulo com a apresentação dos protótipos desenvolvidos entre 1964 e 1969, utilizando a vertente teórica de sondagem e aprendizagem abordada por Lynn et al. (1998) de forma a descrever as sondagens e aprendizagens tecnológicas dos modelos. Nas próximas seções, desenvolveremos um maior entendimento dos fatores observados de forma que na última seção, apresentaremos a análise da influência dos fatores internos e externos no desenvolvimento do veículo elétrico na GM.

Na seção 3, descreveremos a evolução das questões sociais relacionadas à questão da poluição atmosférica entre a década de 40 e o período atual. Como possível consequência das questões sociais, apresentaremos na seção 4 as regulamentações estabelecidas para favorecer o controle da emissão de poluentes veiculares no escopo estadual e federal. Dada a apresentação dos fatores ambientais do aspecto social e regulatório nas seções anteriores, iremos apresentar na seção 5 a política do governo e as estratégias utilizadas pelas montadoras e pela GM para aprofundarmos o nosso entendimento das possíveis inter-relações entre os atores naquele período. Na próxima seção, descreveremos o apoio da GM em tecnologias aeroespaciais e aeronáuticas evidenciando a capacitação tecnológica da firma e as possíveis sinergias consequentes desse potencial tecnológico no desenvolvimento do veículo elétrico. Dessa forma, as seções 3, 4, 5 e 6 foram observadas de forma paralela as vertentes teóricas da PMN, abordada por Geels (2006), e batalhas tecnológicas, abordada por Suarez (2004). Através da trajetória dos engenheiros envolvidos nos fatores observados, tentou-se identificar o processo sob uma perspectiva de desenvolvimento de competências, abordada pela PMN. De forma complementar, os fatores observados foram estruturados de acordo com o arcabouço teórico das batalhas tecnológicas. 
Apresentamos, inicialmente, os protótipos de veículos elétricos desenvolvidos nesse período e continuamos o desenvolvimento das seções de maneira a evidenciar os fatores internos e externos verificados no processo de desenvolvimento da tecnologia. Na seção 7, finalizaremos a descrição do capítulo com a análise dos fatores observados no desenvolvimento da tecnologia do veículo elétrico na firma sob a perspectiva de constatação de possíveis evidências de influências de natureza causal nas fases I e II da estrutura conceitual desenvolvida por Suarez (2004), na trajetória das competências dos agentes envolvidos na formação das regras cognitivas do arcabouço teórico desenvolvido por Geels (2006) e no processo de sondagem e aprendizagem do arcabouço teórico desenvolvido por Lynn et al. (1996).

\subsection{Protótipos de veículo elétrico}

A GM Research Laboratories iniciou um programa de pesquisa de novas plataformas ${ }^{1}$ através do desenvolvimento dos protótipos Electrovair e Electrovan no início da década de 60 (AGARWAL, 1969; CCT, 2011).

\subsubsection{Electrovair I e II}

Em 1964, foi lançado o Electrovair I e, em 1966, foi desenvolvido o Electrovair II e o Electrovan (RAJASHEKARA, 1994).

Os protótipos Electrovair I e II foram desenvolvidos na plataforma do Corvair (YU et al., 2011) pelos engenheiros Edward Rishavy, Paul Agarwal (RISHAVY et al., 1967; AGARWAL, 1969) e George Spix (SALIHI et al., 1967). A diferença tecnológica observada nesses dois modelos foi em relação a robustez do sistema de baterias e do motor de indução utilizado.

O Electrovair I utilizou um sistema de baterias de prata-zinco de 450 volts e motor de indução AC de 90-hp (THEELECTRIC, 2001) enquanto que o Electrovair II utilizou o motor de indução AC (JOHNSTON, 1969) de 115-hp com um sistema de baterias de prata-zinco de 530 volts (THEELECTRIC, 2001). O sistema de baterias de prata-zinco estava sendo desenvolvido pela

\footnotetext{
${ }^{1}$ Nova plataforma: novo sistema de transmissão elétrico ou novo chassi (Yu et al., 2011).
} 
Delco Remy no início da década de 60 para aplicações aeroespaciais (COOPER, INGLING; 1963), sendo utilizadas no míssil balístico Minuteman (YU et al., 2011) e no veículo elétrico orbital lunar rover (CCT, 2011). Essa tecnologia representava o estado da arte em baterias naquele período, mas verificou-se que eram muito caras, pesadas, possuíam um ciclo de vida muito curto e tempo de recarga alta (RAJASHEKARA, 1994).

Em 1963, a Allison estava desenvolvendo a tecnologia de células à combustível para aplicações militares e aeroespaciais (DDC, 1963b) e, em 1966, a GM Research Laboratories desenvolveu o Electrovan em conjunto com a Union Carbide Corporation com a intenção de testar a tecnologia de célula a combustível em veículos. Assim, a GM se tornou pioneira nesse tipo de testes no escopo global (RAJASHEKARA, 1994).

O protótipo utilizou um sistema de propulsão híbrido com células combustíveis a hidrogênio (RAJASHEKARA, 1994), sendo desenvolvido pelos engenheiros Edward Rishavy e Floyd Wyczalek do Power Development Group da GM (MARKS et al., 1967) na plataforma do GMC Handivan (YU et al., 2011). O sistema de direção elétrica era compatível com veículos fora-deestrada, sistemas propulsores de torpedos e de artefatos navais e veículos lunares (AGARWAL, 1969). Os testes evidenciaram que a célula a combustível era pesada e possuía amplas dimensões, os componentes e materiais utilizados eram caros, o arranque era complexo e lento, a separação dos sistemas de fluídos (eletrólito, hidrogênio e oxigênio) era complexa assim como a conversão de potência (RAJASHEKARA, 1994).

\subsubsection{Stir-Lec I, Military 6x6 e Opel Kadette}

Em 1968, a GM desenvolveu duas plataformas novas através dos protótipos Stir-Lec I e o Military 6x6 (RAJASHEKARA, 1994) e uma plataforma derivativa através do protótipo Opel Kadette (ESTADOSUNIDOS, 1975).

O desenvolvimento da tecnologia do motor stirling na GM iniciou, em 1958, devido ao seu interesse em aplicar a tecnologia em propulsão naval, em geradores de potência para locomotivas e para aplicações militares e aeroespaciais (NASA, 1974). Em 1968, a GM Research Laboratories 
desenvolveu, através do pesquisador Paul Agarwal (AGARWAL et al., 1969), o Stir-Lec I (RAJASHEKARA, 1994) na plataforma do Opel Kadette (YU et al., 2011). O seu objetivo era testar o uso do motor stirling em um veículo elétrico híbrido compacto (RAJASHEKARA, 1994), utilizando hidrogênio e baterias chumbo-ácido como fonte de suprimento energético do sistema de propulsão (RAJASHEKARA, 1994). A tentativa de aprendizagem gerada nos testes gerou uma base de informações que constataram a viabilidade técnica da utilização do motor stirling em um sistema de propulsão VEH com um desempenho limitado aceitável para fins urbanos utilizando o motor stirling para prover a potência menor necessária para velocidades estáveis e utilizando o sistema de propulsão elétrica para prover a potência maior através do fornecimento energético do sistema de baterias de zinco-ar em conjunto com o sistema de baterias de chumboácido (ESTADOSUNIDOS, 1975).

O Military 6x6 foi um protótipo desenvolvido pela Delco Remy (RAJASHEKARA, 1994) através dos engenheiros Walter Slabiak da Propulsion Systems Laboratory (U.S. Army TankAutomotive Command) e George Collins da Delco Remy (SLABIAK, COLLINS; 1968) na plataforma de caminhões militares (YU et al., 2011) para testar a tecnologia do motor sem escovas em corrente contínua (RAJASHEKARA, 1994). Essa tecnologia foi originalmente desenvolvida para aplicações em satélites (NASA, 1968) na NASA (NASA, 1964) e foi desenvolvida para aplicações veiculares e aeroespaciais na U.S. Army Tank-Automotive Center pelo Walter Slabiak (SLABIAK, LAWSON; 1966). Nesse sentido, o desenvolvimento do protótipo Military 6x6 foi utilizado como fonte de informações para apoiar o processo de seleção do motor a ser utilizado no veículo orbital lunar rover do programa Apollo (NASA, 1969; SLABIAK, COLLINS, 1968). Os testes do protótipo Military 6x6 demonstraram muitas vantagens na utilização dessa tecnologia, como uma adaptabilidade a diversos modelos de veículos, melhor eficiência no consumo de combustíveis, sistema de propulsão estável em diferentes condições (RAJASHEKARA, 1994).

As baterias de zinco-ar estavam sendo desenvolvidas na GM especificamente para veículos elétricos (HIETBRINK et al., 1971) e foram testadas em conjunto com as baterias de chumboácido no protótipo derivativo Opel Kadette (ESTADOSUNIDOS, 1975). Ele utilizou a propulsão elétrica pura (WESTBROOK, 2001), sendo desenvolvido na categoria de carro de passageiro 
(ESTADOSUNIDOS, 1975) pelos engenheiros Earl Hietbrink, Gary Winebrener e Romeo Witherspoon (HIETBRINK et al., 1971). A bateria de zinco-ar alimentava o sistema de bateria de chumbo-ácido e este gerava a energia responsável pelo movimento mecânico do veículo (ESTADOSUNIDOS, 1975).

As vantagens verificadas nesse protótipo foram a satisfatória autonomia urbana, nenhuma emissão de poluentes atmosféricos ou sonoros e o potencial econômico da tecnologia de bateria de zinco-ar. Em relação às desvantagens, foi constatado que o modelo era pesado, necessitava de um longo período para a recarga, possuía um ciclo de vida (das baterias) curto e o seu custo de desenvolvimento era alto (ESTADOSUNIDOS, 1975).

\subsubsection{GM512}

Em 1969, foi desenvolvido o protótipo GM512 na versão Veículo Elétrico Puro (VEP) e Veículo Elétrico Híbrido (VEH) (RAJASHEKARA, 1994). Esse foi um modelo desenvolvido para duas pessoas, sendo considerado um microcarro (YU et al., 2011).

Foram realizados testes nas duas versões que utilizaram as mesmas especificações no seu sistema de propulsão (RAJASHEKARA, 1994) que era composto pelo motor DC 8-hp que era alimentado por um sistema de baterias de chumbo-ácido de 84-volts (THEELECTRIC, 2001). Esse modelo foi desenvolvido em uma plataforma exclusiva (YU et al., 2011) pelo engenheiro Floyd Wyczalek que foi o gerente do programa desse modelo (WYCZALEC, 1993). Os testes desenvolvidos nos protótipos evidenciaram que a versão elétrica pura obteve uma aceleração mais rápida que a versão híbrida (RAJASHEKARA, 1994). 
Quadro 2 - Protótipos da GM entre 1964 e 1969

\begin{tabular}{|c|c|c|c|c|c|c|c|c|}
\hline Anos & Veículos & Bateria & $\begin{array}{c}\text { Sistema } \\
\text { de } \\
\text { Propulsão }\end{array}$ & \begin{tabular}{|c|} 
Categoria \\
de \\
veículo \\
\end{tabular} & $\begin{array}{l}\text { Protótipo/ } \\
\text { Comercial }\end{array}$ & Plataforma & Engenheiros & Objetivo \\
\hline $1964 / 66$ & $\begin{array}{c}\text { Electrovair } \\
\text { I e II }\end{array}$ & $\begin{array}{l}\text { Prata- } \\
\text { zinco }\end{array}$ & $\begin{array}{l}\text { VEP - } \\
\text { Rede } \\
\text { elétrica }\end{array}$ & $\begin{array}{c}\text { Carro de } \\
\text { passageiro }\end{array}$ & Protótipo & Corvair & $\begin{array}{c}\text { Edward } \\
\text { Rishavy/Paul } \\
\text { Agarwal/ } \\
\text { George Spix }\end{array}$ & $\begin{array}{c}\text { Testar } \\
\text { baterias de } \\
\text { prata-zinco }\end{array}$ \\
\hline 1966 & Electrovan & & FC & Van & Protótipo & $\begin{array}{c}\text { GMC } \\
\text { Handivan }\end{array}$ & $\begin{array}{c}\text { Edward } \\
\text { Rishavy/ } \\
\text { Floyd } \\
\text { Wyczalek }\end{array}$ & $\begin{array}{c}\text { Testar a } \\
\text { tecnologia da } \\
\text { célula a } \\
\text { combustível } \\
\end{array}$ \\
\hline 1968 & $\begin{array}{c}\text { Opel } \\
\text { Kadette }\end{array}$ & $\begin{array}{l}\text { Chumbo- } \\
\text { ácido e } \\
\text { Zinco-ar }\end{array}$ & $\begin{array}{c}\text { VEH - } \\
\text { Gasolina }\end{array}$ & Caminhão & Protótipo & $\begin{array}{c}\text { Opel } \\
\text { Kadette }\end{array}$ & $\begin{array}{c}\text { Earl } \\
\text { Hietbrink/ } \\
\text { Gary } \\
\text { Winebrener/ } \\
\text { Romeo } \\
\text { Witherspoon }\end{array}$ & $\begin{array}{c}\text { Testar } \\
\text { baterias de } \\
\text { zinco-ar em } \\
\text { conjunto com } \\
\text { baterias de } \\
\text { chumbo- } \\
\text { ácido }\end{array}$ \\
\hline 1968 & $\begin{array}{c}\text { Military } \\
\text { 6x6 }\end{array}$ & $\begin{array}{l}\text { Chumbo- } \\
\text { ácido }\end{array}$ & $\begin{array}{c}\text { VEH - } \\
\text { Gasolina }\end{array}$ & $\begin{array}{c}\text { Carro de } \\
\text { passageiro }\end{array}$ & Protótipo & $\begin{array}{l}\text { Military } \\
\text { truck }\end{array}$ & $\begin{array}{l}\text { Walter } \\
\text { Slabiak/ } \\
\text { George } \\
\text { Collins }\end{array}$ & $\begin{array}{l}\text { Testar o } \\
\text { motor sem } \\
\text { escovas de } \\
\text { corrente } \\
\text { contínua } \\
\text { (brushless } \\
\text { motor dc) } \\
\end{array}$ \\
\hline 1968 & Stir-Lec I & $\begin{array}{c}\text { Chumbo- } \\
\text { ácido }\end{array}$ & $\begin{array}{c}\text { VEH - } \\
\text { Gasolina }\end{array}$ & $\begin{array}{c}\text { Carro de } \\
\text { passageiro }\end{array}$ & Protótipo & $\begin{array}{c}\text { Opel } \\
\text { Kadette }\end{array}$ & $\begin{array}{c}\text { Paul } \\
\text { Agarwal }\end{array}$ & $\begin{array}{c}\text { Testar o } \\
\text { motor stirling }\end{array}$ \\
\hline 1969 & $\begin{array}{l}\text { GM512 } \\
\text { VEH e } \\
\text { VEP }\end{array}$ & $\begin{array}{c}\text { Chumbo- } \\
\text { ácido }\end{array}$ & $\begin{array}{l}\text { VEP - } \\
\text { Rede } \\
\text { elétrica }\end{array}$ & $\begin{array}{c}\text { Carro de } \\
\text { passageiro } \\
\text { (micro) }\end{array}$ & Protótipo & Nova & $\begin{array}{c}\text { Floyd } \\
\text { Wyczalec }\end{array}$ & $\begin{array}{c}\text { Testar o } \\
\text { modelo em } \\
\text { versão VEP e } \\
\text { VEH }\end{array}$ \\
\hline
\end{tabular}

FONTE: Adaptado de YU et al., 2011

\subsection{Questões sociais}

\subsubsection{Poluição atmosférica}

Em 1942, começou a surgir as primeiras incidências de irritação ocular na população de Los Angeles e do surgimento de uma camada de aspecto de brilho metálico em algumas plantações da região. Esses malefícios surgiam após o aparecimento de nevoeiros fotoquímicos que foram chamados de smog e não havia um entendimento conclusivo sobre a fonte dessa poluição atmosférica porque os compostos poluentes conhecidos naquele período não causavam aquele tipo de sintomas nas pessoas ou nas plantas (HAAGEN-SMIT, 1970). 
O sul da California é considerado um local de refúgio de algumas cidades do leste dos Estados Unidos que possuem alta densidade populacional e que são consideradas pouco agradáveis para morar. Dessa forma, quando surgiu a questão dos grandes nevoeiros fotoquímicos, os cidadãos e a imprensa de Los Angeles imediatamente reinvidicaram contra a poluição atmosférica (HAAGEN-SMIT, 1970).

Foram realizados testes de interação entre os compostos naturais e poluentes atmosféricos para tentar descobrir a fonte dessa neblina maléfica. Mas percebeu-se que os compostos naturais não possuíam relação com o surgimento desse fenômeno (Haagem-Smit, 1970). E, em 1950 (Dewey, 1999), quando estavam testando a interação entre as substâncias poluentes entre si, o Dr. HaagenSmit tornou pública a sua pesquisa sobre a natureza do nevoeiro que irritava o globo ocular humano e prejudicava as plantações. Ele atribuiu a origem da oxidação fotoquímica de materiais orgânicos à indústria petroquímica e automotiva através do descobrimento da reação fotoquímica (HAAGEN-SMIT, 1970) entre a luz solar combinada com os hidrocarbonetos e os óxidos de nitrogênio, ambos emitidos pelos veículos à propulsão de combustão interna, se interagiam de forma a criar o nevoeiro fotoquímico que estava afetando a região de Los Angeles (MINTZ, COHEN; 1971).

O estado da California possui subdivisões que são chamadas de regiões e cada região abrange um conjunto de municípios. Em relação a regulamentação, as regiões e os municípios atendem a legislação estadual, mas não possuem uma relação direta entre elas. Dessa forma, surgiu a necessidade de uma única agência assumir a autoridade legal e a responsabilidade pelo controle da poluição atmosférica.

Em 1946, foi instituído o State Air Pollution Control Act que alinhava a questão da poluição atmosférica no âmbito regional e municipal ao estado. Essa regulamentação instituía um distrito de controle de poluição atmosférica em cada County do estado, legitimizando autoridade ao County Board of Supervisors (HAAGEN-SMIT, 1970). 
Essas pesquisas foram desenvolvidas com o apoio dos primeiros gestores de controle de poluição atmosférica da região de Los Angeles (Air Pollution Control Officer of Los Angeles County Air Pollution Control District), que foi instituído em 1946 (HAAGEN-SMIT, 1970).

Em 1948, ocorreu um episódio de poluição atmosférica de proporções desastrosas na cidade de Donora (Pensilvânia), que foi vinculado a causa de 20 óbitos e o adoecimento grave de aproximadamente 50\% dos cidadãos (BRESLOW, GOLDSMITH; 1958). A poluição atmosférica envolvida nesse caso foi dessemelhante ao que estava ocorrendo na região de Los Angeles. Mas, devido às gravíssimas proporções desse incidente (HEIMANN, 1964) e a possibilidade da recorrência dessa tragédia em outros locais (BRESLOW, GOLDSMITH, 1958), o Public Health Service iniciou o seu envolvimento nessa questão (HEIMANN, 1964), elevando a relevância da poluição atmosférica ao escopo da saúde pública nacional.

Dois anos depois desse incidente, Dr. Haagen-Smit ofereceu um suporte fundamental para que os gestores da agência de controle de poluição atmosférica da região de Los Angeles iniciassem as suas ações com o foco na indústria petroquímica e automotiva (HAAGEN-SMIT, 1970).

Em 1953, de forma paralela ao gestor da agência de controle de poluição atmosférica da região de Los Angeles, o supervisor dessa região, Kenneth Hahn, solicitou que as montadoras apoiassem as pesquisas focadas em diminuição de emissões de gases poluentes. Mas as respostas foram vagas (MELOSI, 2011). Foram indicadas as montadoras e as refinarias da indústria de petróleo como as causadoras dos malefícios das reações fotoquímicas na população da Califórnia, mas as montadoras se negaram a assumir a responsabilidade e as refinarias de petróleo patrocinaram pesquisas que contestassem essa "acusação". A indústria automobilística estava em um momento de alta legitimidade política devido a seu envolvimento na manufatura bélica durante a guerra e por suas contribuições no índice de empregabilidade no período pós-guerra (PENNA, GEELS; 2012).

Em 1954, ocorreu uma reincidência do nevoeiro fotoquímico em Los Angeles que se prolongou por duas semanas e houve uma demanda imediata para a mitigação dessa questão. Goodwin Knight, governador da Califórnia, considerou declarar emergência pública, mas hesitou e 
assegurou que, naquele momento, essa questão não ameaçava a saúde ou a vida dos cidadãos. Pouco mais de uma semana após esse pronunciamento, Knight anunciou o "all-out smog war" que era um programa direcionado a mitigar a questão do nevoeiro fotoquímico utilizando todos os recursos técnicos do estado (KRIER, URSIN; 1977).

Nesse período (AWM, 2009), a gestão da agência de controle de poluição atmosférica da região de Los Angeles desenvolveu uma nova metodologia de controle das emissões de poluentes atmosféricos. Foi concedido ao ex-capitão da polícia, Mr. Louis Fuller, apoio incondicional para que ele organizasse um time para executar e inspecionar os aspectos regulamentares estabelecidos em relação a poluição atmosférica. Os oficiais uniformizados com credenciais de xerife ajudaram a estabelecer a confiança nos esforços de controle do distrito (HAAGEN-SMIT, 1970).

Em 1955, foi concedido ao Public Health Service (subsidiaria do Department of Health, Education, \& Welfare) uma autoridade especial para realizar pesquisas para verificar os efeitos da poluição atmosférica, estabelecer mecanismos de controle, fornecer assistência técnica as autoridades locais e estaduais e treinar especialistas para atuarem nessa questão (HEIMANN, 1964)

Apesar das regiões do estado terem assumido um papel fundamental no controle da poluição atmosférica, a experiência prática ensinou ao governo estadual que ele não poderia se eximir da responsabilidade final em alguns aspectos gerais desse controle. A formação do Bureau of Air Sanitation in the State Department of Public Health previu um papel mais proeminente que o estado iria exercer. A agência foi encarregada de realizar estudos sobre as causas da poluição atmosférica, auxiliando os distritos regionais na diminuição da poluição atmosférica e na determinação dos seus efeitos na saúde e outros efeitos que poderiam causar (HAAGEN-SMIT, 1970).

Em relação ao posicionamento da indústria automotiva, após obter os resultados conclusivos da pesquisa do Dr. Haagen-Smit, indústria continuou postergando a responsabilidade das suas ações, alegando que a elevada incerteza vinculada ao entendimento das causas da poluição atmosférica a 
impedia de assumir a responsabilidade dessa questão. E contra-argumentou que as características regionais e topográficas da região de Los Angeles estavam vinculadas a causa do nevoeiro fotoquímico (PENNA, GEELS, 2012)

Dessa forma, em 1959, o Bureau estabeleceu o primeiro padrão de qualidade para a atmosfera da California, representando o evento mais significativo da primeira década de trabalho político (HAAGEN-SMIT, 1970).

Nos anos 60, a questão da poluição atmosférica começou a ser alardeada em Nova Iorque e Filadélfia, por exemplo, acompanhando o movimento de aumento de aquisição de veículos nesses estados. Profissionais da área da saúde (médicos) se envolveram na campanha contra as emissões de poluentes e o entendimento de que a poluição poderia causar mortes gerou uma situação alarmante nessas regiões. Novos grupos ativistas (Clean Air Council e Group Against Smog and Pollution) se uniram a grupos ambientalistas e a representantes do segmento de profissionais da área da saúde para estabelecer um movimento social com a intenção de influenciar a opinião pública (PENNA, GEELS; 2012) a favor do controle das emissões de poluentes.

A região de Los Angeles estava sendo considerado um caso crítico nacional para a questão relacionada a poluição atmosférica, recebendo uma relevante influência de políticos, como Kenneth Hahn por exemplo, para a mobilização da opinião pública a questão da poluição atmosférica desde a década anterior (DEWEY, 1998b).

\subsubsection{Segurança dos veículos}

Em 1966, Ralph Nader (advogado e desenvolvedor-chefe das regulamentações federais de segurança automotiva) denunciou a falta de segurança dos automóveis através do livro Unsafe at any speed, destacando o modelo Corvair da GM (VINSEL, 2011). Esse fato influenciou os compradores potenciais do Corvair de forma que, em 1966, a GM comercializou 88.951 unidades do modelo. Dois anos depois as vendas diminuíram de forma vertiginosa constatando-se 12.977 unidades vendidas e, em 1969, o número de unidades comercializados desse modelo 
despencaram para apenas 4.280 veículos (KURYLKO, 2011). Em meramente 3 anos, as vendas do Corvair tiveram uma queda abrupta de quase $95 \%$.

A GM tentou descredibilizar o Ralph Nader através de investigações da sua vida pessoal (PENNA, GEELS; 2012). Nesse contexto, em Março de 1966, o Senador Abraham Ribicoff conduziu uma ação para esclarecer essa situação e as audiências ocorreram, não coincidentemente, no Federal District Court em Los Angeles (DEWEY, 1998b). A reputação da indústria foi abalada pela denúncia de Ralph Nader e pelas audiências subsequentes do Senador Abraham Ribicoff, que evidenciaram as campanhas secretas de reparos em que um a cada cinco veículos necessitou de recondicionamento devido a questões relacionadas a defeitos de itens de segurança (PENNA, GEELS; 2012).

O presidente da GM, James Roche, se retratou publicamente ao Ralph Nader. E as audiências forneceram suporte para o estabelecimento do National Traffic and Motor Vehicle Safety Act, em Setembro de 1966, e do Department of Transportation Act, em Outubro de 1966 (USDOT, 2009).

Em Abril de 1967 (USDOT, 2009), foi oficialmente estabelecido o Departament of Transportation (DOT) dos Estados Unidos, que estava previsto no Department of Transportation Act (BOYD, 1968; ISSEL, 1999). O DOT representou o avanço da questão do transporte nacional ao nível ministerial (USDOT, 2009) de maneira que a sua responsabilidade principal era a coordenação dos aspectos físicos, econômicos, sociais e políticos do sistema de transporte do país, sendo a dimensão das políticas econômicas a mais crítica em relação à necessidade de coerência e alinhamento (BARNESS, 1970).

\subsubsection{Sindicato dos trabalhadores automotivos}

Em 22 de Abril de 1970 (DEWEY, 1998a), houve aumento de pressão social no evento Earth Day quando o United Auto Workers (UAW) se uniu ao Coalition for Clean Air para fazer lobby no Senado de forma a tornar a regulamentação em emissões de poluentes mais rigorosa (PENNA, GEELS; 2012). 
O sindicato automotivo dos Estados Unidos estava envolvido na causa ambientalista, provavelmente, devido ao aumento do poder de barganha para reinvindicar benefícios de longo prazo, contrapondo com a visão de estabilidade econômica de curto-prazo entre a firma e o sindicato. A classe trabalhadora estava condicionada a reinvidicar questões de curto-prazo, mas percebeu-se que ao alinhar as causas individualistas sindicais as causas sociais poderia-se maximizar os benefícios tanto do ponto de vista do sindicato quanto do ponto de vista da sociedade. Dessa forma, houve uma tentativa de modificação dos valores dos trabalhadores no sentido de se obter maiores benefícios de longo prazo (HULTIN, 1972).

Três meses depois do evento, o UAW se uniu ao Sierra Club, ao Wilderness Society, ao National Audubon Society, ao Environmental Action, ao Friends of the Earth e ao Zero Population Growth para submeter uma carta ao congresso solicitando que os padrões de controle de poluição atmosférica se tornassem tão severos que os motores a combustão interna fossem banidos dos automóveis em cinco anos de forma a garantir a segurança e a pureza atmosférica em 1975 (DEWEY, 1998a). Dessa forma, essa pressão social representava a intenção do sindicato dos trabalhadores automotivos e dos grupos ambientalistas de abordar a questão da poluição atmosférica através da substituição do motor de combustão interna dos veículos terrestres por tecnologias alternativas como a tecnologia de motor a vapor (DEWEY, 1998a) ou a tecnologia de propulsão elétrica (SANDALOW, 2009).

\subsection{Regulamentação}

O carro se tornou o pilar central da idealização da liberdade nos Estados Unidos. Como um governo eleito democraticamente tenta controlar os aspectos prejudiciais (poluição atmosférica e insegurança dos veículos, por exemplo) de uma tecnologia que é tão central na maneira que os cidadãos imaginam-se? Como regulamentar essa tecnologia quando o governo possui a tradição de interferir em atividades individuais e empresariais o menos possível? (VINSEL, 2011).

Uma forma encontrada para lidar com essas questões foi conhecida como padrões de desempenho. Ela especifica os tipos de tecnologias que as firmas poderiam utilizar para resolver uma questão, estabelece uma meta a ser seguida e as firmas podem atingi-la da maneira que lhe 
for conveniente. Caso seja estabelecido um padrão de desempenho com uma meta que as firmas não consigam atingir a não ser que inovem, ela é chamada de padrão technology-forcing (VINSEL, 2011).

Outra forma de controle seria o reconhecimento do governo como um parceiro do processo de transição, iniciando mudanças institucionais e desenvolvendo novos instrumentos como incentivos fiscais e subsídios, por exemplo. De maneira que esse processo se encaminhe para uma política chamada market-driven (VOLLENBROEK, 2002). Esse posicionamento considera o desenvolvimento tecnológico e mercadológico de maneira coordenada (LARRUE, 2003), constatando-se uma significativa coerência entre a política e os preços para geração de incentivo a inovação (VOLLENBROEK, 2002).

Independente da abordagem de comando utilizada pelo governo, o congresso frequentemente renúncia uma parte do controle do processo regulatório para delegar autoridade a uma agência regulatória, que está melhor contextualizada para tomar decisões com base técnica (GERARD et. al., 2003).

\subsubsection{Contexto}

Nesse período, os Estados Unidos foi governado pelos Presidentes Kennedy, Johnson (VINSEL, 2011) e Nixon (REEVES, 2001). A administração de Kennedy e Johnson enfatizou a alocação de recursos para questões sociais, sendo que Kennedy priorizou a proteção aos consumidores e trabalhadores; e Johnson focou na questão dos direitos civis (VINSEL, 2011). A energia nuclear estava sendo fortemente alardeada (WETMORE, 2003) pelo contexto de desenvolvimento de armamento bélico na guerra da fria (PAULSEN, 1994) e o setor energético dos Estados Unidos estava sendo administrado pelo Atomic Energy Comission (AEC) (STINE, 2009).

O presidente Nixon não compartilhava o ímpeto em expandir o papel do governo, defendido por Kennedy e Johnson, mas compartilhava com o conceito de exercer o papel de construtor da estrutura política (VINSEL, 2011). 


\subsubsection{Política}

O governo estava começando a intervir gradualmente no controle de emissões de poluentes nos veículos desde a década de 40, mas o contexto gerado pela denúncia do Ralph Nader e as audiências subsequentes do Senador Abraham Ribicoff catalizaram o processo de mudança de comportamento dos políticos em relação aos abusos realizados pela indústria automotiva. Esse reposicionamento político gerou a instituição de regulamentações mais severas que iniciaram uma batalha legal entre o governo e a indústria automotiva.

Dessa forma, o governo estava direcionando as suas ações para favorecer o desenvolvimento de dispositivos de controle de emissões de poluentes nos veículos para que houvesse uma renovação tecnológica no setor que havia estagnado a sua capacidade de inovação desde 1939 com o desenvolvimento da transmissão automática (MINTZ, COHEN; 1971).

\subsubsection{Regulamentação estadual}

O estado da California iniciou o processo de regulamentação no país (VINSEL, 2011) de forma mais concreta ao aprovar, em 1960, o California Health and Safety code, div.20, ch.3 (KENNEDY, 1963). Ela estabelecia a criação do Motor Vehicle Pollution Control Board (HAAGEN-SMIT, 1970) e foi designada especificamente para requerer dispositivos de controle de emissões de poluentes atmosféricos. Caso fosse constatada que a região não necessitava de controle de poluição atmosférica, ela poderia se eximir dessa regulamentação (KENNEDY, 1963).

O estabelecimento da intervenção do governo, através da instituição regulatória, foi um movimento lógico no sentido de que os automóveis, por exemplo, não estavam respeitando os limites locais. Essa transferência de autoridade viabilizou o favorecimento do estado em exercer pressão na indústria automobilística (HAAGEN-SMIT, 1970). 
No ano posterior a denúncia do Ralph Nader, o governador Ronald Reagan estabeleceu o Mulford-Carrell Air Resources Act (ARB, 2012) que dissolveu o Motor Vehicle Pollution Control Board e estabeleceu o Air Resources Board (HAAGEN-SMIT, 1970).

\subsubsection{Agência reguladora estadual}

A pressão social contínua exercida pelo Kenneth Hahn, desde a década anterior, resultou no apoio do estado para a instituição da agência reguladora Motor Vehicle Pollution Control Board (DEWEY, 1998b), por exemplo. Ela estava prevista na regulamentação California Health and Safety Code, div.20, ch.3 e exerceu a função primária de determinar os critérios de aprovação dos dispositivos de controle de poluentes e testar os dispositivos selecionados.

O Motor Vehicle Pollution Control Board (MVPCB) atuava em conjunto com o Motor Vehicle Bureau of Air Sanitation (MVBOAS) de forma que o primeiro estabelecia as especificações e testes e o segundo solicitava a instalação da tecnologia (ARB, 2012; HAAGEN-SMIT, 1970). Caso dois ou mais dispositivos fossem aprovados, os motores veiculares não poderiam ser registrados ou comercializados se não estivessem equipados com esses itens (KENNEDY, 1963; ARB, 2012) de segurança de poluição atmosférica. As ações do MVPCB tiveram como efeito a instalação, em todos os veículos, de dispositivos no cárter (a partir de 1961) e de dispositivos no escapamento (a partir de 1966) (HAAGEN-SMIT, 1970).

Em 1967, foi estabelecido o Air Resource Board (ARB) que estava previsto na regulamentação estadual Mulford-Carrel Act (HAAGEN-SMIT, 1970). Houve a fusão do MVPCB e do MVBOAS (e seus laboratórios) (ARB, 2012) de forma que o ARB foi firmado com autoridade e

poder mais amplo em relação ao MVPCB e exercia a responsabilidade final nos programas de poluição atmosférica na California (HAAGEN-SMIT, 1970).

\subsubsection{Regulamentação federal}

O início do comprometimento nacional na questão da poluição atmosférica através de regulamentações foi representado pelo Clean Air Act de 1963 (MELOSI, 2011). Ela legitimou a 
autoridade e responsabilidade do controle das emissões de poluentes atmosféricos do Department of Health, Education and Welfare (DHEW) e do Public Health Service (subsidiária do DHEW) que foram encarregadas a implementar a regulamentação (HEIMANN, 1964).

Em 1962, o Senador Abraham Ribicoff ocupava o posto de Secretário do DHEW (USDHEW, 1962) e alocou esforços para influenciar positivamente na instauração do Clean Air Act de 1963 (AUGUSTINE, 2003).

Em 1965, foi estabelecida uma emenda do Clean Air Act que autorizava o DHEW a estabelecer padrões em emissão de hidrocarbonetos e monóxido de carbono para os modelos de veículos de passeio e caminhões leves a partir de 1968 (LEE et al., 2010). No ano seguinte, o Senador Abraham Ribicoff conduziu as audiências para esclarecer a questão da denúncia realizada pelo Ralph Nader no distrito de Los Angeles. Esse distrito estava sofrendo de doses massivas de poluição atmosférica e o representante estadual da região de Los Angeles Kenneth Hahn esteve, desde a década passada, continuamente pressionando as montadoras e o poder público para apoiá-lo na questão do controle da poluição atmosférica. O Senador Abraham Ribicoff, o desenvolvedor-chefe das regulamentações federais automotivas Ralph Nader e o representante estadual da região de Los Angeles Kenneth Hahn exerceram uma influência significativa na mobilização social e legislativa a favor do controle de emissões de poluentes atmosféricos e da instalação de itens de segurança nos veículos de forma a pressionar os gestores das montadoras a se conscientizarem dos danos causados pelos seus produtos na saúde da população de maneira a atuarem na prevenção e remediação dos malefícios e prejuízos de forma concreta.

O composto de chumbo utilizado como aditivo na gasolina, desde os anos 20, (HEYWOOD et al., 1974) gerou impacto negativo na saúde da população e na vida útil dos dispositivos de controle de emissões (PENNA, GEELS; 2012) que estavam sendo solicitados como itens necessários nos veículos nas regulamentações (Clean Air Act, por exemplo). Para abordar essa questão, em 1967, foi instituída a regulamentação Air Quality Act. Essa foi a primeira ação concreta do governo para controlar as emissões de chumbo, no contexto regulatório (MELOSI, 2011). 
Essa regulamentação foi estabelecida após o contexto das pressões sociais estabelecidas pelo Ralph Nader e pelo Los Angeles County Board of Supervisors, quando a questão de segurança e da poluição atmosférica fortaleceu a disposição política em estabelecer legislações mais severas (PENNA, GEELS; 2012). Foram disponibilizados US\$125 milhões para o P\&D de tecnologias de prevenção e controle de emissões de gases de efeito estufa (DOE, 2008b) e oferecida uma estrutura para definir as regiões de controle de qualidade do ar baseada em fatores meteorológicos e topográficos de poluição atmosférica (ARB, 2012). Foi estabelecido que a California poderia se eximir no cumprimento dessa legislação sob o argumento de que esse estado necessitava de um controle mais rígido em emissões de poluentes, firmando os seus próprios padrões em emissões para novos veículos (ARB, 2012).

O grande aumento das preocupações ambientais, a insatisfação das leis federais existentes, o vago envolvimento dos estados e a alta legitimidade política que havia se estabelecido em conjunto com o sindicato automobilístico viabilizaram uma janela de oportunidade para o Clean Air Act Amendment de 1970. Essa foi a regulamentação mais rigorosa que houve nos EUA em relação ao controle de poluição atmosférica. Ela estabelecia um padrão mais elevado de redução de emissões para veículos novos e outros veículos motorizados que emitam poluentes que possam afetar de forma negativa a saúde humana (MELOSI, 2011).

Essa regulamentação requeria a redução de $90 \%$ das emissões de hidrocarbonetos e monóxidos de carbono em 1975 e de óxidos de nitrogênio em 1976. Foi especificada uma multa de US\$10.000 por veículo caso não estivesse de acordo com a legislação proposta (PENNA, GEELS; 2012).

\subsubsection{Agência reguladora}

Em 2 de Dezembro de 1970, foi instituído o Environmental Protection Agency (EPA) com a finalidade de centralizar as diversas atividades que estavam sendo encaminhadas em pesquisas federais, monitoramento e padronização voltadas para garantir a segurança ambiental (EPA, 2012). Essa agência foi responsável por implementar a emenda do Clean Air Act de 1970 e pelo controle da questão dos combustíveis (PENNA, GEELS; 2012), como, por exemplo, o caso do 
uso do chumbo como aditivo nos combustíveis. Para solucionar essa questão, em 1971, o EPA estabeleceu padrões de diminuição progressiva do chumbo para que, em 1975, a gasolina fosse comercializada sem esse aditivo (PENNA, GEELS; 2012).

A emenda do Clean Air Act de 1970, oferecia uma flexibilização temporária de um ano caso as montadoras demonstrassem esforços de boa fé para alcançar as metas propostas. Alguns críticos questionaram se as montadoras realmente realizaram esse ato de boa fé porque estavam investindo em P\&D de tecnologias de controle de emissões com recursos financeiros alheios a organização. O EPA negou os pedidos de ampliação de prazo sob o argumento de que as montadoras estariam aptas a cumprir as metas de 1975 e essa ação gerou a reação de quatro montadoras, que processaram o EPA por se recusar a estender o prazo (MELOSI, 2011).

\subsection{Estratégia}

\subsubsection{Montadoras}

A estratégia estipulada pelas montadoras americanas seguiu a trajetória de oferta de veículos maiores e mais luxuosos para o seu mercado interno. O governo apoiou esse percurso através de incentivos que desencadearam fatores como, por exemplo, maior renda per capita, preço da gasolina acessível, maiores distâncias percorridas nas viagens e maior amplitude das rodovias (GOMEZ-IBANEZ, HARRISON; 1982).

De forma recíproca, o montador externo estaria de certa forma relutante a produzir veículos no estilo americano que não iria ser significativamente comercializado no seu país de origem (KLIER, 2009). A grande maioria dos veículos importados era de pequeno porte, mas também abrangiam veículos esportivos ou especializados que poderiam considerar a economia de escala como um fator secundário (GOMEZ-IBANEZ, HARRISON; 1982).

Os Big Three (GM, Ford e Chrysler) tiveram uma reação inicial relutante aos veículos compactos importados. Eles eram percebidos como pouco atrativos, de difícil obtenção de lucros vantajosos e prováveis de canibalizar as vendas dos veículos mais lucrativos (FREYSSENET et al., 1998). 
Mas elas reagiram ao primeiro movimento de aumento do número de veículos importados na década passada e, como consequência da reação, em 1962, a representatividade dos veículos importados havia recuado para 4,9\% do mercado automotivo americano (KWOKA, 1984). De forma que houve um declínio de mais de $50 \%$ do volume de carros estrangeiros em um período de três anos.

Mas os veículos importados estavam voltando a ganhar mercado então os Big Three tentaram modificar as preferências dos consumidores ao desenvolver veículos com conceitos de maior poder, estilo e diversão em dirigibilidade em relação aos veículos do padrão americano (FREYSSENET et al., 1998).

Em relação ao contexto das regulamentações estabelecidas, no início dos anos 60 , as montadoras instalaram o sistema de ventilação positiva no cárter (atua na prevenção da emissão) nos veículos argumentando que não seria necessário estabelecer uma regulamentação para ocorrer o seu envolvimento e que a California era um caso especial. Mas quando outros estados (Nova Iorque e Filadélfia) iniciaram a sua adesão as leis de controle de emissões a indústria automobilística modificou o seu posicionamento e começou a requerer a padronização a nível federal para conter os movimentos de escopo estadual (PENNA, GEELS; 2012).

As montadoras resistiram a instalar os conversores catalíticos (atua na remediação da emissão) desenvolvidos por fornecedores, mas a GM, por exemplo, criou o seu próprio programa de P\&D para obter a tecnologia. A estrutura fortemente verticalizada das montadoras não aceitou a compra dessas novas tecnologias para comercializar seus veículos com dispositivos de alto valor agregado fornecido por terceiros (PENNA, GEELS; 2012)

As montadoras americanas compartilhavam a crença de que a poluição atmosférica era trivial e que o conceito de segurança não possuía apelo comercial. A resistência da indústria em relação à questão de segurança nos veículos e poluição atmosférica é motivada, em parte, da barreira ideológica de autonomia gerencial. A reação da indústria estava baseada, em parte, na batalha mais ampla em relação a minimizar a autoridade do governo no direcionamento do futuro automobilístico (PENNA, GEELS; 2012). 
Em relação ao desenvolvimento da tecnologia do veículo elétrico, na década de 60, a França estabeleceu um programa de desenvolvimento da tecnologia de veículos elétricos a célula combustível de maneira que a participação da fornecedora de energia Electricité de France foi altamente relevante (CALLON, 1980). Em 1965, o Japão iniciou um programa de desenvolvimento de veículos elétricos que foi considerado um programa técnico de pesquisa fundamental (COWAN, HULTEN, 1996). E, de modo dessemelhante a França e ao Japão, por exemplo, a Grã-Bretanha manteve a sua frota de veículos elétricos desde o início do século XX (HOYER, 2008) de maneira que, nessa década, ela possuía uma frota de mais de 40.000 veículos elétricos licenciados (LINFORD, 1967).

\subsubsection{GM}

Nesse período, a estratégia abordada pela GM focava, principalmente, no ponto de vista de marketing que está relacionado a vender o maior número de veículos possíveis (DE GIER, 2010). Ela desencorajava as inovações tecnológicas (FLINK, 1985) e de certa forma negligenciava a produtividade ou as técnicas de produção abordada pela Ford. Essa estratégia foi denominada como Sloanismo (DE GIER, 2010) em homenagem ao CEO Alfred Sloan que reestruturou a firma nos anos 20 de forma a ultrapassar a Ford no final daquela década (FLINK, 1985), e estava participando das atividades da empresa como presidente da diretoria e CEO (DAVIDSON, 2007) no momento em que ela se tornou a primeira organização a atingir US\$1 bilhão de faturamento no escopo global, em 1955 (FINKELSTEIN, 2003).

Para adotar a estratégia de inovação sugerida pelo governo, a GM, possivelmente, necessitaria reconstruir parte da estrutura e capacidade de produção adquirida desde os anos 20 quando a estratégia de marketing utilizada por Alfred Sloan direcionou a organização ao topo das sociedades anônimas no escopo mundial. Ao perceber a sinalização do governo em incentivar tecnologias que apoiassem o controle da poluição atmosférica, a GM iniciou o direcionamento dos seus programas de $\mathrm{P} \& \mathrm{D}$ nessa trajetória.

Esse fato pode ser ilustrado através da realização do seu próprio programa de $\mathrm{P} \& \mathrm{D}$ para desenvolver a tecnologia de conversores catalíticos para atender as solicitações estabelecidas na 
legislação (PENNA, GEELS, 2012). Nesse período, a GM estava desenvolvendo tecnologias de baterias para o setor militar (JOHN, 2000) e testes dessas tecnologias em protótipos de veículos elétricos terrestres para verificar o estágio de desenvolvimento das tecnologias disponíveis naquele período na aplicação terrestre (CHAN, 2002). Como, historicamente, o período de transferência tecnológica dos laboratórios para a linha de produção na GM era entre 10 e 15 anos (KOERNER, 1989), possivelmente, a organização estava ensaiando as primeiras tentativas de desenvolvimento do veículo elétrico visando a possibilidade de lançamento comercial da tecnologia nas décadas seguintes. Essa seria uma maneira de manter a liderança no mercado realizando a renovação tecnológica de forma gradual e sustentável de forma a manter as margens de lucro esperadas pelos seus acionistas.

Mas, como havia um conflito entre o governo e a indústria automotiva em relação aos limites de poder institucional de uma forma mais abrangente, a GM também adotou um posicionamento de postergar a implementação das regulamentações seguindo o comportamento da indústria automotiva em relação a essa questão (PENNA, GEELS; 2012). Essa estratégia estabeleceria ao governo um limite em relação a sua autoridade no direcionamento do futuro da indústria automotiva e ofereceria o benefício da firma obter um prazo maior para tentar desenvolver e aperfeiçoar a tecnologia do veículo elétrico no seu laboratório.

Como forma de reação aos veículos importados, que estavam começando a voltar a crescer, em 1962, a GM lança o Corvair (FREYSSENET et al., 1998). Esse foi o veículo que o Ralph Nader utilizou como referência do seu livro Unsafe at any speed, lançado em 1966, que desencadeou a mobilização das políticas públicas de forma favorável a instituir maior rigidez e severidade nas regulamentações relacionadas a poluição atmosférica e segurança dos veículos.

Mesmo com o abalo da imagem gerada pela denúncia de Ralph Nader, pelas subsequentes quedas abruptas nas vendas do Corvair e pelo aumento da representatividade dos veículos importados, a GM manteve pelo menos $45 \%$ de participação de mercado americano ao longo de toda a década (WARDSAUTO, 2012). Mas, sob outro ponto de vista, essa concentração e poder de mercado gerou complacência nos gestores que tiveram um tempo de resposta lento no contexto de aumento de importações e de mudança de preferência dos consumidores. No final da década, as 
importações representavam quase $15 \%$ do mercado americano (KLIER, 2009) contrastando com a representatividade de $4,9 \%$ que ela exerceu no início do período.

Após a pulverização do modelo Corvair pelo contexto gerado pela denúncia realizada em 1966, a GM tentou desenvolver um novo modelo para representar a categoria de veículo compacto para deter o crescimento das importações. Em 1970, foi desenvolvido o veículo econômico Chevrolet Vega (KWOKA, 1984). Semanas antes do início da produção desse veículo, o UAW realizou uma greve, aumentando a pressão social para o estabelecimento da emenda da regulamentação federal Clean Air Act, em 31 de Dezembro de 1970 (GERARD et al., 2003).

\subsection{Tecnologia de bateria}

No período da SGM, a GM teve uma participação relevante no desenvolvimento de itens para fins militares. Em 1941, a Delco Remy (divisão da GM) converteu 100\% da sua produção para desenvolver motores de partida, geradores, reguladores de tensão, baterias, controles automáticos para aeronaves, por exemplo, que foram utilizados em aplicações navais, terrestres e aéreas (THEHISTORY, 2012). E a Allison (divisão da GM) produziu mais de 70.000 motores para aeronaves de caça americanas (Bowman, 2012).

\subsubsection{Veículo orbital}

Em 1960, a National Aeronautics and Space Administration of the United States (NASA), a Rand Corporation e a Institute of Aeronautic Sciences promoveram um debate, em Los Angeles, em relação a possibilidade da construção de uma estação espacial com presença humana permanente na lua (UNOOSA, 2004). Mas devido ao pioneirismo da União Soviética no lançamento do satélite Sputnik I, em 1957 (KILLIAN, 1982), os Estados Unidos iniciaram a corrida espacial com os soviéticos, em 1960, de forma a objetivar a aterrizagem do homem na superfície lunar e retornar a Terra de forma segura (STINE, 2009), postergando os planos de construção da estação espacial com presença humana permanente na lua (UNOOSA, 2004). 
Nesse sentido, em 1961, a GM novamente foi selecionada para apoiar o governo e participou na corrida espacial através do seu apoio ao programa Apollo. Nesse programa, a GM realizou um projeto em conjunto com a NASA, a Boeing e a Radio Corporation of America (RCA) para desenvolver o (BEKKER, 1974) veículo elétrico Lunar Rover que iria ser utilizado para se locomover no solo lunar (THE ELECTRIC, 2001). As baterias de prata-zinco (CCT, 2011), o sistema de mobilidade que incluíam as rodas, o "drive traction", a suspensão, a direção e o sistema de controle de direção eletrônica utilizadas nesse modelo foram desenvolvidos pela GM (NASA, 2002) através do pesquisador Jon Bereisa (CCT, 2011).

\subsubsection{Míssil balístico}

A maioria dos veículos aeroespaciais utiliza algum tipo de bateria como fonte de eletricidade. Em muitos veículos, a bateria representa a fonte energética primária e em outros ela poderá ser utilizada para auxiliar em períodos de pico. Nesse período, o setor aeroespacial estava buscando desenvolver tecnologias de bateria que pudessem oferecer o desempenho de aproximadamente 25.000 ciclos de carga e descarga para serem incorporadas nos veículos orbitais (COOPER, INGLING; 1963).

Em 1962, a Delco Remy foi patrocinada pela Força Aérea e contratada pela Jet Propulsion Laboratory para realizar o $\mathrm{P} \& \mathrm{D}$ da tecnologia das baterias de prata-zinco (óxido de prata-zinco) no seu laboratório que poderia verificar o desempenho de até 1760 ciclos de carga e descarga (COOPER, INGLING; 1963).

A tecnologia das baterias de prata-zinco, desenvolvidas pela divisão da GM, foi utilizada como fonte energética do sistema de navegação do míssel Minute-man (YU et al., 2011) entre 1962 e 1978 (JACKSON, 2012a). Esse míssil foi um armamento bélico nuclear desenvolvido no período da guerra fria (PAULSEN, 1994). As baterias geravam energia por menos de dois minutos porque após esse período o curso balístico estava direcionado para um alvo de 15 minutos (JACKSON, 2012b) e poderia alcançar entre 10.200 a 14.000 km (NAIC, 1996). 
As baterias de níquel-cádmio e prata-zinco para aplicações em mísseis e baterias de chumboácido para outras aplicações, desenvolvidas pela Delco Remy, estavam recebendo a influência direta do pesquisador John Joseph Lander.

\subsubsection{Veículo elétrico terrestre}

Nessa década, as montadoras exploraram novas opções de tecnologias de baterias com o intuito de elevar o desempenho oferecido pelas baterias de chumbo-ácido. Os sistemas de baterias disponíveis para serem utilizadas em veículos elétricos eram as de níquel-cádmio, chumbo-ácido e prata-zinco (LINFORD, 1967).

A GM estava realizando o P\&D das baterias de prata-zinco e níquel-cádmio para aplicação aeroespacial e baterias de chumbo-ácido para outras aplicações (JOHN, 2000). Foram realizados testes de baterias do setor aeronáutico e verificou-se que as baterias de níquel-cádmio eram consideradas a melhor opção para a aplicação em veículos elétricos terrestres. As baterias de chumbo-ácido utilizadas no setor aeronáutico seguiam como a segunda melhor opção (AGRUSS, 1970) e a tecnologias das baterias de prata-zinco foram percebidas como a terceira opção para aplicação em veículos elétricos terrestres.

As tecnologias de baterias que estavam em estágio experimental para veículos elétricos na GM eram o sistema de zinco-ar que foi desenvolvido no departamento eletroquímico da Research Labs (HIETBRINK et al., 1971) para a tecnologia do veículo elétrico (WITHERSPOON, 1969) e o sistema de cloreto de lítio que foi desenvolvido pela Delco Remy. A aplicação desta tecnologia estava sendo testada para veículos à propulsão elétrica e satélites utilizando à célula de combustível como fonte energética (DRDOGMC, 1964). 


\subsection{História dos engenheiros}

\subsubsection{George Spix}

O engenheiro George Spix iniciou a sua carreira na Força Aérea entre 1942 e 1946 como instrutor de radares. Entre 1951 e 1958, Spix trabalhou no desenvolvimento de sistemas de navegação e controle de mísseis na Martin Company e Douglas Aircraft Company. Após obter experiência e conhecimento no setor militar e aeronáutico, em 1958, ele se mudou para a GM exercendo a função de supervisor do departamento de projetos militares de desenvolvimento e produção de fonte de energia para mísseis. Spix adquiriu 5 anos de experiência nesse departmento e, em 1963, foi transferido para a General Motors Research Laboratories, atuando como engenheiro pesquisador associado de primeiro nível no departamento de propulsão elétrica de forma a participar ativamente do desenvolvimento do protótipo Electrovair I e II (SALIHI et al., 1967).

\subsubsection{Jon Joseph Lander}

Na Segunda Guerra Mundial (SGM), John Joseph Lander (Sam) serviu no U.S. Navy como primeiro tenente no Naval Research Laboratory (NRL) onde ele conduziu pesquisas sobre baterias de chumbo-ácido para submarinos. Após a guerra, ele continuou o seu trabalho na NRL como cientista experimental e se tornou mundialmente reconhecido pelo seu trabalho com baterias de chumbo-ácido. Ele desenvolveu o trabalho pioneiro da liga de chumbo com adições de estanho-prata e cálcio para reduzir a corrosão do polo positivo. Seu trabalho também incluiu emissões de baterias submarinas, incluindo estibina, arsina e limites explosivos dos compostos hidrogênio-oxigênio e hidrogênio-ar (JOHN, 2000).

Em 1956, ele começou a trabalhar no Electric Auto-Lite Co. assumindo o cargo de gerente de pesquisa da divisão de baterias. Em 1958, ele foi para a Delco Remy Division da General Motors Corp. em Anderson, Indiana, exercendo a função de diretor de pesquisa eletroquímica. Além da pesquisa com chumbo-ácido, foram incluídas pesquisas de níquel-cádmio e prata-zinco para mísseis (JOHN, 2000). 
Em 1968, Sam se mudou para a Wright Patterson Air Force Base (WPAFB) onde ele permaneceu até a sua aposentadoria, em 1983. Dr. Lander ocupava a posição P.L. 313 como pesquisador sênior e prestou serviços como conselheiro científico aos gestoreas da U.S. Air Force Aero Propulsion and Power Laboratory. Ele foi responsável pela realização do programa de P\&D, dentro da organização, de baterias especiais para a força aérea. O laboratório ofereceu especialização e treinamento em projeto, fabricação e testes das baterias de prata-zinco e das baterias aeronáuticas e aeroespaciais de níquel-cádmio aos técnicos e engenheiros da Força Aérea. Ele iniciou o trabalho que conduziu ao desenvolvimento do processo de disseminação eletroquímica para os eletrodos de níquel e cádmio que são utilizados atualmente nas baterias de níquel-cádmio e níquel-hidrogênio no setor aeroespacial (JOHN, 2000).

Sam exerceu um papel ativo na resolução das questões relacionadas aos sistemas de baterias incluindo energia de emergência em silos de mísseis, confiabilidade dos minérios e da fusão e questões de especificações de baterias aeronáuticas de níquel-cádmio para a Força Aérea. Ele estabeleceu os separadores de membrana de polietileno enxertados por radiação que aliviou a questão da barreira de gás nas baterias aeronáuticas de níquel-cádmio e preveniu a formação de dentritos de zinco nas baterias de prata-zinco. Foi dessa forma que Sam aconselhou e ofereceu assistência aos programas de bateria da U.S. Navy, da Electric Auto-Lite Co, General Motors e Força Aérea ao longo da sua carreira científica experimental (JOHN, 2000).

\subsubsection{Jon Bereisa}

Jon Bereisa iniciou a sua carreira na NASA, participando do desenvolvimento do sistema de propulsão nuclear de um projeto (ALPERT, 1992) e participou do desenvolvimento do lunar rover (CCT, 2011). Em 1974, Bereisa se mudou para a General Motors e auxiliou no desenvolvimento de microcontroladores que são utilizados até os dias atuais em, virtualmente, todos os automóveis para limitar as emissões de poluentes atmosféricos e regular o sistema de transmissão, por exemplo (ALPERT, 1992).

Durante os anos 50 e 60, a GM produziu baterias e sistemas de propulsão elétrica para mísseis balísticos e o projeto Apollo. Depois que o homem aterrisou na lua, a GM se focou no 
desenvolvimento do lunar rover (FIALKA, 2009). O programa de veículos elétricos terrestres na GM foi iniciado paralelamente ao programa do lunar rover de forma que a GM desenvolveu as baterias e a transmissão elétrica desse veículo (CCT, 2011).

Bereisa se tornou presidente do USABC (AUTOCHANNEL, 1997), engenheiro-chefe do sistema de propulsão elétrica do Impact (ALPERT, 1992) e do EV1, diretor de engenharia avançada dos sistemas de propulsão de células combustíveis a hidrogênio (CCT, 2011) de forma a apoiar o desenvolvimento do Hy-Wire (ADRIANCHERNOFF, 2012) e foi o diretor de engenharia avançada e desenvolvimento tecnológico da Chevrolet (LANNING, 2011) sendo o arquiteto do sistema do Volt (CCT, 2011).

Após se aposentar na GM, Bereisa está atualmente se dedicando as atividades de gestão da Auto Lectrification LLC, atuando como CEO e presidente da organização (BROOKE, 2012).

\subsection{Análise}

De acordo com os dados empíricos coletados, evidenciou-se que os fatores que influenciaram de forma relevante no desenvolvimento dos protótipos de veículo elétrico na GM nesse período podem ser classificados segundo Suarez (2004) em fatores externos e internos. Os fatores externos identificados são a pressão social contra a poluição atmosférica, a subsequente regulamentação governamental da emissão de poluentes e o campo tecnológico. Os fatores internos relevantes identificados são a credibilidade da GM frente às várias organizações do governo americano (NASA, Força Aérea, etc.) e a estratégia de sondagem e aprendizagem tecnológica.

Os resultados apresentados neste capítulo mostram que a pressão social contra a poluição atmosférica, em algumas regiões metropolitanas nos Estados Unidos, foi o início de uma sequencia de eventos que direcionou o desenvolvimento de uma série de protótipos de veículo elétrico na GM nesse período. Entretanto a articulação dessa pressão social foi um processo de longa duração, conforme podemos observar no quadro 3. As reclamações da sociedade sobre o smog na região de Los Angeles ganharam destaque, em 1942. Naquela época não havia um 
entendimento conclusivo sobre a causa dessa poluição atmosférica. Depois de diversos estudos, que levaram vários anos, foram identificadas as principais indústrias geradoras do nevoeiro fotoquímico: petroquímica e automotiva. Entretanto, a indústria automotiva realizou manobras para não assumir a responsabilidade. Mesmo assim, esses estudos forneceram subsídios para que os políticos do estado da Califórnia elaborassem as primeiras regulamentações regionais para tentar reduzir o nível de smog. A primeira intervenção regulatória no sentido de controlar a poluição atmosférica nas montadoras foi introduzida no Califórnia, em 1960. E no escopo federal verificou-se uma morosidade de três anos para a instituição da primeira regulamentação federal.

Os fatos levantados evidenciam, de forma bem clara, que as regulamentações governamentais foram reações dos governos à pressão social contra a poluição atmosférica. Entretanto o arcabouço conceitual do Suarez (2004) não menciona a pressão social como um fator externo, de forma a estabelecer a regulamentação como um fator a ser considerado. Uma possível explicação se fundamenta na ressalva realizada pelo próprio Suarez no sentido de que esse arcabouço teórico foi elaborado a partir da realidade das indústrias de informática e de telecomunicações. Nessas indústrias, o principal papel de regulamentação é o estabelecimento de padrões tecnológicos de modo a ter compatibilidade operacional entre diferentes equipamentos e softwares. Portanto a origem da regulamentação governamental e setorial é essencialmente endógena nestas indústrias. No caso da poluição atmosférica, a função da regulamentação é a de reduzir os impactos sociais exógenos negativos das indústrias.

As regulamentações governamentais sobre a poluição atmosférica exigem que as montadoras realizem modificações técnicas nos seus veículos que implicam o aumento de custos e consequente redução das margens. Assim, é natural a resistência destas empresas contra estas medidas. As informações coletadas nesse trabalho evidenciam diversas manobras realizadas para bloquear ou para adiar a passagem dessas regulamentações nas assembleias estaduais e no Congresso americano. Além realizar oposição às regulamentações, as montadoras, incluindo a GM, iniciaram a gerar alternativas para a redução da emissão de poluentes. Assim, foram investidos recursos para o desenvolvimento da tecnologia do veículo elétrico na firma. O presente estudo não coletou dados sobre os projetos de $\mathrm{P} \& \mathrm{D}$ da GM em VE neste período e a razão principal é a dificuldade de acesso às informações internas da companhia. Pois, geralmente, as 
empresas mantém sigilo dos projetos de $\mathrm{P} \& \mathrm{D}$. Em outros termos, a observação da Fase I do Suarez (2004) é mais complexa. Nesse sentido, optamos observar os protótipos de VE da GM (Fase II do Suarez), pois em geral as empresas anunciam essas realizações.

O primeiro protótipo de VE da GM, neste período, foi construído em 1964, quatro anos depois da passagem da primeira regulamentação de emissão no estado de Califórnia e 22 anos depois dos primeiros episódios de smog no sul da California, conforme podemos verificar na tabela 1 . Depois deste protótipo (Electrovair I), a GM construiu mais sete protótipos em menos de oito anos, antes de eclodir a primeira crise de petróleo, em 1973. A nossa conclusão é que a GM, além de tentar atender as exigências das regulamentações, resolveu apostar na alternativa de VE.

\section{Quadro 3 - Análise das políticas públicas do driver poluição atmosférica}

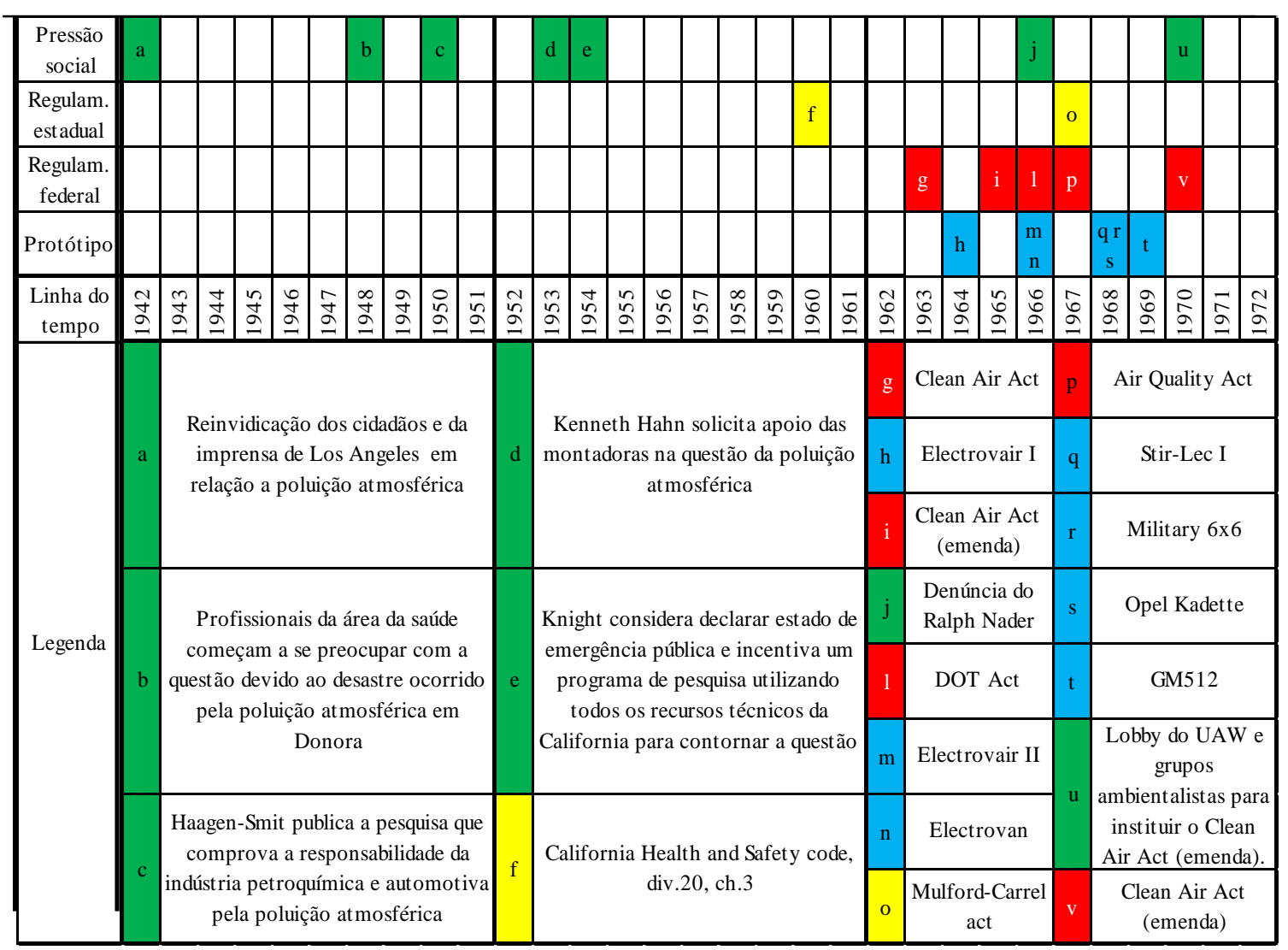

Fonte: elaboração da autora 
Para identificar os outros motivos (além de regulamentação) que conduziram a GM investir em VE é necessário ter acesso aos documentos internos da empresa. Como este tipo de acesso é difícil e o escopo de uma dissertação de mestrado é limitado, a presente pesquisa objetivou a coleta de informações disponíveis para compreender a forma que a GM acumulou competências fundamentais que viabilizaram o desenvolvimento da sequência de protótipos de VE nesse período. Os dados levantados indicam que alguns eventos precedentes possibilitaram a aquisição de conhecimento sobre componentes chaves de VE (baterias, sistema de propulsão elétrico, etc.) pela GM. Esses eventos precedentes são: a participação da GM na produção de equipamentos militares durante a Segunda Guerra Mundial, e o envolvimento da GM na corrida espacial e na Guerra Fria logo depois da Segunda Guerra Mundial.

A participação da GM no esforço de produção de equipamentos militares durante a Segunda Guerra Mundial, em particular a produção de baterias para veículos militares, aproximaram os executivos e engenheiros da empresa aos militares. Estas relações provavelmente geraram credibilidade da empresa em relação aos tomadores de decisão das forças armadas americanas. Em um momento posterior, com o acirramento da Guerra Fria e o início da corrida espacial para a Lua, esta credibilidade provavelmente exerceu influência na convocação da GM pelo setor militar para apoiá-la em desenvolvimentos tecnológicos pertinentes como, por exemplo, baterias especiais e veículos lunares. Esses envolvimentos levaram a GM adquirir conhecimentos sobre novas tecnologias de baterias que posteriormente foram incorporadas em protótipo de VE na década de 60. Um exemplo é o desenvolvimento das baterias de prata-zinco para o míssil Minuteman e para o veículo lunar rover que foi utilizada posteriormente no protótipo Electrovair I.

Além da tecnologia de baterias, a GM estava desenvolvendo outras tecnologias para o setor militar ou aeronáutico em um momento anterior ao seu envolvimento com a tecnologia de veículos elétricos. Por exemplo, em 1958, a GM desenvolveu a tecnologia do motor stirling e, em 1963, a Allison (divisão da GM) estava desenvolvendo a tecnologia de células combustíveis. De forma que a aplicação dessas tecnologias estava sendo direcionada para o setor militar e aeroespacial. Assim, quando a GM desenvolveu o protótipo Electrovan utilizando a tecnologia de células a combustível e o protótipo Stir-Lec I aplicando a tecnologia do motor stirling no seu 
sistema de propulsão, a firma estava se beneficiando de uma competência adquirida previamente com o setor militar e aeroespacial para aplicar na sondagem e aprendizagem tecnológica do veículo elétrico.

A interação entre os engenheiros e as respectivas instituições no desenvolvimento de tecnologias é descrita como o campo tecnológico pelo Suarez (2004). O campo tecnológico do Suarez geralmente se refere a um segmento/ setor industrial tal como o de computadores pessoais. Entretanto, no caso de baterias de VE, observamos que esse campo abrange vários segmentos industriais que utilizam baterias (veículos espaciais, equipamentos militares e VE). Mesmo assim, os engenheiros que são ativos nesse campo tecnológico transferiram seus conhecimentos adquiridos numa aplicação (por exemplo, mísseis balísticos) para outra aplicação (por exemplo, o VE) dentro da sua empresa. Esse fato pode ser evidenciado através da participação do engenheiro George Spix, que adquiriu experiência no desenvolvimento de sistemas de navegação e controle de mísseis no setor aeronáutico em um momento anterior a sua participação no setor automobilístico, sendo um dos desenvolvedores do Electrovair I e II.

Outra observação importante em relação a estes eventos precedentes que permitiram a GM obter conhecimentos sobre novas tecnologias de baterias: eles não foram planejados com o objetivo de desenvolver o VE. Ou seja, são eventos fortuitos do ponto de vista do desenvolvimento de VE na GM. Sem os quais, acreditamos que a capacidade de construir protótipos de VE da GM seria bem menor.

Conforme comentado anteriormente, a fase I da estrutura conceitual desenvolvida por Suarez é de difícil acesso devido à questão de confidencialidade nas empresas. Mas, quando possível, as instituições públicas as disponibilizam devido a questão de transparência nas suas operações e legitimidade da utilidade do investimento do orçamento do governo. Dessa forma, a presente pesquisa analisou a fase de $\mathrm{P} \& \mathrm{D}$ da tecnologia de baterias para veículos elétricos desenvolvidas em instituições governamentais, que estreitaram a sua relação com a GM no desenvolvimento da tecnologia ao longo dos três períodos desenvolvidos na pesquisa. 
Em relação a análise dos protótipos construídos nesse período, verificamos que eles são caracterizados pela diversidade de tecnologias de VE incorporadas e pela sua quantidade relativamente alta se forem comparados com os dois períodos posteriores. Mas, esta comparação dos protótipos construídos nos três períodos estudados nesta pesquisa será feita posteriormente, no capítulo final desta dissertação. Nesse ponto do trabalho destacam-se somente as dimensões desta diversidade tecnológica nos protótipos. Esses protótipos incorporaram diferentes tecnologias de baterias, de sistemas de propulsão e até uma nova plataforma veicular. Entretanto, nesse período, a GM se absteve da realização de testes de campo de longa duração, contrastando com os dois períodos subsequentes. Estes fatos sugerem que a GM estava testando e avaliando diferentes combinações de tecnologias de VE nesse período de forma que observamos a ausência de desenvolvimento de processo produtivo visando o lançamento comercial. Lynn et al., (1996) observaram um processo de sondagem e aprendizagem de mercados para produtos envolvendo inovações radicais. No caso de desenvolvimento de VE da GM, observamos um processo similar, mas em relação a sondagem e aprendizagem tecnológica. Essa observação foi viabilizada devido ao objetivo da presente pesquisa estar fundamentada na observação do processo sob a perspectiva de uma empresa (GM) na batalha tecnológica. A estrutura conceitual desenvolvida por Suarez (2004) foca nas fases tecnológicas de um segmento de produtos. Portanto, a análise dos esforços individuais das empresas envolvidas na batalha tecnológica foi suprimida no arcabouço conceitual do Suarez. Assim, consideramos que esta é uma das contribuições da presente pesquisa à literatura de gestão tecnológica. 


\section{CRISES DO PETRÓLEO}

\subsection{Introdução}

No capítulo anterior, descrevemos os fatores influenciadores do desenvolvimento do veículo elétrico na GM no período direcionado pela questão da poluição atmosférica.

Nesse período, o direcionador do desenvolvimento do veículo elétrico na GM foi a questão econômica da crise do petróleo. Dessa forma, nesse capítulo, ampliaremos o nosso entendimento sobre a trajetória do desenvolvimento dessa tecnologia que se iniciará pela descrição dos protótipos na seção 2. Essa seção utilizou as vertentes teóricas desenvolvidas por Suarez (2004), Veryzer (1998) e Baer et al., (1976) de forma que a observação do desenvolvimento dos protótipos corresponde a fase II das batalhas tecnológicas, a fase de prototipagem exploratória e a fase de testes de campo.

Nas seções 3 e 4, desenvolveremos um maior entendimento da questão da crise do petróleo sob três perspectivas complementares. Na seção 3, abordaremos as políticas internas dos Estados Unidos em relação ao setor de energia de forma abrangente bem como apresentaremos as políticas externas entre os Estados Unidos, o Oriente Médio e a Ex-União Soviética no sentido de viabilizar um entendimento acurado dos eventos de causa e efeito do direcionador desse período. Em relação a seção 4, descrevemos as políticas internas do Estados Unidos sob a perspectiva do desenvolvimento da tecnologia do veículo elétrico de forma a convergir as duas perspectivas anteriores na perspectiva da firma.

Além dos fatores políticos e econômicos, a crise do petróleo influenciou outros aspectos na sociedade. Na seção 5 , descreveremos a influência da crise da questão das pressões sociais da poluição atmosférica. E nas seções 6 e 7, iremos apresentar a sua influência no setor privado de forma que, na seção 6, desenvolveremos um maior entendimento da questão do comportamento do consumidor enquanto que, na seção 7, abordaremos as estratégias desenvolvidas pelas montadoras e pela GM para reagir ao contexto causado por questões descritas nas seções 3, 4 e 5 . 
Dessa forma, finalizaremos o desenvolvimento desse capítulo com a apresentação da seção 8 . Nessa seção, descreveremos os desenvolvimentos tecnológicos das baterias de forma a convergir os entendimentos da seção 2 e 4 que correspondem ao desenvolvimento de protótipos e a instituição de regulamentações visando o incentivo do desenvolvimento da tecnologia do veículo elétrico para reagir ao contexto gerado pela crise do petróleo, descrito na seção 3.

\subsection{Protótipos de veículo elétrico}

\subsubsection{Electrovette I e II}

Nesse período, foram desenvolvidos os protótipos Electrovette I e II na categoria de carro de passageiro (RAJASHEKARA, 1994), utilizando a plataforma do Chevette e a tecnologia de propulsão elétrica pura (YU et al., 2011). A diferença entre eles está fundamentalmente na tecnologia do sistema de bateria.

Em 1976, foi desenvolvido o Electrovette I (CABRAL e CARVALHO, 2009) que utilizou a tecnologia de baterias de chumbo-ácido (YU et al., 2011) enquanto que a segunda versão incorporou a tecnologia das baterias de níquel-zinco (RAJASHEKARA, 1994). O Electrovette II foi desenvolvido para testar a aplicação dessas baterias, realizando 12 meses de teste que acumularam 35.500 milhas (aprox.57.000 km) ao longo do programa (RAJASHEKARA, 1994).

Os testes do Electrovette II demonstraram que as baterias de níquel-zinco eram confiáveis, seguras e apresentavam um bom custo-benefício para a utilização diária (RAJASHEKARA, 1994).

Esses protótipos foram desenvolvidos através da participação do engenheiro Kenneth Baker (MCGRATH, 2000), Paul Agarwal (PERRY, 2010b) e Jon Bereisa (VALES-DAPENA, 2009). Kenneth Baker iniciou a sua carreira na GM (UOM, 2012) enquanto que Paul Agarwal e Jon Bereisa obtiveram experiência em outros setores antes de se mudarem para a GM (SALIHI et al., 1967; CCT, 2011). Paul Agarwal iniciou, em 1951, a sua carreira profissional no setor acadêmico, percorrendo a trajetória inicial da carreira até exercer o cargo de Professor no 
Departamento de Engenharia Elétrica da Universidade de Massachusetts de Amherst, atuando paralelamente como consultor da GE entre 1954 e 1961 (SALIHI et al., 1967). Enquanto que Jon Bereisa iniciou a sua carreira na NASA, adquirindo experiência prévia no desenvolvimento do sistema de propulsão nuclear de um projeto e do desenvolvimento do lunar rover (CCT, 2011).

Paul Agarwal iniciou a sua carreira na GM em 1961 (SALIHI et al., 1967), de forma que participou do desenvolvimento dos protótipos Electrovair I e II, Electrovan (AGARWAL, 1969) e Stir-Lec I (AGARWAL et al., 1969) no período direcionado pela questão da poluição atmosférica. Em 1969, Kenneth Baker foi integrado a GM (UOM, 2012) e, em 1974, Jon Bereisa se uniu as atividades da GM (CCT, 2011). Assim, nesse período, os três engenheiros tiveram a oportunidade de trabalhar em conjunto no desenvolvimento do Electrovette I e II

Esses protótipos foram desenvolvidos com a intenção de lançamento comercial (CAIRNS, ALBERTUS, 2010). Mas, quando o embargo do petróleo se encerrou, em 1981 (HAMMES et al., 2005) e os preços da gasolina favoreceram o mercado automotivo corrente, os planos de inserção comercial do veículo elétrico foram descontinuados (CAIRNS, ALBERTUS; 2010).

\subsubsection{AT\&T van}

Em 1979, a GMC Truck and Coach Division desenvolveu 35 veículos na categoria van que utilizaram a tecnologia de propulsão elétrica híbrida que foram disponibilizadas para que se realizassem testes na empresa AT\&T (RAJASHEKARA, 1994). Esse modelo foi desenvolvido pelo engenheiro Robert Bish (BISH, TIETMEYER, 1983) e utilizou baterias de chumbo-ácido de 12 volts que ofereciam um sistema de potência de 216 volts, alimentando um motor DC de 50hp que gerava uma autonomia de $65 \mathrm{~km}$ (THEELECTRIC, 2001).

Foram acumuladas 300.000 milhas $(555.600 \mathrm{~km})$ de testes e observou-se que os hábitos do motorista, o tipo de terreno e as técnicas de recarga podem influenciar em cerca de $20 \%$ dos custos de energia, sendo que a questão do sistema regenerativo do veículo poderia resultar em $12 \%$ de economia energética. Foi constatado que os veículos possuíam uma autonomia limitada e 
um sistema de baterias pesado com materiais e componentes de custo elevado (RAJASHEKARA, 1994).

A AT\&T participou como operadora de testes de campo do programa Electric and Hybrid Vehicle Demonstration Program desenvolvido pelo Department of Energy (DOE). Dessa forma, a GM desenvolveu a tecnologia desse protótipo com o apoio do governo, correspondendo a etapa de testes de campo abordada por Baer et al. (1976). Esse é um exemplo para ilustrar a prescrição teórica desenvolvida por Harborne e Hendry (2009) referente ao desenvolvimento de tecnologias radicais nas firmas com o apoio dos programas de demonstração co-financiadas pelo governo.

Quadro 4 - Protótipos da GM entre 1976 e 1979

\begin{tabular}{|c|c|c|c|c|c|c|c|c|c|}
\hline Anos & Veículos & Bateria & $\begin{array}{c}\text { Sistema } \\
\text { de } \\
\text { Propulsão }\end{array}$ & $\begin{array}{l}\text { Categoria } \\
\text { de veículo }\end{array}$ & $\begin{array}{l}\text { Protótipo } \\
\text { /Comercial }\end{array}$ & Plataforma & Engenheiro & Objetivo & $\begin{array}{c}\text { Teste de } \\
\text { campo }\end{array}$ \\
\hline 1976 & $\begin{array}{c}\text { Electrovette } \\
\text { I }\end{array}$ & $\begin{array}{l}\text { Chumbo- } \\
\text { ácido }\end{array}$ & $\begin{array}{l}\text { VEP- } \\
\text { Rede } \\
\text { elétrica }\end{array}$ & $\begin{array}{c}\text { Carro de } \\
\text { passageiro }\end{array}$ & Protótipo & Chevette & $\begin{array}{c}\text { Jon } \\
\text { Bereisa/ } \\
\text { Paul } \\
\text { Agarwal/ } \\
\text { Kenneth } \\
\text { Baker } \\
\end{array}$ & & \\
\hline 1979 & $\begin{array}{l}\text { Electrovette } \\
\text { II }\end{array}$ & $\begin{array}{l}\text { Níquel- } \\
\text { zinco }\end{array}$ & $\begin{array}{l}\text { VEP- } \\
\text { Rede } \\
\text { elétrica }\end{array}$ & $\begin{array}{c}\text { Carro de } \\
\text { passageiro }\end{array}$ & Protótipo & Chevette & $\begin{array}{c}\text { Jon } \\
\text { Bereisa/ } \\
\text { Paul } \\
\text { Agarwal/ } \\
\text { Kenneth } \\
\text { Baker } \\
\end{array}$ & $\begin{array}{l}\text { Teste das } \\
\text { baterias } \\
\text { de } \\
\text { níquel- } \\
\text { zinco }\end{array}$ & $\begin{array}{c}12 \text { meses } \\
\text { e aprox. } \\
57.000 \\
\mathrm{~km} .\end{array}$ \\
\hline 1979 & Van AT\&T & $\begin{array}{l}\text { Chumbo- } \\
\text { ácido }\end{array}$ & $\begin{array}{l}\text { VEP- } \\
\text { Rede } \\
\text { elétrica }\end{array}$ & Van & Protótipo & $\begin{array}{c}\text { Padrão de } \\
\text { van }\end{array}$ & Robert Bish & $\begin{array}{c}\text { Teste na } \\
\text { AT\&T }\end{array}$ & $\begin{array}{c}35 \text { meses } \\
\text { e aprox. } \\
555.600 \\
\mathrm{~km} .\end{array}$ \\
\hline
\end{tabular}

FONTE: Adaptado de YU et al., 2011

\subsection{Questão social}

A atenção pública para a poluição atmosférica foi gradualmente diminuindo devido ao aumento da relevância das questões econômicas relacionadas à crise do petróleo e da eficiência de consumo do combustível nos veículos (PENNA, GEELS; 2012). 
A crise energética de 1973 não apenas conduziu a diminuição da atenção da mídia para questões ambientais e de poluição atmosférica como também contribuiu para a recessão econômica entre 1973 e 1975. Dessa forma, para diminuir a insegurança relacionada à questão da possibilidade de desemprego, o UAW modificou o seu posicionamento em relação as questões ambientalistas e se uniu a indústria automotiva para aumentar a base de apoio na articulação política a favor das flexibilizações dos prazos das regulamentações que solicitavam a adequação da indústria aos padrões de controle de emissões de poluentes (PENNA, GEELS; 2012).

\subsection{Questões econômicas}

\subsubsection{Contexto}

Os Estados Unidos estava em um contexto de crença de que a supervalorização do dólar estava acrescentando uma taxa de desemprego significativa na sua economia. As despesas internacionais relacionadas a comprometimentos militares, investimentos externos diretos e bens e serviços requeridos superavam ou a sua capacidade produtiva ou o seu desejo de se endividar. E em 1970, o país excedeu a sua capacidade produtiva de petróleo se tornando um importador desse produto (VINSEL, 2011).

Para contornar esse contexto econômico, no dia 15 de Agosto de 1971, o presidente Nixon anunciou o fim do sistema Bretton Woods (GILPIN, 1975) que extinguiu o lastro da moeda ao ouro (VINSEL, 2011).

A nova política econômica fez o dólar flutuar e desvalorizar de forma significativa, abordando a questão do aumento da taxa de desemprego no país. Mas esse fato causou um descontentamento de proporções elevadas nos membros da OPEC, que desindexaram o valor do petróleo e refixaram no padrão ouro, aumentando instantaneamente os preços do petróleo, especialmente nos Estados Unidos que estava com o dólar desvalorizado. Nesse contexto, se iniciou o aumento da preocupação em relação ao racionamento energético e a necessidade de uma política energética adequada a essa questão (VINSEL, 2011). 


\subsubsection{Crise do petróleo}

A crise energética se instalou gradualmente nos Estados Unidos após a retirada do sistema Bretton Woods de forma que, no inverno de 1972, houve racionamento de gás natural e, no verão de 1973, foi constatada uma elevação considerável nos preços da gasolina (VINSEL, 2011).

Mas a data oficial do início do embargo da OPEC foi em 20 de Outubro de 1973 devido ao apoio dos Estados Unidos a Israel na guerra do Yom Kippur (VINSEL, 2011). Nesse período, os Estados Unidos representavam $6 \%$ da população mundial enquanto o seu consumo energético representava um terço da produção global (DOE, 1994).

As consequências da vitória de Israel geraram um efeito imediato na América do Norte quando a Organization of Arab Petroleum Exporting Countries (OAPEC) instituiu o embargo do petróleo exportado aos Estados Unidos. Em Novembro, as reservas de petróleo estavam severamente baixas, gerando o maior racionamento energético desde a Segunda Guerra Mundial (DOE, 1994).

Dessa forma, o Presidente Nixon estabeleceu o Project Independence que visava a autossuficiência energética do país em 1980. Em Dezembro de 1973, Nixon instituiu o Federal Energy Office (FEO) que institucionalizou pela primeira vez a responsabilidade do governo federal pela escassez energética do período pós-guerra (DOE, 1994).

Essa regulamentação foi implementada através Federal Energy Administration (FEA) que assumiu a responsabilidade pelas análises e informações relacionadas a energia, alocação e precificação do petróleo, a reserva de petróleo estratégica, conservação de energia e a utilização dos recursos energéticos de forma mais eficiente (DOE, 1994).

Em 1974, o Presidente Ford instituiu o Energy Reorganization Act que previu o estabelecimento do Energy Research and Development Administration (ERDA). Essa agência iniciou o processo de unificação das atividades de P\&D em energia de forma a promover a aceleração do desenvolvimento de alternativas tecnológicas, incorporando a maior parte dos recursos humanos e orçamentários da Atomic Energy Commission (AEC) e das funções de P\&D e projetos de 
demonstração de sistemas automotivos inovadores do Environmental Protection Agency (EPA) (DOE, 1994).

Mas, apesar da instituição de medidas regulatórias para contornar a crise, a população abstraiu esse acontecimento e percebeu o contexto do racionamento energético como algo temporário. Mas, no inverno de 1976 e 1977, a população se abalou pela incerteza energética (DOE, 1994).

Dessa forma, em 04 de Agosto de 1977, o Presidente Carter estabeleceu o Department of Energy (DOE) (DOE, 1994), nomeando James Schlesinger para exercer o cargo de Ministro de Energia. Schlesinger havia exercido o cargo de presidente do AEC, Ministro da Defesa e diretor do Central Intelligence Agency (DOE, 1994).

Assim, a experiência prévia do Schlesinger no AEC influenciou nas suas reações ao contexto da primeira crise do petróleo.

Ao assumir o cargo no DOE, Schlesinger iniciou a reestruturação das agências e atividades que estavam sob a administração do ERDA e do FEA de forma a classificar os projetos de acordo com o seu estágio de desenvolvimento e evolução da P\&D em relação à etapa de aplicação e comercialização, divergindo da classificação por tipos de fonte energética (DOE, 1994).

Mas, ao longo do processo de reestruturação, Schlesinger concluiu que não existia um suporte interno das agências para a instituição de um programa energético, existindo muitas bases de apoio divergentes (DOE, 1994).

Em 1979, ocorreu a Revolução Iraniana de forma que foram encerradas as exportações de petróleo, gerando um contexto de racionamento energético global. E para contornar essa questão, o DOE desenvolveu uma planta nuclear em Three Mile Island. Mas, em Março, ocorreu um acidente de proporções graves nessa planta e a Presidential Commission concluiu que a falha foi um resultado de questões de relacionamento humano que não estavam vinculadas aos equipamentos e que, retirando as questões humanas, o acidente no Three Mile Island teria sido de proporções significativamente menores (DOE, 1994). 
Dessa forma, o governo refletiu sobre o desenvolvimento dessa tecnologia para contornar a situação de escassez energética de forma que o Presidente Carter reconheceu que o acidente do Three Mile Island elevou a complexidade do contexto de tentar encontrar uma solução para a crise energética estabelecida (DOE, 1994).

Em Junho de 1979, a OPEC elevou o preço do petróleo em 15\%, estabelecendo a segunda crise do petróleo, gerando uma mudança de atitude do Presidente Carter em relação a política energética nacional. Após uma reunião com mais de 100 líderes nacionais em uma conferência doméstica, a administração do Presidente Carter propôs uma reformulação da política enérgica nacional. Assim, James Schlesinger renunciou ao cargo e Charles Duncan assumiu como o segundo Ministro de Energia (DOE, 1994).

Duncan promoveu a retirada gradual da proteção governamental na precificação do petróleo nacional e da interferência do governo nas questões relacionadas às firmas da indústria de petróleo. Dessa forma, foi estabelecido um limite claro da influência do governo no contexto da crise do petróleo e a crise energética foi abruptamente aliviada à medida que a população foi se adequando ao contexto da crise e as longas filas dos postos de combustíveis cessaram (DOE, 1994).

Em 24 de Agosto de 1979, Charles Duncan declarou que a sua atividade seria implementar o programa energético de forma a objetivar as questões nacionais estabelecidas pelo Presidente e assegurar a população americana um futuro energético seguro. O novo ministro se comprometeu a manter um canal de comunicação ativo com a sociedade para as questões relacionadas a energia nacional. E enfatizou que as forças de mercado deveriam operar livremente de forma a regular o preço e a alocação dos recursos energéticos como, por exemplo, o petróleo. Assim, o DOE não deveria se envolver com o mercado petrolífero que pertence ao setor privado, podendo usufruir da força, da tecnologia, das habilidades e da experiência em gestão e marketing adquiridos ao longo do tempo (DOE, 1994).

Através dessas medidas, Duncan concluiu que a alocação e a gestão dos recursos federais assim como o provimento dos incentivos apropriados para o setor privado para que se responsabilizem 
pelos investimentos necessários direcionaria o processo de transição de uma economia dependente de petróleo para uma economia diversificada energéticamente (DOE, 1994).

\subsubsection{Guerra Fria}

Antes da Segunda Guerra Mundial, os Estados Unidos possuíam pouco interesse ou relação com os países do Oriente Médio. Mas, em meados da década de 40, o valor estratégico das vastas reservas de petróleo da região se tornou a razão mais relevante do envolvimento do país no Oriente Médio (MASSEY, 1995).

As reservas de petróleo e a localização estratégica nas rotas aéreas e navais entre a Europa, a África, o sudeste e o leste da Ásia elevou a relevância do Oriente Médio no contexto da Guerra Fria (MASSEY, 1995). Dessa forma, a Doutrina Truman se tornou o alicerce da política de segurança nacional em termos globais ao longo do período da Guerra Fria, declarando que os Estados Unidos possuíam o direito de apoiar outras nações, quando fosse necessário, com o objetivo de evitar que regiões inteiras fossem influenciadas pelo comunismo (MASSEY, 1995).

Em 5 de Janeiro de 1957, foi estabelecida a Doutrina Eisenhower que abordou a Doutrina Truman de forma mais específica. Assim, a Doutrina Eisenhower relacionou a independência e integridade das nações do Oriente Médio com a segurança americana, declarando que o país estava preparado para utilizar a força armada para apoiar nações contra agressões armadas de países controlados pelo comunismo internacional (MASSEY, 1995).

Nos governos dos Presidentes Kennedy e Johnson, a questão do Oriente Médio estava em um contexto secundário devido ao envolvimento dos Estados Unidos com a Guerra do Vietnã. No governo do Presidente Nixon, após o término da Guerra do Vietnã, os Estados Unidos assumiu um papel mais ativo na relação com os países do Oriente Médio (MASSEY, 1995).

A política externa dos Estados Unidos focou na resolução de cinco questões inter-relacionadas

que consistiam no conflito Árabe-Israelense, nas dificuldades causadas pelas disputas Árabicas, na importação de petróleo, na propagação de influência Soviética e no desenvolvimento do 
processo de estabilização do Golfo Pérsico. Devido a essas cinco questões persistentes, os interesses dos Estados Unidos no Oriente Médio se focaram primordialmente na prevenção do controle da região por influências divergentes (MASSEY, 1995).

Dessa forma, entre 1969 e 1979, os fatores influenciadores das políticas externas dos Estados Unidos no Oriente Médio foram a contenção da influência soviética na região, a redução ou eliminação das projeções de elevação do conflito Árabe-Israelense e a manutenção de um fluxo seguro e estável de petróleo aos Estados Unidos e seus aliados (MASSEY, 1995).

A União Soviética estava alterando o equilíbrio do conflito Árabe-Israelense através de fornecimento de armamento bélico aos países árabes mais radicais, tornando a paz na região uma questão de maior complexidade de resolução. Assim, os objetivos dos Estados Unidos se focaram na diminuição da influência soviética e na negociação da paz no conflito Árabe-Israelense para assegurar o fornecimento de petróleo ao país e aos seus aliados (MASSEY, 1995).

Nesse período, a União Soviética estava fornecendo armamento bélico ao Egito (MASSEY, 1995) que estava em um processo de conflito com Israel em relação à devolução do Monte Sinai que estava em posse de Israel (BAZERMAN, 2005). O Egito é o país que incorpora a nação árabe mais populosa em escopo global (MASSEY, 1995) e possuía um valor estratégico para Israel devido a questão de defesa nacional, mas o Egito estava em condições de pleitear o retorno da região ao seu território (BAZERMAN, 2005).

Assim, a crise do petróleo de 1973 e 1979 foi um movimento explicitamente político. A nação árabe direcionou os seus esforços de embargo e diminuição da produção de petróleo com a intenção de pressionar os Estados Unidos (único país que poderia influenciar Israel) a intervir de forma favorável a garantia do reconhecimento dos direitos legítimos dos Palestinos nas regiões que foram concedidas a Israel na guerra de 1967 (LICKLIDER, 1988).

Nesse contexto, houve uma série de negociações mediadas por Henry Kissenger (MASSEY, 1995) que resultaram no acordo entre o Egito e Israel em relação à posse do Monte Sinai, em Janeiro de 1974. Assim, o embargo de petróleo foi efetivamente encerrado em Março. Mas as 
negociações prosseguiram e, em 1979, foi estabelecido o acordo de paz entre o Egito e Israel, representando o maior marco da política externa do governo do Presidente Carter (LICKLIDER, 1988).

Assim, a diplomacia e o diálogo estabelecido nos governos dos Presidentes Nixon, Ford e Carter gerou um contexto de viabilização de paz em Israel. Através dos acordos realizados em Camp David, a influência econômica e armamentista da União Soviética na região foi anulada (MASSEY, 1995)

Entre 1973 e 1979, Israel foi gradualmente se tornando dependente do fornecimento de petróleo do Irã de forma que, em 1975, houve uma necessidade de elevação das importações do Irã devido ao acordo realizado entre o Egito e Israel que estabelecia a cessão dos campos do Monte Sinai ao Egito. Assim, com a instituição da Revolução Iraniana, em 1979, Israel foi privada de 60\% das suas necessidades energéticas em petróleo e instituiu-se um contexto de insegurança em relação as fontes de suprimento energético. Mas antes da oficialização do embargo iraniano, os Estados Unidos haviam oferecido apoio para suprir o petróleo necessário a Israel (BAHBAH, 1982) assim como ao Egito (MASSEY, 1995).

A revolução Iraniana foi uma reação do Islamismo em relação aos acordos de nações árabes que apoiaram a política dos Estados Unidos, especialmente em relação a sua intervenção nos conflitos com Israel (STROBBE, 1985). Sadat, Presidente do Egito (MASSEY, 1995), foi fortemente criticado pelos líderes árabes na sua negociação com Israel de forma que foi retirado da aliança formada pelas nações árabes. O Egito representava a maior força militar das nações árabes e, ao eliminá-la da aliança, houve a perda de um forte aliado (STROBBE, 1995). Dessa forma, houve uma reposição das vantagens relativas no conflito Árabe-Israelense, favorecendo Israel.

Em 1981, foi estabelecido o fim da segunda crise do petróleo (HAMMES et al., 2005). De forma que houve um ressurgimento da abundância de petróleo e os preços oficiais da maior parte dos países produtores foram reduzidos (BAHBAH, 1982). 


\subsection{Regulamentação}

\subsubsection{Política}

Nesse período, a política energética dos Estados Unidos foi caracterizada pelo estabelecimento de uma série de objetivos nacionais ambiciosos, confiando na sua habilidade de atingi-las através da centralização de agências e no comprometimento de uma alta escala de recursos financeiros para o desenvolvimento tecnológico de novas alternativas energéticas. As questões tecnológicas eram desafiadoras, mas as questões políticas eram vertiginosamente mais instigantes devido às disparidades regionais e de classe associadas que estavam fragilmente comprometidas a qualquer política vigente. De forma divergente ao Japão e a maioria dos países europeus, os Estados Unidos estavam em um contexto de complexidade dado os interesses individuais dos estados que estavam direcionados a focar nos benefícios do aumento do consumo energético (MILLER, 1995), divergindo com o contexto da crise do petróleo.

\subsubsection{Contexto}

No período da crise do petróleo, de 1973, o Argonne National Laboratory (ANL), o Atomic Energy Comission (AEC) e o Environmental Protection Agency (EPA) estavam realizando a P\&D de sistemas de baterias para a tecnologia de veículos elétricos (BEARDSLEY, 1972; NASA, 1973b). A tecnologia do veículo elétrico estava sendo desenvolvida no Japão, que havia anunciado um programa nacional de veículos elétricos, e na Europa, que estava incentivando a tecnologia através de programas de desenvolvimento. Existia uma clara percepção de que a tecnologia do veículo elétrico estava evoluindo, mas não existia um programa federal nos Estados Unidos para promover a tecnologia (NASA, 1973b).

Nesse período, os Estados Unidos foi administrado pelos Presidentes Nixon, Ford e Carter. A administração de Nixon defendeu a habilidade do governo em conduzir o desenvolvimento de novas tecnologias. Mas a ideologia de independência das importações de petróleo se comprovou pouco aderente à realidade e foi rapidamente descontinuada pelo governo Ford. No mandato do Presidente Carter, foi priorizado o desenvolvimento de um programa energético nacional robusto 
com autoridade centralizada (MILLER, 1995). Apesar dos Presidentes Nixon e Ford terem utilizado uma abordagem de construção institucional, essa questão foi fragilmente vinculada aos seus mandatos enquanto que a administração de Nixon representou o retorno do ativismo governamental da administração de Johnson (VINSEL, 2011).

\subsubsection{Regulamentação Federal}

O embargo árabe de petróleo, de 1973, reposicionou a política energética dos Estados Unidos. Antes desse período, a P\&D do setor de energia estava desenvolvendo a tecnologia nuclear sob a supervisão da AEC. Como forma de reagir à crise do petróleo, o Congresso alocou o AEC (incluindo as instalações do Manhattan Project) no Energy Research and Development Administration (ERDA), que se tornou o foco do P\&D energético nacional (STINE, 2009). Dessa forma, em 1976, o ERDA foi responsabilizado pelo desenvolvimento das pesquisas da tecnologia do veículo híbrido e elétrico através da instauração da regulamentação Electric and Hybrid Vehicle Research, Development, and Demonstration Act, Public Law 94-413 (DOE, 2008).

Essa regulamentação previa o estabelecimento do Department of Energy (DOE), sucessor do ERDA (DOE, 2008). Assim, em 1977, foi instituída a nova agência que unificou não apenas a maioria dos programas energéticos nacionais como assumiu paralelamente as responsabilidades da defesa nacional. Dessa forma, pela primeira vez na história do país, unificou-se a administração do setor energético (DOE, 1994) bem como foi instituído o programa de P\&D de baterias para a tecnologia do veículo elétrico com um suporte de amplo escopo governamental (NASA, 1977).

Em relação às regulamentações de controle de emissões veiculares atmosféricas, a questão da crise do petróleo ofereceu um argumento favorável às montadoras no sentido de que a instalação dos dispositivos de controle causaria um aumento dos custos em U\$860,00 por veículo, elevando o preço de venda em $30 \%$ de forma a causar uma catástrofe empresarial. Assim, a operacionalização da regulamentação do Clean Air Act de 1970 se tornou árdua e, em 1973, as montadoras foram favorecidas no processo contra o EPA. De forma que o prazo original para a redução de $90 \%$ das emissões de hidrocarbonetos e monóxidos de carbono em 1975 foi estendido 
para 1977 e de 90\% de óxidos de nitrogênio em 1976 foi estendido para 1978 (PENNA, GEELS; 2012). A prorrogação do prazo representou financeiramente a abstenção temporária das montadoras da multa de U\$10.000 por veículo que estivesse fora dos padrões estipulados ou do aumento de custos de U\$860 por veículo para se adequar as regulamentações estabelecidas.

Em 1977, paralelamente a criação do DOE (DOE, 2008), foi estabelecida a emenda do Clean Air Act que incorporou a classificação das áreas que estavam sujeitas e das áreas que estavam isentas da adequação aos padrões de emissões veiculares de poluentes atmosféricos, estipulou novas fontes de padronização de desempenho, definiu a prevenção de deterioração relevante e estipulou padrões mais rígidos de controle de emissões de poluentes veiculares (AUGUSTINE, 2003). A emenda foi estabelecida no mesmo período do prazo concedido no processo contra o EPA, em relação à adequação aos padrões de emissões de hidrocarbonetos e monóxido de carbono.

Mas a crise do petróleo motivou o congresso a estender novamente o prazo estipulado às montadoras, garantindo um período de três anos a partir de 1977. Dessa forma, a crise do petróleo atenuou o entusiasmo político para se estabelecer regulamentações de controle de poluentes com maior severidade (MELOSI, 2011), direcionando os seus esforços para a questão econômica da crise do petróleo (PENNA, GEELS; 2012).

\subsubsection{Agência reguladora}

A implementação do Electric and Hybrid Vehicle Research, Development, and Demonstration Act, Public Law 94-413 foi realizado pelo Transportation Program Office/ Electric and Hybrid division do DOE (WEBSTER, YAO; 1980). Em relação à questão tecnológica, o DOE promoveu tanto o desenvolvimento da tecnologia de propulsão elétrica (NASA, 1982) quanto da tecnologia do sistema de baterias (DOUGLAS, BIRK; 1980) de forma que a agência selecionou a NASA Lewis Reseach Center para se responsabilizar pelo P\&D de todo o sistema de propulsão do Electric and Hybrid Vehicle (EHV) Program (NASA, 1982). No período inicial, o DOE priorizou a realização do P\&D de baterias para veículos elétricos puros (DOE, 2008), selecionando a ANL para se responsabilizar pela $\mathrm{P} \& \mathrm{D}$ de baterias, focando no sistema de baterias de chumbo-ácido para os objetivos de curto-prazo do programa (WEBSTER, YAO; 1980). As baterias que estavam 
sendo desenvolvidas para os objetivos de prazo intermediário eram as avançadas de chumboácido e as de níquel-zinco (NASA, 1977).

Sob a perspectiva de testes e avaliações tecnológicas em campo, o DOE apoiou financeiramente o Site Operator Program, delegando a administração do programa ao Idaho National Engineering and Environmental Laboratory. Os objetivos do programa estavam baseados na avaliação de campo da tecnologia dos veículos elétricos em ambientes e aplicações reais, no suporte da evolução da tecnologia, no desenvolvimento da infraestrutura necessária para apoiar a utilização do veículo e no aumento da conscientização e da aceitação da tecnologia do veículo elétrico pelo mercado (FRANCFORT et al., 1998).

Foram disponibilizados ao DOE o valor de U\$160 milhões para realizar a P\&D e projeto de demonstração da tecnologia dos veículos elétricos e híbridos (DOE, 2008; COWAN, HULTEN; 1996), visando desenvolver componentes e sistemas tecnológicos veiculares que permitissem a comercialização gradual de (DOUGLAS, BIRK, 1980) 2.500 veículos elétricos e híbridos entre Junho de 1978 e Dezembro de 1979 e, em seguida, aumentar a produção para uma escala entre 5.000 e 50.000 anualmente (COWAN, HULTEN; 1996) de forma a atingir a meta estimada pela regulamentação de 10.000 veículos elétricos em um período de 10 anos (DOUGLAS, BIRK; 1980), correspondendo à fase de comercialização inicial da tecnologia (KALHAMMER et al., 2007).

O programa de veículos elétricos possuía cinco projetos que foram classificados como demonstração mercadológica, avaliação e melhoria do veículo, comercialização do veículo elétrico puro, comercialização do veículo elétrico híbrido e desenvolvimento avançado do veículo. A estratégia geral do programa estava baseada no equilíbrio entre o desenvolvimento tecnológico para induzir a demanda para veículos elétricos e híbridos e na criação de demanda para oferecer novos produtos com interesse comprovado (WEBSTER, YAO; 1980). 


\subsection{Comportamento do consumidor}

O aumento significativo do preço da gasolina causou uma mudança drástica nas preferências do consumidor para veículos de pequeno porte com consumo energético eficiente. A comercialização de veículos de pequeno porte representou 57\% do mercado em 1979. A produção nacional de veículos de pequeno porte estava virtualmente produzindo toda a sua capacidade, mas não foi possível atender a demanda (KLIER, 2009). Dessa forma, os consumidores se voltaram para os veículos importados, surgindo uma oportunidade para as montadoras estrangeiras satisfazerem esse mercado (GOMEZ-IBANEZ, HARRISON; 1982).

Esse pode ser um exemplo do processo de transição sócio-técnica abordada por Geels (2002). As pressões causadas pela paisagem (crise do petróleo) e a instabilidade ocorrida no regime (mudança da preferência do consumidor no mercado de veículos de grande porte) geraram uma oportunidade para o mercado de nicho (veículos importados de pequeno porte) se desenvolver nesse processo. O tipo de inovação ocorrida nesse processo não corresponde as inovações radicais de produto abordadas na teoria do surgimento do projeto dominante, mas viabiliza-se a utilização desse evento para exemplificar uma mudança de paradigma tecnológica sem a ocorrência do surgimento do projeto dominante no sentido das competências distintas geradoras das inovações no processo estarem resultando no mesmo produto, por exemplo, na Toyota.

\subsection{Estratégia}

\subsubsection{Montadoras}

A crise do petróleo, em 1973, causou a mobilização para pesquisa, desenvolvimento e análise de diversas alternativas para inovações de produtos (GODIWALLA et al., 1979) de forma a reestruturar os seus projetos e processos de desenvolvimento das montadoras (LALL, 1980). Em 1978, os novos veículos foram rapidamente reprojetados para objetivar a redução do consumo energético e da diminuição do volume e da dimensão dos motores (MECHTENBERG, 2009). 
A indústria automotiva estava entre o debate econômico relacionado ao protecionismo em relação ao livre-mercado. Para indústrias importadoras, como a têxtil e a siderúrgica, o protecionismo se adequava ao seu contexto. Mas, para as indústrias com intenções exportadoras, como a automotiva, por exemplo, a abordagem de livre-mercado era vantajosa. Para as montadoras, o aumento dos veículos importados ameaçava a sua lucratividade de longo prazo. Dessa forma, ao invés de fazer lobby a favor do protecionismo, as montadoras utilizaram quatro estratégias de competição estabelecidas através da aquisição de participações minoritárias das montadoras japoneses, da redução dos custos fixos da organização através do aumento da produtividade, do lançamento de uma nova geração de veículos para competir com os veículos importados (ARENA, 2009) e do desenvolvimento do carro mundial na década de 80, representando um processo de expansão das atividades das subsidiárias (LALL, 1980).

Em relação a estratégia do desenvolvimento do carro mundial, a estruturação do processo foi concentrada na Europa. Esse veículo foi planejado para compartilhar uma escala significativa de componentes que seriam produzidos por unidades dispersas globalmente de forma que o projeto final poderia incorporar algumas adaptações de estilo e desempenho para mercados diferenciados (LALL, 1980).

Os grandes volumes foram relacionados ao aumento da velocidade e da efetividade da inovação nas montadoras. Dessa forma, as pressões internas do mercado nacional para a produção de veículos de menor porte, atuando em conjunto com essa estratégia de expansão internacional, direcionaram uma nova estrutura internacional de produção automotiva para o período de uma década (LALL, 1980).

Em relação às regulamentações favoráveis ao controle de poluição atmosférica, a indústria desenvolveu campanhas para pressionar os congressistas e mobilizou uma equipe de apoio dentro do congresso para adiar a operacionalização das regulamentações nas audiências do congresso. Assim, a estratégia das montadoras foi conduzida no sentido de postergar a operacionalização das regulamentações favoráveis ao controle de poluentes atmosféricos de forma a adotar uma cultura de resistência às questões ambientais, fundamentando esse posicionamento na percepção da baixa aderência às preferências dos consumidores a esses fatores (PENNA, GEELS; 2012). 


\subsubsection{GM}

Para reagir à competição globalizada, o Vice-Presidente da GM European Operations desenvolveu um processo de reestruturação organizacional das subsidiárias europeias, integrando as suas operações e modificando as perspectivas tradicionais dos gestores nas subsidiárias. $\mathrm{O}$ reposicionamento foi baseado em torno do conceito de cooperação entre as subsidiárias e entre as subsidiárias e as divisões dos Estados Unidos para realizar P\&D, desenvolvimento de novos produtos, manufatura e marketing, preservando a sua autonomia. Dessa forma, a GM poderia desenvolver a competência para realizar em paralelo o carro mundial e carros regionais (DOZ, PRAHALAD; 1984). Essa observação pode exemplificar a literatura desenvolvida por Anderson e Tushman (1990) em relação a prescrição para o desenvolvimento de diversas aptidões na firma de forma a influenciar e ser influenciada no processo de evolução tecnológica, iniciando ou reagindo às descontinuidades de forma ágil.

A GM desenvolveu uma estratégia de curto-prazo, que envolvia o lançamento de veículos compactos com consumo mais eficiente de energia. Em 1977, a GM lançou uma família de veículos enxutos e de consumo energético mais eficiente, mantendo a qualidade de dirigibilidade e conforto (GODIWALLA et al., 1979).

De forma paralela, a firma desenvolveu duas estratégias de prazo intermediário. Um percurso foi desenvolvido através da realização de pesquisas para projetar um veículo que satisfizesse a demanda da década de 80 compactando os veículos com a utilização da tecnologia de combustão interna existente. Outro percurso seguiu a trajetória do desenvolvimento tecnológico através de inovações, como, por exemplo, o desenvolvimento de vans elétricas experimentais (GODIWALLA et al., 1979). De forma que a GM anunciou a sua intenção de desenvolver uma linha de produção de veículos elétricos em meados da década de 80 (DELUCHI, WANG, SPERLING; 1989).

Para desenvolver o carro mundial, a GM havia construído centros de projetos para unificar todos os tipos de especializações para alicerçar o desenvolvimento de novos produtos utilizando uma ferramenta computacional projetada para a racionalização de custos (GODIWALLA et al., 1979) 
Essa poderia ser uma forma de operacionalizar a estratégia de prazo intermediário utilizando a tecnologia de combustão interna existente.

A reestruturação das operações da firma foi realizada de forma a viabilizar um processo de inovação mais veloz e efetivo (GODIWALLA et al., 1979) indo ao encontro da estratégia de inovação de prazo intermediário da firma. Esse poderia ser um exemplo empírico da estrutura conceitual utilizada por Utterback e Abernathy (1975), que aborda a questão da relevância da inovação no crescimento econômico da firma.

\subsection{Tecnologia de bateria}

A tecnologia de baterias para veículos elétricos foi desenvolvida de forma independente das regulamentações federais no seu período inicial. Em 1973, o EPA estava apoiando o desenvolvimento da tecnologia de baterias de chumbo-ácido para veículos elétricos e híbridos. Mas como naquele período não existia uma política definida em relação ao desenvolvimento da tecnologia do veículo elétrico, a agência focou os seus investimentos no desenvolvimento de inovações na tecnologia do motor de combustão interna. A ANL estava realizando pesquisas sobre a tecnologia do sistema de baterias de alta temperatura de lítio devido a sua relevância para a AEC. A tecnologia nuclear estava em evidência naquele período e estava sendo considerada como fonte energética para substituir os combustíveis fósseis utilizados no setor de transporte, mas a sua viabilização dependia do desenvolvimento de tecnologias de armazenamento energético, como, por exemplo, a bateria (NASA, 1973b).

A GM estava realizando o P\&D de baterias de forma independente das regulamentações (NASA, 1973b). No período em que o governo não havia legitimado o seu apoio regulatório, a GM desenvolveu a tecnologia das baterias de chumbo-ácido utilizadas em vans experimentais, por exemplo. O envolvimento da General Motors Corporation Truch and Coach Division no desenvolvimento da tecnologia indicava que os veículos elétricos estavam em um estágio de desenvolvimento mercadológico (CAIRNS, HIETBRINK; 1981). A GM também estava desenvolvendo a tecnologia de sistema de bateria de lítio-sulfeto de ferro de forma que 
representava o estado da arte da tecnologia em conjunto com a ANL e a Varta (Alemanha) (DOUGLAS et al., 1980).

O protótipo GM512, desenvolvido no período do direcionador da poluição atmosférica, foi utilizado para testar o sistema de baterias de níquel-zinco (CAIRNS, HIETBRINK; 1981). Essa tecnologia estava sendo considerada como a melhor candidata a substituir a tecnologia do sistema de baterias de chumbo-ácido (NASA, 1973b) e a sondagem realizada no protótipo indicou uma elevação de desempenho excedendo dois fatores em relação ao desempenho obtido com a tecnologia das baterias de chumbo-ácido (CAIRNS, HIETBRINK, 1981).

Em 1976, foi estabelecida a regulamentação federal Electric and Hybrid Vehicle Research, Development, and Demonstration Act, Public Law 94-413 (DOE, 2008), consolidando a P\&D energética nacional (DOE, 1994) e provendo uma fundamentação institucional de amplo escopo para o desenvolvimento da tecnologia de baterias para a tecnologia do veículo elétrico (NASA, 1977).

Nesse contexto de apoio governamental, a GM manteve o seu posicionamento de realização de P\&D da tecnologia de baterias com recursos próprios (RAND, 1979; GARVEY, 1980; DOUGLAS et al., 1980) devido a sua percepção de que a P\&D tendia a estar mais relacionada aos veículos do que a pesquisa básica ou aplicada (LINDEN et al., 1976). Para reagir ao contexto gerado pela crise do petróleo, a GM testou a tecnologia das baterias de níquel-zinco no protótipo Electrovette II com a intenção de lançamento comercial do modelo (CAIRNS, ALBERTUS, 2010) e a sondagem realizada sugeriu que a tecnologia estava em um estágio de desenvolvimento que oferecia confiabilidade, segurança e uma boa relação de custo-benefício ao consumidor para a sua utilização de forma contínua (RAJASHEKARA, 1994).

\subsection{Análise do driver das crises do petróleo}

Nesse período, observamos que os fatores externos que influenciaram a batalha tecnológica de forma relevante foram a política de apoio a P\&D de veículos elétricos, a questão econômica estabelecida pela crise do petróleo, a guerra fria, o comportamento do consumidor e o campo 
tecnológico. Em relação aos fatores internos, verificamos a influência do setor industrial associado, da credibilidade e da sondagem e aprendizagem tecnológica nas ações da GM para desenvolver a tecnologia do veículo elétrico.

As evidências apresentadas neste capítulo revelam que a crise do petróleo redirecionou o posicionamento de diversos agentes da sociedade de forma a gerar um avanço no desenvolvimento da tecnologia do veículo elétrico na GM. O contexto político da influência comunista da ex-URSS no conflito existente entre os países do oriente médio, gerou um desequilíbrio nas relações entre Israel e os países árabes produtores de petróleo. Dessa forma, o fortalecimento dos países árabes pela influência do movimento comunista desencadeou um processo de reinvidicação da intervenção dos Estados Unidos na política externa de Israel de forma que o país cedesse direitos políticos adquiridos previamente em territórios palestinos. Nesse sentido, o embargo dos países produtores de petróleo aos Estados Unidos e países aliados foi um movimento explicitamente político.

O conflito foi centralizado entre o Egito e Israel. O Egito era o país com a maior população árabe em escala global e estava pleiteando o retorno do território do Monte Sinai, que estava em posse de Israel devido a direitos adquiridos anteriormente. E, através das negociações mediadas pelos Estados Unidos, os países entraram em um acordo de forma que Israel foi privada das reservas de petróleo da região do Monte Sinai, causando uma elevação da dependência de Israel ao petróleo importado do Irã. Mas as negociações mediadas pelos Estados Unidos prosseguiram e, em 1979, o Egito entrou em um acordo de paz com Israel, eliminando a influência comunista na região.

Em contrapartida, o descontentamento dos países árabes com esse acordo de paz desencadeou a segunda crise do petróleo pelo Irã, privando Israel de $60 \%$ do seu suprimento energético, por exemplo. E o Egito foi eliminado da aliança árabe. Assim, a ausência do aliado que possuía a maior força militar dos países árabes reequilibrou as relações árabe-israelenses e, em 1981, os preços do petróleo se reduziram substancialmente de modo que a crise do petróleo se encerrou.

Nesse contexto, a crise do petróleo estabeleceu a reestruturação da política energética americana de forma que houve uma elevação do interesse governamental em desenvolver alternativas 
energéticas visando a independência e segurança energética do país. Conforme podemos observar na tabela 2, enquanto a política externa do país se envolveu em eliminar a influência comunista no oriente médio, a política interna buscou unificar, urgentemente, as agências que realizavam P\&D em energia no Energy Research and Development Administration (ERDA). E, ao assumir a responsabilidade pela crise energética, o país instituiu, emergencialmente, a agência independente Federal Energy Administration (FEA) com o objetivo de utilizar os recursos energéticos de forma mais eficiente. Outra medida do governo foi o estabelecimento da primeira regulamentação federal de apoio explícito ao desenvolvimento da tecnologia do veículo elétrico. Devido ao término da vigência do prazo das políticas emergenciais ERDA e FEA, o governo federal instituiu o Electric and Hybrid Vehicle Research, Development, and Demonstration Act, Public Law 94-413. Desse modo, as agências independentes ERDA e FEA foram dissolvidas para que as suas atividades se consolidassem no Department of Energy (DOE), estabelecido nessa legislação, que unificou a administração do setor energético do país em termos históricos.

Assim, os esforços desenvolvidos anteriormente pela ERDA e pela FEA se convergiram no DOE de maneira a viabilizar o desenvolvimento da tecnologia do veículo elétrico para o estágio comercial em um período de dez anos. Nesse sentido, o envolvimento direto do governo no cofinanciamento de projetos de demonstração para a realização de testes de campo beneficiou a GM, que desenvolveu testes de campo nos seus protótipos, como a AT\&T van, por exemplo. Esses testes envolvem um alto custo e risco para as empresas. Mas, o DOE compartilhou o custo e o risco com a GM, indo ao encontro da prescrição teórica desenvolvida por Harborne e Hendry (2009) que sugere a participação do governo no co-financiamento de projetos de demonstração em tecnologias radicais do setor energético. 
Quadro 5- Análise das políticas públicas do driver das crises do petróleo

\begin{tabular}{|c|c|c|c|c|c|c|c|c|c|c|}
\hline Guerra Fria & $\overline{\mathrm{a}}$ & & & & & & & 1 & & \\
\hline Crise do petróleo & & $\mathrm{b}$ & & $\mathrm{f}$ & & & & $\mathrm{m}$ & & $\mathrm{p}$ \\
\hline Regulam. federal & & c d & e & & & h i & & & & \\
\hline Protótipo & & & & & g & & & $\mathrm{n} \quad \mathrm{o}$ & & \\
\hline Linha do tempo & 1972 & 1973 & 1974 & 1975 & 1976 & 1977 & 1978 & 1979 & 1980 & 1981 \\
\hline \multirow{10}{*}{ Legenda } & a & \multicolumn{6}{|c|}{$\begin{array}{c}\text { Egito inicia articulação política para uma } \\
\text { guerra com Israel }\end{array}$} & \multirow{2}{*}{1} & \multirow{2}{*}{\multicolumn{2}{|c|}{$\begin{array}{c}\text { Acordo de } \\
\text { paz entre o } \\
\text { Egito e } \\
\text { Israel }\end{array}$}} \\
\hline & $\mathrm{b}$ & \multicolumn{6}{|c|}{ Início da primeira crise do petróleo. } & & & \\
\hline & c & \multicolumn{6}{|c|}{$\begin{array}{c}\text { O governo institui o Federal Energy } \\
\text { Agency (FEA) }\end{array}$} & \multirow{2}{*}{$\mathrm{m}$} & \multirow{2}{*}{\multicolumn{2}{|c|}{$\begin{array}{l}\text { Inicio da } \\
\text { segunda } \\
\text { crise do } \\
\text { petróleo - } \\
\text { embargo } \\
\text { iraniano. }\end{array}$}} \\
\hline & d & \multicolumn{6}{|c|}{$\begin{array}{l}\text { Prorrogação do prazo para atender o Clean } \\
\text { Air Act de } 1970\end{array}$} & & & \\
\hline & e & \multicolumn{6}{|c|}{$\begin{array}{l}\text { O governo estabelece o Energy Research } \\
\text { and Development Agency (ERDA) }\end{array}$} & \multirow{2}{*}{$\mathrm{n}$} & \multirow{2}{*}{\multicolumn{2}{|c|}{$\begin{array}{c}\text { Electrovette } \\
\text { II }\end{array}$}} \\
\hline & $\mathrm{f}$ & \multicolumn{6}{|c|}{$\begin{array}{l}\text { Israel eleva a sua dependência de petróleo } \\
\text { do Irã }\end{array}$} & & & \\
\hline & $\mathrm{g}$ & \multicolumn{6}{|c|}{ Electrovette I } & \multirow[b]{2}{*}{ o } & \multirow{2}{*}{\multicolumn{2}{|c|}{ AT\&T van }} \\
\hline & $\mathrm{h}$ & \multicolumn{6}{|c|}{$\begin{array}{l}\text { O governo aprova a regulamentação que } \\
\text { institui o Department of Energy (DOE) } \\
\text { com a intenção explicita de apoiar o } \\
\text { desenvolvimento da tecnologia do veículo } \\
\text { elétrico. } \\
\end{array}$} & & & \\
\hline & $\mathrm{i}$ & \multicolumn{6}{|c|}{ Clean Air Act } & \multirow[b]{2}{*}{$\mathrm{p}$} & \multirow{2}{*}{\multicolumn{2}{|c|}{$\begin{array}{l}\text { Fim da crise } \\
\text { do petróleo }\end{array}$}} \\
\hline & $\mathrm{j}$ & \multicolumn{6}{|c|}{$\begin{array}{c}\text { Prorrogação do prazo para atender o Clean } \\
\text { Air Act de } 1970\end{array}$} & & & \\
\hline
\end{tabular}

Fonte: elaboração da autora

A crise do petróleo desencadeou o aumento do preço dos combustíveis no mercado americano, gerando uma mudança abrupta nas preferências dos consumidores por veículos compactos e econômicos. E, devido ao aumento das importações de veículos no mercado americano, o sindicato automotivo se encontrou em um contexto de iminência de desemprego nas montadoras. Assim, o sindicato abandonou o seu posicionamento favorável a causa ambientalista e reorientou as suas ações para o favorecimento da base de apoio das montadoras para solicitação de prorrogação de prazo nas regulamentações de controle de poluição atmosférica. Assim, esse fato 
evidencia uma das razões da diminuição substancial da pressão social contra as emissões de poluição atmosférica.

A relevância da indústria aeroespacial se tornou evidente, novamente, ao receber a responsabilidade pelo $\mathrm{P} \& \mathrm{D}$ de todo o sistema de propulsão do Electric and Hybrid Vehicle (EHV) Program do DOE. A influência direta do DOE para solicitar o apoio da NASA no desenvolvimento da tecnologia do veículo elétrico é outra evidência da participação do governo como um agente influenciador relevante no processo de seleção da tecnologia.

Em relação ao campo tecnológico, observamos a transferência de conhecimento do setor aeroespacial para o setor automotivo e entre os protótipos desenvolvidos na GM desse período. Essa constatação pode ser evidenciada através da transferência do engenheiro Jon Bereisa da NASA para a GM e através da participação do engenheiro Paul Agarwal no desenvolvimento dos protótipos Electrovair I e II e Stir-lec I. Assim, ao participar do desenvolvimento dos protótipos Electrovette I e II, Jon Bereisa e Paul Agarwal beneficiaram os protótipos com os seus conhecimentos adquiridos previamente. Esse foi o protótipo que a GM estava desenvolvendo com a intenção de lançar comercialmente no período da segunda crise do petróleo. Mas, ao encerrar a crise do petróleo, a GM retrocedeu essa intenção.

Os protótipos desenvolvidos nesse período apresentaram dessemelhanças em relação ao período anterior. Verificamos uma diminuição na quantidade de sondagem e aprendizagem tecnológicas, sugerindo um processo de seleção das tecnologias testadas previamente. De modo que houve a sondagem e aprendizagem tecnológica de dois tipos de baterias (níquel-zinco e chumbo-ácido) e duas categorias de veículos (carro de passageiro e van). As plataformas utilizadas foram desenvolvidas anteriormente $\mathrm{e}$ as tecnologias de baterias testadas foram desenvolvidas internamente na firma com a finalidade específica para veículos elétricos. Por exemplo, a firma realizou testes da bateria de níquel-zinco no protótipo de carro de passageiro micro GM512, que foi uma plataforma desenvolvida no período anterior. Outra observação foi a expansão do processo de sondagem e aprendizagem tecnológica para a etapa de testes de campo dos protótipos, sugerindo um amadurecimento da tecnologia do veículo elétrico na firma. A realização de 12 meses de teste de campo (aprox. $57.000 \mathrm{~km}$ ) do Electrovette II e de 35 meses de 
testes de campo (aprox. $555.600 \mathrm{~km}$ ) da AT\&T van evidencia tanto a expansão do processo de sondagem e aprendizagem tecnológica quanto a maior influência no governo no desenvolvimento da tecnologia do veículo elétrico na GM. 


\section{POLUIÇÃO ATMOSFÉRICA II}

\subsection{Introdução}

No capítulo anterior, abordamos os fatores que influenciaram o percurso da evolução da tecnologia do veículo elétrico na GM no período direcionado pela primeira e segunda crise do petróleo. Nesse período, a questão da poluição atmosférica retornou a direcionar o desenvolvimento da tecnologia na firma. Assim, iniciaremos o capítulo com o desenvolvimento dos protótipos e do primeiro lançamento comercial da GM na seção 2. Nessa seção, evidenciaremos as possíveis influências de tecnologias associadas e as transferências de conhecimento realizadas através dos engenheiros da GM e da Aerovironment ${ }^{2}$. Descreveremos a questão social da poluição atmosférica e a sua relevância no direcionamento desse período na seção 3. Na seção 4, abordaremos a questão do estabelecimento de consórcios que objetivaram incentivar o desenvolvimento da tecnologia de baterias e do veículo elétrico de forma que, na seção 5, descreveremos as regulamentações que foram influenciadas pelo lançamento comercial da GM, descrito na seção 2, bem como pelas questões sociais abordadas na seção 3. De maneira complementar, os consórcios descritos na seção 4 foram relevantemente influenciados pelo conteúdo regulatório desenvolvido na seção 5. Iniciamos o capítulo descrevendo os protótipos e o primeiro lançamento comercial de veículo elétrico na GM (seção 2) de modo que continuamos o desenvolvimento do capítulo através da abordagem dos fatores sociais (seção 3), tecnológicos (seção 4) e políticos (seção 5) que influenciaram o processo de desenvolvimento do veículo elétrico na firma. Nessa direção, na próxima seção, ampliaremos a nossa compreensão do processo ao verificarmos a questão estratégica das montadoras e da GM e a sua relação com fatores regulatórios e sociais em um contexto econômico e político dessemelhante ao contexto vigente no primeiro período estudado. Dessa forma, na seção 7, finalizaremos o capítulo com a abordagem das questões mercadológicas do veículo elétrico em um escopo global no sentido de verificar as possíveis estratégias adotadas em países como, por exemplo, a França. Assim, viabilizamos a expansão da compreensão das diferenças estratégicas entre a inserção mercadológica da GM em relação a Toyota, por exemplo, em um contexto globalizado.

\footnotetext{
${ }^{2}$ Firma originada do setor aeronáutico
} 


\subsection{Protótipos de veículo elétrico}

\subsubsection{G-Van}

Nesse período, o Professor C.C. Chan, considerado o pai dos veículos elétricos na Ásia, desenvolveu o sistema de transmissão alternative current (ac) para aplicação em veículos elétricos (TUOHK, 2010). A vantagem desse sistema de transmissão é a significativa redução da dimensão, do peso (50\% mais leves) e do custo do motor de tração (75\% mais econômicos) (PATIL, 1990; DELUCHI, WANG, SPERLING, 1989) em relação ao sistema de transmissão direct current (dc) (TUOHK, 2010).

Assim, em 1981, a Ford e a General Electric propuseram ao DOE o desenvolvimento de um sistema de transmissão ac com um eixo único com a intenção de incentivar a tecnologia do sistema de transmissão ac em vans. Dessa forma, nesse período, a maior parte dos projetos de demonstração e desenvolvimento de veículos elétricos nos Estados Unidos focou nessa categoria de veículo (DELUCHI, WANG, SPERLING; 1989).

Em 1985, a Bedford (divisão da GM no Reino Unido) começou a disponibilizar Griffon vans para os Estados Unidos (PATIL, 1990). Elas utilizavam o sistema de transmissão dc e, para suceder esse modelo (DELUCHI, WANG, SPERLING, 1989), o Electric Power Research Institute (EPRI) (BRAGA, 1992), a GM, a CMP Batteries Limited, a Chloride EV Systems e a Vehma International (subsidiária da Magna International) desenvolveram o G-Van (PATIL, 1990; MORALES et al., 1991) com a intenção de produzir comercialmente esse modelo (GATHRIGHT, 1990; UOM, 2012b) de forma a ser comparável a Van Vandura da GM em termos de qualidade, confiabilidade, durabilidade e segurança (BRAGA, 1992). Esse modelo foi considerado como um dos veículos mais estimados nos anos 80 na mídia televisionada, sendo veiculado através da série “A-Team” (CHANG, 2010). Nessa direção, o veículo foi projetado para oferecer um alto padrão de conforto e comodidade em relação aos modelos da categoria de vans de carga (GMC, 1989). 
Em 1989, foi lançado o protótipo do G-Van (MORALES et al., 1991) com o sistema opcional do sistema de transmissão ac (BRAGA, 1992) que foi incorporado no sistema de propulsão classificado como veículo elétrico puro (VEP) (DELUCCHI, WANG, SPERLING, 1989) de forma a utilizar o sistema de baterias de chumbo-ácido (BRAGA, 1992) como fonte energética do modelo desenvolvido na plataforma GMC Vandura (MORALES et al., 1991).

\subsubsection{Sunraycer}

O desenvolvimento da tecnologia do veículo elétrico na GM progrediu de forma vertiginosa, após 1985, quando a Hughes Aircraft participou das atividades da firma (PINKSE, BOHNSACK, KOLK, 2011). Nesse período, a indústria aeroespacial da California estava em declínio, devido ao contexto do fim da Guerra Fria ${ }^{3}$ (LARRUE, 2003). Nesse sentido, o convite para participar da corrida automobilística World Solar Challenge na Austrália (KALM, 2007), em Janeiro de 1987, foi percebido como uma oportunidade para evidenciar a transferência de tecnologias do setor aeroespacial para o setor automotivo (SHNAYERSON, 1996).

Através da sua liderança no desenvolvimento de tecnologias de mobilidade solar, Paul MacCready foi o inspirador do Hans Tholstrup, fundador do World Solar Challenge (UOMSC, 2005). Em 7 de Julho de 1981, o avião Solar Challenger, desenvolvido por Paul MacCready, voou da França à Inglaterra em uma trajetória de 262,3km utilizando a energia solar como fonte energética sem a utilização de um sistema de armazenamento de energia (NOTH, 2008)

Dessa maneira, a Hughes Aircraft convidou a AeroVironment, fundada por Paul MacCready, para participar da equipe de desenvolvimento do Sunraycer (SHNAYERSON, 1996). Através do seu envolvimento, a Hughes Aircraft desenvolveu o modelo (MACCREADY, 1988) em uma nova plataforma (YU et al., 2011) que utilizou o sistema de baterias de prata-zinco e células fotovoltaicas fornecidas pela firma que foram interligadas no invertedor DC para AC desenvolvido pela AeroVironment (SHNAYERSON, 1996) de modo a viabilizar o fornecimento

\footnotetext{
${ }^{3}$ O fim da Guerra Fria gerou um corte abrupto nos contratos militares na Califórnia, representando parte da causa da severa recessão ocorrida nesse período. E o desenvolvimento da indústria do veículo elétrico estava sendo considerado como uma oportunidade de conversão tecnológica do setor militar para o setor civil no sentido de revitalizar a economia da Califórnia e, possivelmente, em um contexto maior, de toda a indústria dos Estados Unidos (Larrue, 2003).
} 
energético do sistema de propulsão BEV solar para o protótipo de carro de corrida (YU et al., 2011).

O Sunraycer foi projetado para gerar 1500 watts no sol do meio dia e percorrer uma velocidade média de 90km/h (AEROVIRONMENT, 2011). Assim, em Novembro de 1987, no sexto dia de corrida, o Sunraycer foi o vencedor do primeiro World Solar Challenge (SHNAYERSON, 1996), obtendo uma vantagem de 60 horas do segundo colocado (KALM, 2007).

\subsubsection{Impact}

Para Paul MacCready, a clara vantagem tecnológica do Sunraycer em relação ao segundo colocado na corrida foi considerada como um prenúncio de que poderia ser desenvolvido um projeto maior. Nesse sentido, no começo de 1988, a Hughes Aircraft e a AeroVironment apresentaram uma proposta de desenvolvimento de um protótipo de veículo elétrico com a intenção de desenvolvimento comercial. Assim, ao se impressionar com o desempenho do projeto do modelo proposto, a GM aprovou o projeto do veículo elétrico que foi denomeado Santana devido aos ventos Santa Ana que carregam os nevoeiros fotoquímicos geradores de poluição atmosférica na região de Los Angeles (SHNAYERSON, 1996).

Mas, durante o desenvolvimento do projeto, a GM descobriu que o nome Santana estava registrado em um modelo da Volkswagem da Europa. Dessa forma, o modelo foi renomeado para Impact (SHNAYERSON, 1996).

O Impact, desenvolvido pela GM com a participação da AeroVironment (SHNAYERSON, 1996), foi o primeiro protótipo de veículo elétrico da categoria de carro de passageiro com intenção de produção comercial (RAJASHEKARA, 1994). Dessa maneira, esse modelo para dois passageiros foi desenvolvido em uma nova plataforma que utilizou o sistema de baterias de chumbo-ácido como fonte energética do sistema de propulsão elétrica pura (YU et al., 2011).

Assim, em 3 de Janeiro de 1990, o Impact foi apresentado no L.A. Auto Show (SHNAYERSON, 1996). O protótipo não apenas despertou o interesse da mídia como incentivou o CARB a 
estabelecer (GARUD, GEHMAN, 2012), em Setembro de 1990, o ZEV Mandate ${ }^{4}$ (LARRUE, 2003).

\subsubsection{EV-1}

Em 1991, foi desenvolvido um estudo de marketing que influenciou relevantemente nas decisões estratégicas da GM para o lançamento do EV1. Nessa pesquisa, foi utilizada a metodologia Information Acceleration (IA) que se baseia na simulação de informações disponíveis ao consumidor no momento de decisão de compra em um ambiente virtual. As questões do estudo foram vinculadas aos atributos do veículo e ao atendimento das metas estabelecidas pelo ZEV Mandate. Nesse sentido, a tecnologia híbrida não foi considerada devido a tecnologia elétrica pura atender a regulamentação de forma mais consistente (URBAN, WEINBERG, HAUSE; 1996).

Os resultados do estudo evidenciaram que, no cenário em que a firma atingisse uma redução de custos e desenvolvesse um modelo de multipassageiros em que a firma fosse a pioneira em um mercado de competição moderada a estimativa de vendas seria de 11,465 veículos, em 1998. Essa escala de vendas poderia atender ao ZEV Mandate. Mas, a taxa de retorno de investimentos continuaria abaixo do mínimo que a empresa requeria devido ao custo adicional em projetar e produzir um modelo de multipassageiros. Dessa forma, o estudo assumiu a premissa da obtenção da vantagem do pioneiro ao lançar o veículo de dois passageiros antes dos concorrentes para considerar a estimativa de vendas de 6,265 unidades em um cenário otimista (URBAN, WEINBERG, HAUSE, 1996).

No processo de desenvolvimento do EV1, Kenneth Baker desenvolveu o modelo com o apoio do Jon Bereisa (GAGNON, 1999). Jon Bereisa havia exercido o cargo de engenheiro-chefe do sistema de propulsão elétrica do Impact (ALPERT, 1992) de modo no projeto do EV1 foi mantida a mesma responsabilidade (CCT, 2011). No projeto Electrovette, desenvolvido no período anterior, Kenneth Baker havia assumido a responsabilidade pelo seu desenvolvimento de

\footnotetext{
${ }^{4} \mathrm{O}$ conteúdo referente ao ZEV Mandate será desenvolvido posteriormente na seção 5.
} 
maneira que Jon Bereisa havia apoiado o seu desenvolvimento. Assim, no projeto do EV1, eles puderam trabalhar juntos novamente.

E, de forma paralela as atividades do EV1, Kenneth Baker e Jon Bereisa exerceram o cargo da Presidência da United States Advanced Battery Consortium (USABC), fundada por Kenneth Baker (PRNEWSWIRE, 2012; AUTOCHANNEL, 1997), em 1991 (DOE, 1993).

O desenvolvimento do EV1 foi apoiado pelo esforço conjunto da Energy Conversion Devices, da Hughes Corporation, da Delco Remy, da EPRI (PILKINGTON, DYERSON; 2002) e da AeroVironment, por exemplo (BOTSFORD, SZCZEPANEK, 2009). Dessa forma, através desses representantes, os consórcios USABC, ALABC, CALSTART e a parceria $\mathrm{PNGV}^{5}$ apoiaram o desenvolvimento da tecnologia do veículo elétrico bem como da cadeira de fornecedores desse segmento industrial.

A AeroVironment havia desenvolvido o Impact de forma conjunta com a GM (SHNAYERSON, 1996). No sentido em que Paul MacCready foi considerado como o pai do Impact (SPERLING, CANNON; 2004). E, após o estabelecimento da regulamentação ZEV Mandate, a AeroVironment apoiou no desenvolvimento do EV-1 de forma que a idéia proposta por Paul MacCready no projeto Santana (SHNAYERSON, 1996) pode se tornar realidade através do EV-1 (HOLZMAN, 1997).

Em 1996, a GM lançou o EV1 que se estabeleceu como o primeiro veículo elétrico comercial com um desempenho de estrada comparável aos veículos convencionais a combustão interna (WESTBROOK, 2001) que foi comercializado pelo valor de US\$33.959,00 e gerava uma autonomia por carga de $112 \mathrm{~km}$ na cidade e $144 \mathrm{Km}$ na estrada (CHAN, 2002). Esse modelo para dois passageiros utilizou a plataforma do Impact para incorporar o sistema de propulsão elétrico puro que foi alimentado por um sistema de baterias de chumbo-ácido (YU et al., 2011) com um sistema isento de manutenção, indo ao encontro da meta de desenvolvimento tecnológico do ALABC (MOSELEY, 1998).

\footnotetext{
${ }^{5} \mathrm{O}$ conteúdo referente aos consórcios USABC, ALABC, CALSTART e a parceria PNGV será desenvolvido posteriormente na seção 4 .
} 
Dessa forma, o EV1 e o Impact foram tecnologicamente semelhantes em relação ao sistema de propulsão elétrica pura e ao sistema de baterias de chumbo-ácido (YU et al., 2011).

Quadro 6 - Protótipos e lançamento comercial da GM entre 1987 e 1996

\begin{tabular}{|c|c|c|c|c|c|c|c|c|}
\hline Ano & Veículo & Bateria & $\begin{array}{l}\text { Sistema de } \\
\text { propulsão }\end{array}$ & $\begin{array}{l}\text { Categoria } \\
\text { de veículo }\end{array}$ & $\begin{array}{l}\text { Protótipo/ } \\
\text { Comercial }\end{array}$ & $\begin{array}{c}\text { Plataform } \\
\mathbf{a}\end{array}$ & $\begin{array}{c}\text { Engenheiro } \\
\mathrm{s}^{2}\end{array}$ & Objetivo \\
\hline 1987 & Sunraycer & $\begin{array}{l}\text { Prata- } \\
\text { zinco }\end{array}$ & VEP solar & $\begin{array}{l}\text { Carro de } \\
\text { corrida }\end{array}$ & Protótipo & Nova & $\begin{array}{c}\text { Paul } \\
\text { MacCready }\end{array}$ & $\begin{array}{c}\text { Transferência da } \\
\text { tecnologia } \\
\text { aeroespacial para } \\
\text { o setor } \\
\text { automotivo. } \\
\end{array}$ \\
\hline 1989 & G-Van & $\begin{array}{l}\text { Chumbo- } \\
\text { ácido }\end{array}$ & VEP & Van & Protótipo & $\begin{array}{c}\text { GMC } \\
\text { Vandura }\end{array}$ & & $\begin{array}{c}\text { Produção de vans } \\
\text { elétricas } \\
\text { comparáveis a } \\
\text { Van GMC } \\
\text { Vandura. } \\
\end{array}$ \\
\hline 1990 & Impact & $\begin{array}{l}\text { Chumbo- } \\
\text { ácido }\end{array}$ & VEP & $\begin{array}{c}\text { Carro de } \\
\text { passageiro }\end{array}$ & Protótipo & Nova & $\begin{array}{c}\text { Paul } \\
\text { MacCready; } \\
\text { Jon Bereisa }\end{array}$ & $\begin{array}{l}\text { Intenção de } \\
\text { lançamento } \\
\text { comercial }\end{array}$ \\
\hline 1996 & EV-1 & $\begin{array}{c}\text { Chumbo- } \\
\text { ácido/ } \\
\text { NiMH }\end{array}$ & VEP & $\begin{array}{c}\text { Carro de } \\
\text { passageiro }\end{array}$ & Comercial & Impact & $\begin{array}{c}\text { Paul } \\
\text { MacCready, } \\
\text { Kenneth } \\
\text { Baker, } \\
\text { Jon Bereisa; }\end{array}$ & $\begin{array}{c}\text { Lançamento } \\
\text { Comercial }\end{array}$ \\
\hline
\end{tabular}

FONTE: Adaptado de YU et al., 2011

\subsection{Questão social}

No início da década de 80, a questão da poluição atmosférica em grandes cidades retornou a se tornar relevante (HOYER, 2008). Foi constatada a diminuição da poluição gerada por partículas de dióxido de enxofre e monóxido de carbono, mas as concentrações de dióxido de nitrogênio e de ozônio se mantiveram significativamente altas. Dessa forma, o EPA investiu esforços para instituir uma emenda do Clean Air Act (AUGUSTINE, 2003). 
O governo Reagan gerou um contexto relevantemente distinto para a política ambiental. Ele buscou reduzir a regulamentação governamental, transferir responsabilidades para os estados e incentivar o setor privado de forma mais incisiva. Desse modo, as regulamentações ambientais foram consideradas como adversas a economia (AUGUSTINE, 2003).

O incentivo do governo Reagan a desregulamentação ambiental e o impasse burocrático desse período fortaleceram o entusiasmo público para a proteção ambiental. Nessa direção, no governo do presidente Bush (DOE, 1994), foi investido esforços para o estabelecimento da emenda do Clean Air Act através de pressões sociais do National Clean Air Coalition e do American Medical Association (AUGUSTINE, 2003). Em 1981, o National Clean Air Coalition, iniciou a reinvidicar fortemente contra a política anti-ambientalista do governo Reagan (SHABECOFF, 1981). O ozônio é um dos principais componentes do nevoeiro fotoquímico da região de Los Angeles (GOKLANY, 1999). E, nesse mesmo ano, foi desencadeada uma série de audiências na câmara dos deputados para mitigar a questão do efeito estufa. Em 1985, foi descoberta uma relevante área de camada de ozônio destruída na região da Antártida, alavancando o ímpeto ambientalista para mitigar a questão do aquecimento global (MAZUR, LEE; 1981). No verão de 1988, considerado pelos registros históricos como o mais quente dos Estados Unidos, foi ressaltada a relevância da mudança climática e a necessidade de se alocar uma atenção maior à questão da proteção ambiental (AUGUSTINE, 2003).

Nesse sentido, na campanha política presidencial de 1993, o apoio do movimento ambientalista representou, pela primeira vez em termos históricos, um posicionamento político real no poder executivo de forma que Bill Clinton foi eleito presidente e Al Gore, defensor da campanha do aquecimento global, foi eleito vice-presidente (DOE, 1994).

\subsection{Consórcio}

\subsubsection{Contexto}

Em 1976, no período da crise do petróleo, foi instituído o Electric and Hybrid Vehicle Development and Demonstration Program (EHVDD) no DOE com o objetivo de desenvolver um 
esforço conjunto entre o governo, a indústria e as universidades de forma que gerasse uma redução da dependência de petróleo no país. Mas, a medida que a crise foi desaparecendo, o incentivo ao desenvolvimento da tecnologia do veículo elétrico acompanhou essa tendência e, na década de 80, o EHVDD foi pouco incentivado pelo departamento (BURKE, KURANI, KEENEY; 2000).

Mas, o estabelecimento do ZEV Mandate elevou de maneira vertiginosa o interesse do DOE e da indústria automotiva na tecnologia do veículo elétrico puro, resultando em uma ampla expansão dos programas federais relacionados ao veículo elétrico bem como no estabelecimento de consórcios entre o governo e a indústria e entre integrantes da indústria como modo de atingir as metas estabelecidas pelo ZEV Mandate com sucesso (BURKE, KURANI, KEENEY; 2000).

No seu momento de formação, os recursos humanos envolvidos na esfera governamental dos consórcios estavam envolvidos previamente nos programas EHVDD do DOE e o seu vínculo nos consórcios estabelecidos após o ZEV Mandate se manteve de maneira relevantemente direta (BURKE, KURANI, KEENEY; 2000).

Dessa forma, em 1996, o DOE estabelece o Office of Advanced Automotive Technologies (OAAT) com o objetivo de consolidar os programas automotivos de P\&D do departamento em um programa integrado para veículos leves através do desenvolvimento conjunto de alianças entre agências governamentais, laboratórios nacionais, universidades e indústrias de modo a desenvolver e validar as tecnologias desenvolvidas (NRC, 1998).

Os consórcios público-privados foram instituídos de maneira que houvesse um incentivo ao desenvolvimento tecnológico nas áreas que possuíam um alto custo e alto risco de fracasso no sentido que as firmas individuais não estavam dispostas a financiar sozinhas essas tecnologias. Assim, os consórcios público-privados incentivaram o desenvolvimento de P\&D em uma combinação de, geralmente, $50 \%$ para o setor privado de maneira que a participação do DOE foi primordial na instituição desses consórcios. Em outras situações, os consórcios foram formados por membros da mesma indústria que focaram no compartilhamento do custo do P\&D de forma a beneficiar todos os membros da aliança (BURKE, KURANI, KEENEY; 2000). 


\subsubsection{United States Advanced Battery Consortium (USABC)}

Na década de 80, o governo americano cessou os investimentos em P\&D da tecnologia de bateria avançada para veículos elétricos (BURKE, KURANI, KEENEY; 2000), como, por exemplo, a bateria de íon de lítio (Li-ion), de maneira que a cadeia de baterias avançadas se tornou defasada em relação à tecnologia desenvolvida em firmas estrangeiras como, por exemplo, a Sony ou Samsung (LOWE et. al., 2010). Dessa forma, em 1991, foi estabelecido o acordo de cooperação USABC entre o DOE, institutos de pesquisa nacionais, montadoras e firmas independentes (por exemplo, Energy Conversion Devices) para a realização de P\&D em tecnologia avançada de baterias para veículos elétricos (DOE, 1993) com metas de médio e longo prazo das tecnologias de baterias de níquel metal-hidreto (NiMH) e de íons de lítio (Li-ion), por exemplo, (WESTBROOK, 2001) como forma de atingir o requerimento do ZEV Mandate (SYMONS, BUTLER; 2002).

Os projetos de P\&D do DOE Advanced Battery Systems foram reformulados (DOE, 1993) no sentido de atingir as metas estabelecidas pelo ZEV Mandate (BURKE, KURANI, KEENEY; 2000). E, através de 50\% de financiamento do DOE, a GM, a EPRI e a Ovonics Battery Company, por exemplo, realizaram P\&D em tecnologia avançada de baterias para veículos elétricos (DOE, 1993).

Em 1992, a Ovonic Battery Company (DOE, 1993) (subsidiária da Energy Conversion Devices) foi subcontratada pela USABC para desenvolver e demonstrar a tecnologia de baterias NiMH para veículos elétricos (DOE, 1993; DOE, 2008). E, em 1996, o estabelecimento do OAAT estipulou o Vehicle High-Power Energy Storage Program (VHPESP) que objetivou o desenvolvimento das tecnologias de baterias de $\mathrm{NiMH}$ e de Li-ion para veículos elétricos híbridos. Assim, o VHPESP transferiu as tecnologias avançadas que estavam sendo desenvolvidas através da aliança com o USABC para as montadoras como, por exemplo, a tecnologia da bateria NiMH da Texaco-Ovonic para a GM (WEINSTOCK, 2002). 


\subsubsection{Advanced Lead-Acid Battery Consortium (ALABC)}

Mas a tecnologia de baterias de chumbo-ácido não foi incorporada no USABC (ALABC, 2012). Dessa forma, o alto custo, o alto risco e a perspectiva de longo prazo do USABC sem uma carteira de projetos de curto prazo para assegurar a carteira de projetos incentivou a International Lead Zinc Research Organization (ILZRO) a instituir o Advanced Lead-Acid Battery Consortium (ALABC), em 1992, como um consórcio independente formado com 55 institutos de pesquisa e instituições do setor privado (COLE, 1992; BURKE, KURANI, KEENEY, 2000).

O consórcio estabeleceu o seu objetivo no desenvolvimento da tecnologia de bateria de chumboácido no sentido de otimizar o seu desempenho em aplicação de veículos elétricos (COLE, 1992) para assegurar a sua posição como opção tecnológica no futuro (ALABC, 2012).

Assim, nesse período, o ALABC focou no desenvolvimento da tecnologia de baterias de chumbo-ácido regulado por válvula (COLE, 1992) que foi a tecnologia utilizada na primeira geração do lançamento comercial EV1 (MOSELEY, 1998).

\subsubsection{CALSTART}

Em 1993, foi estabelecido o DARPA Consortia como forma de reagir ao encerramento da Guerra Fria de maneira a realizar a transferência tecnológica do setor militar para o setor civil através de projetos de cooperação (BURKE, KURANI, KEENEY, 2000). Assim, foi estabelecido o CALSTART, instituído por empresas do setor aeronáutico da Califórnia, como, por exemplo, a Hughes Aircraft (LYNCH, 1993).

Nesse sentido, a CALSTART foi instituída como uma organização não governamental (CALSTART, 2012) cujo objetivo se encontra no direcionamento das tecnologias sofisticadas da indústria aeroespacial para a aplicação no mercado comercial de maneira a viabilizar a aceleração do desenvolvimento da indústria do veículo elétrico através da absorção dos recursos humanos e da infraestrutura ociosos do setor aeroespacial (LYNCH, 1993). 


\subsubsection{Partnership for a New Generation of Vehicles (PNGV)}

Nesse mesmo ano, foi estabelecido o Partnership for a New Generation of Vehicles (PNGV) para apoiar o desenvolvimento da tecnologia híbrida (DOE, 2008). Desse modo, o objetivo do PNGV se encontrava na melhoria da eficiência da utilização dos combustíveis fósseis para que alcançassem um desempenho três vezes maior dos veículos convencionais (BURKE, KURANI, KEENEY; 2000) através de um consumo de combustível de 4litros/100km (HOYER, 2008).

A PNGV financiou a Ovonic Battery Company para o desenvolvimento da bateria NiMH para veículos elétricos híbridos. Assim, a Ovonic Battery Company projetou com sucesso essa tecnologia para veículos elétricos híbridos que foi licenciada, através da ECD Ovonics, para grandes firmas de baterias japonesas, por exemplo. Dessa maneira, a tecnologia do sistema de baterias NiMH foi incorporada nos modelos existentes e com planejamento de lançamento futuro em modelos de veículos elétricos híbridos (DOE, 2008).

O programa ZEV e o PNGV desenvolveram uma aproximação maior, em 1996, quando o CARB instituiu o Partial ZEV Credits (PZEV) para viabilizar o desenvolvimento da tecnologia híbrida pelas montadoras como uma trajetória para atingir parcialmente a composição de $10 \%$ da frota de ZEV, em 2003 (BURKE, KURANI, KEENEY; 2000). Nesse sentido, o ZEV, o PNGV e o OAAT estavam convergindo para uma abordagem de padrão Market-Driven de forma a oferecer às montadoras a opção de seguir trajetórias tecnológicas diversificadas para atingir as metas estabelecidas pelo ZEV Mandate (LARRUE, 2003).

A mudança de foco tecnológico para a tecnologia híbrida no final dos anos 90 estabeleceu a tecnologia do sistema de baterias NiMH como padrão tecnológico em baterias (DOE, 2008), naquele período. 


\subsection{Regulamentação}

\subsubsection{Contexto}

Quando Ronald Reagan assumiu a presidência, em 1981, ele se comprometeu a revitalizar a economia dos Estados Unidos. No contexto da Guerra Fria, a nação prosperou relevantemente quando o orçamento do setor militar estava elevado (DEGRASSE, 1983). Assim, o governo de Ronald Reagan acentuou essa tendência ao elevar o orçamento militar por cinco anos consecutivos e, entre 1980 e 1987, o orçamento militar se elevou em U\$84,4 bilhões ou 50,7\%. Nesse sentido, esse foi o maior orçamento disponibilizado para o setor militar em termos históricos nos Estados Unidos (RIGGS, 1994).

O governo neoliberal do Presidente Reagan se posicionou favoravelmente ao livre mercado e a desregulamentação do setor energético (VINSEL, 2011). Dessa forma, enquanto Reagan exerceu o cargo de Presidente, entre 1981 e 1989 (DOE, 1994), o Clean Air Act se manteve em estado de reautorização (AUGUSTINE, 2003). De forma paralela, houve um corte severo nos recursos humanos e orçamentários para a realização de P\&D no DOE. Mas, houve um acréscimo no orçamento de P\&D para a tecnologia de energia nuclear e investiu-se na diversificação da matriz energética através do apoio ao desenvolvimento da tecnologia limpa de carvão no portfólio de investimentos do DOE (DOE, 1994) e através da continuidade de escopo dos investimentos realizados nas tecnologias de energia solar com aplicação no setor aeroespacial (RAHM, 1993). Entre 1986 e 1991, estimou-se que houve a extinção de 60,000 postos de trabalho no setor aeroespacial, gerando um potencial a ser reabsorvido pelo mercado (LYNCH, 1993). No final dos anos 80, a economia industrial da região sul da Califórnia estava estruturalmente defasada em relação a países como, por exemplo, o Japão, a Alemanha e a Itália (STORPER, SCOTT; 1995).

E, em 1990, o Presidente Bush oficialmente declarou o fim da Guerra Fria (DOE, 1994). Nesse sentido, a Califórnia se encontrou em um contexto de severa recessão, parcialmente causada pelos cortes em investimento do setor de defesa militar, que havia contribuído consideravelmente para movimentar a economia da Califórnia. Assim, gerou-se a necessidade de encontrar novos setores de alta tecnologia para absorver os recursos do setor de defesa militar e a indústria Zero 
Emission Vehicle estava sendo considerada como uma opção atrativa para realizar essa conversão tecnológica (LARRUE, 2003).

No DOE, o término da Guerra Fria exerceu um papel relevante no processo de reversão dos investimentos do departamento no sentido de transferir o orçamento das atividades do Departamento de Defesa para as atividades relacionadas à preservação de recursos e de segurança energética através do incentivo ao desenvolvimento de tecnologias alternativas limpas como a tecnologia do veículo elétrico, por exemplo. Nessa direção, o estabelecimento do projeto de conservação da tecnologia de baterias para veículos elétricos USABC obteve um suporte considerável do departamento (DOE, 1994).

\subsubsection{Regulamentação estadual ZEV Mandate}

A apresentação do Impact da GM no L.A. Auto Show, em Janeiro de 1990, despertou o interesse do CARB (GARUD, GEHMAN 2012). E, em Setembro desse mesmo ano, o CARB estabeleceu o ZEV Mandate que foi considerada a regulamentação mais severa em termos históricos na Califórnia, sendo considerada como um padrão technology-forcing. Nesse sentido, foi requerido que, em 1998, para as montadoras que comercializassem mais de 35,000 veículos na Califórnia, $2 \%$ das vendas dos veículos da categoria leve estivessem na classificação Zero Emission Vehicle, em 1998 (LARRUE, 2003).

Para o período de 2001, foi estipulada a composição de 5\% de ZEVs na frota dos veículos leves comercializados. E, para o ano de 2003 , estava prevista a composição de $10 \%$ de veículos ZEVs (WESTBROOK, 2001). Assim, essa estimativa representava uma frota equivalente a 6,600 veículos para a GM, em 1998, com o crescimento gradual para 16,500 unidades em 2001 e 33,000 em 2003 (LARRUE, 2003).

A meta estipulada pela regulamentação excedia na representatividade do veículo mais comercializado pela GM na categoria equivalente, representado pelo Camaro e a firma argumentou que a regulamentação estava incentivando que outras montadoras se inserissem na 
competição por um nicho de mercado de proporção relativamente pequena (COLLANTES, SPERLING, 2008).

Dessa forma, essa regulamentação direcionou a mudança da estratégia de desenvolvimento do protótipo Impact para o lançamento comercial devido ao incentivo a entrada de novos entrantes no mercado ZEV (LARRUE, 2003).

\subsubsection{Regulamentação federal}

\subsubsection{Energy Policy Act Public Law 102-486}

Para apoiar o ZEV Mandate estabelecido na Califórnia, o governo federal instituiu o Energy Policy Act Public Law 102-486, em 1992. Essa regulamentação estabelecia o incentivo fiscal de $10 \%$ do valor do veículo elétrico, abrangendo o limite máximo de US\$4,000. Para o desenvolvimento de infraestrutura, foi aprovado um orçamento de US\$100,000 de crédito para incentivar a construção de postos de recarga, sendo US\$40 milhões o valor total do subsídio. Foi estabelecido que as frotas públicas e que os provedores de combustíveis iniciassem a conversão dos seus veículos para se adequar ao uso de combustíveis alternativos, em 1996, e para veículos elétricos, em 1998 (SCHOT et al., 1994).

Dessa maneira, essa regulamentação direcionou a realização de projetos de pesquisa, de desenvolvimento e de demonstração para as tecnologias de veículos a células a combustível (CANIS, 2011), incluindo um programa de demonstração de veículos elétricos (DOE, 2008), de forma a gerar um potencial de redução das importações de petróleo de 4,7 milhões de barris

diários em 2010 que representariam uma redução US\$400 bilhões de fluxo financeiro para o exterior (DOE, 1994). 


\subsubsection{Regulamentação federal Clean Air Act}

Em 1989, George Bush assumiu a presidência dos Estados Unidos e adotou uma perspectiva favorável a questão do ambiental. Dessa forma, em 1990, foi estabelecida a emenda do Clean Air Act (AUGUSTINE, 2003).

Essa emenda instituiu padrões mais rigorosos para o controle de emissões para automóveis e caminhões entre o período de 1996 e 2003 e classificou as cidades de acordo com a gravidade das suas emissões e do grau de implementação das metas de controle de poluentes atmosféricos estabelecidos (MELOSI, 2011). De forma que estava prevista a determinação do Maximum Achievable Control Technology (MACT) pelo EPA. Nesse sentido, o EPA estaria apto a estipular os equipamentos de controle de poluição atmosférica a serem instalados nas instalações industriais que emitissem pelo menos uma das 189 substâncias nocivas classificadas na legislação (AUGUSTINE, 2003).

Assim, essa regulamentação foi considerada como um padrão technology-forcing dado que o EPA incentivou o desenvolvimento e utilização das tecnologias mais avançadas que estavam disponíveis naquele período (AUGUSTINE, 2003).

\subsection{Estratégia}

\subsubsection{Montadoras}

Entre 1980 e 1982, as Big Three acumularam uma perda de U\$4,73 bilhões. A sua participação de mercado se reduziu de $84 \%$, em 1977, para $72 \%$, em 1981, enquanto que as importações japonesas se elevaram de 9\% para 17\%. As montadoras americanas responsabilizaram o sucesso japonês a injusta competição que se estabeleceu devido ao baixo salário dos funcionários no Japão e pelo fortalecimento da moeda americana (PENNA, GEELS; 2012).

A indústria continuou a resistir ao movimento ambientalista, que não estava incorporada na sua missão e a crença das montadoras não se modificou ao longo do tempo. Dessa maneira, foi 
argumentado que as inovações ambientalistas não geravam receita e aumentavam os custos (PENNA, GEELS; 2012).

Mas, a instituição do ZEV Mandate na Califórnia, em 1990, incentivou as montadoras a desenvolver a tecnologia do veículo elétrico. Nesse sentido, a regulamentação incentivou tanto a questão da poluição ambiental quanto a questão da recessão estabelecida na Califórnia (LARRUE, 2003) de forma que o objetivo de curto prazo da legislação estava baseado na questão da poluição atmosférica e o objetivo em um escopo mais amplo foi fundamentado no início da transição permanente para o paradigma automotivo não poluente (MCGRATH, 2000).

O posicionamento das montadoras (Ford e Chrysler, por exemplo) divergia da GM em relação ao estabelecimento da regulamentação. Mas, dado o contexto da elevação das pressões sociais em relação a poluição ambiental, da declaração da viabilidade da produção de veículos elétricos pela GM, do posicionamento tanto do CARB (COLLANTES, SPERLING, 2008) quanto da GM em relação ao sério comprometimento no desenvolvimento da tecnologia do veículo elétrico e da representatividade de 15\% do mercado automotivo nacional (MCGRATH, 2000), as montadoras perceberam que a realização de uma forte oposição a regulamentação não seria favorável ao seu contexto (COLLANTES, SPERLING, 2008).

\subsubsection{GM}

O embargo da OPEC gerou uma queda brusca na demanda dos veículos da GM e à medida que o processo de recessão econômica nos Estados Unidos foi se instaurando, no final dos anos 70, a participação de mercado da GM foi acompanhando essa tendência (FINKELSTEIN, 2003).

Nessa direção, na década de 80, a GM adotou a estratégia de substituir os recursos humanos da sua estrutura produtiva por recursos robotizados e automatizados como forma de reduzir os custos de produção no sentido de reagir, por exemplo, às importações do Japão (FINKELSTEIN, 2003). 
Essa transição revolucionária foi considerada como o processo de reestruturação mais abrangente ocorrida na firma no sentido de ter envolvido o investimento no escopo de aproximadamente US $\$ 45$ bilhões. Em termos comparativos, pelo valor de US\$34,7 bilhões, a GM poderia ter adquirido a Toyota e a Nissan e duplicado a sua participação de mercado de modo a elevar a sua representatividade global em 40\% (FINKELSTEIN, 2003).

Assim, Roger Smith, presidente executivo da GM nos anos 80, se posicionou a favor da abordagem do foco relevantemente tecnológico para reagir ao contexto de perda considerável de mercado (FINKELSTEIN, 2003).

Nessa direção, a GM apoiou o processo de transferência tecnológica do setor de defesa militar aeronáutico para o setor civil automotivo através da participação da Hughes Aircraft nas suas atividades a partir de 1985 (PINKSE, BOHNSACK, KOLK, 2011).

Ao receber o convite para participar da corrida de veículos elétricos solares na Austrália, em 1987, Howard Wilson (vice-presidente da Hughes) apresentou a proposta para Lloyd Reuss, diretor das operações Norte Americanas. Mas, o empreendimento foi vetado sob o argumento da pouca relação entre a participação da GM no evento de veículos elétricos solares na Austrália e as vendas de veículos nos Estados Unidos. Dessa forma, Wilson imediatamente apresentou a proposta para Bob Stempel, vice-presidente da Truck and Bus, que se envolveu e apoiou o desenvolvimento do projeto desde o Sunraycer (SHNAYERSON, 1996) até o desenvolvimento do EV1 (BUNKLEY, 2011) no sentido de ser considerado que a ausência do seu apoio ao longo da trajetória do desenvolvimento do veículo elétrico nesse período, provavelmente, teria inviabilizado o estabelecimento do lançamento comercial do EV1 na GM, do ZEV Mandate na California e da corrida pelo desenvolvimento do veículo elétrico em termos globais (SHNAYERSON, 1996).

Em 1990, a GM lançou o Impact no L.A. Auto Show (SHNAYERSON, 1996) e esse evento incentivou o CARB a estabelecer o ZEV Mandate que visava melhorar tanto a qualidade atmosférica da região quanto incentivar o desenvolvimento econômico do estado. Dessa maneira, o estabelecimento dessa regulamentação causou o reposicionamento estratégico da GM em 
relação ao lançamento comercial do EV1 devido a questão do incentivo a participação de outras montadoras no desenvolvimento do veículo elétrico (LARRUE, 2003).

Entre 1990 e 1992, Stempel se tornou o sucessor do Roger Smith. E, após ter apoiado o desenvolvimento do Sunraycer e do Impact quando estava exercendo o cargo de VP da Truck and Bus Group, ele aprovou o projeto do EV1 enquanto exerceu o cargo de presidente executivo (BUNKLEY, 2011, SHNAYERSON, 1996).

Em 1994, quando a GM instituiu a GM Ovonics de maneira a estabelecer uma aliança com a Ovonic Battery visando desenvolver e comercializar baterias NiMH para o setor automotivo (DOE, 2008), Stempel se torna o presidente do conselho da Energy Conversion Devices Inc. e da Ovonic Battery bem como diretor da GM Ovonic (STEMPEL et al., 1998). E, através do apoio financeiro da indústria e do PNGV, a GM Ovonic e a Energy Conversion Devices desenvolveram a tecnologia do sistema de baterias NiMH (WOUK, 1997) que foi utilizada na segunda geração do EV1, em 1998 (FLUITTER, 2008).

A operação da Truck and Bus, estabelecida em 1981, incorporou a Bedford Commercial Vehicle do Reino Unido (MEYER, 2008). Entre 1980 e 1982, Stempel foi indicado para exercer o cargo de diretor na Adam Opel AG na Alemanha. Nesse período, ele desenvolveu uma experiência sinérgica com a operação internacional de forma que, ao retornar a Detroit, ele manteve o seu vínculo com as atividades internacionais da GM (GMHERITAGECENTER, 2012).

Em 1986, Stempel iniciou as suas atividades como vice-presidente da Truck and Bus Group (GMHERITAGECENTER, 2012) e, possivelmente, o desenvolvimento do projeto do G-Van foi incentivado pela sua gestão devido a relação direta do grupo nas operações da Bedford (divisão da GM no Reino Unido) que desenvolveu a Griffon van, antecessora da G-Van. Outra possível evidência da relação da influência da gestão de Stempel no desenvolvimento do protótipo está relacionada a utilização do chassi da Vandura Van no projeto de desenvolvimento do protótipo e na utilização do modelo Vandura Van como referência comparativa de atributos a serem desenvolvidos no protótipo. Esse modelo pertencia ao GMC Truck que possuía relação direta com a Truck \& Bus Group (MEYER, 2008). 


\section{$5.7 \quad$ Mercado}

Na década de 60, a França estabeleceu um programa de desenvolvimento da tecnologia de veículos elétricos a célula combustível. No final da década, esse programa foi descontinuado (CALLON, 1980) e, nos anos 70, o país estabeleceu um dos programas mais ambiciosos de tecnologia de veículos elétricos em escopo global. (COWAN, HULTEN, 1996) de maneira que a fornecedora de energia Electricité de France participou de forma altamente relevante no primeiro programa (CALLON, 1980) assim como no segundo programa (COWAN, HULTEN, 1996).

Em 1965, o Japão iniciou o programa de desenvolvimento de veículos elétricos que foi considerado um programa técnico fundamental e, entre 1971 e 1976, foram desenvolvidas duas gerações de veículos elétricos (COWAN, HULTEN, 1996). Nesse período, os Estados Unidos estavam desenvolvendo a tecnologia de baterias para veículos elétricos, mas não havia um programa federal para promover a tecnologia (NASA, 1973b).

Em 1976, o Japanese Electric Vehicle Council estabeleceu uma meta de produção de 200,000 veículos elétricos para 1986. E, nesse mesmo ano, foi estabelecida nos Estados Unidos a regulamentação Electric and Hybrid Vehicle Research, Development, and Demonstration Act, PL 94-413 que instituiu o programa de P\&D da tecnologia de baterias para veículos elétricos (DOE, 2008) com a meta estimada de 10,000 veículos elétricos para 1986 (DOUGLAS, BIRK, 1980).

A crise do petróleo incentivou o desenvolvimento de programas de veículos elétricos em diversos países, mas, a maior parte desses programas utilizou o pressuposto de que a tecnologia de baterias poderia ser desenvolvida rapidamente. Nesse sentido, ao verificar a pouca aderência do pressuposto com a realidade, nenhuma das metas estabelecidas para os anos 70 e 80 se concretizou (COWAN, HULTEN, 1996).

Na década de 90, a Europa e os Estados Unidos estabeleceram três estratégias para modificar o sistema tecnológico dominante no sentido de estabelecer comercialmente a tecnologia do veículo elétrico: gestão estratégica de nicho, technology-forcing e criação de novas alianças (SCHOT et al., 1994). 
Na Europa, uma estratégia utilizada foi a trajetória experimental da gestão estratégica de nicho onde os participantes desses experimentos objetivaram o desenvolvimento de um novo mercado. O objetivo desses experimentos práticos era alimentar o processo de desenvolvimento do projeto com os resultados obtidos no sentido de influenciar os próximos desenvolvimentos da tecnologia (SCHOT et al., 1994).

Os Estados Unidos optou pelas estratégias technology-forcing (ZEV Mandate) e criação de novas alianças (por exemplo, Calstart). Indo ao encontro da estratégia technology-forcing, o Japão estabeleceu o Electric Vehicle Marketing Programme, em 1991, com o objetivo de instituir 200,000 veículos elétricos, em 2000 (SCHOT et al., 1994).

Em relação a Europa, em 1990, a PSA Peugeot Citroën Group lançou os VEPs Peugeot J5 e o Citroën C25 para serem comercializados em frotas públicas. Em 1993, através da participação conjunta de montadoras, fornecedores, fornecedora pública de energia, agências governamentais, a PSA Peugeot Citroën Group desenvolveu 50 veículos elétricos Citroën AX e Peugeot 106 para serem comercializados na França a um valor competitivo para o consumidor individual privado e para organizações públicas e privadas. No início da década, a Fiat lançou Os VEPs Cinquecento Elettra para carros de multi-passageiros, o Ducato Elettra para vans elétricas e Zic para carros de dois passageiros (CHAN, CHAU, 2001). Em 1993, a representação de veículos elétricos estava composta por escalas relevantemente heterogêneas. Por exemplo, no Reino Unido havia entre 20,000 e 25,00 veículos, na Suíça havia entre 1,500 e 2,000 veículos, na Suécia havia entre 200 e 300 veículos, na França havia entre 600 e 1000 veículos e na Alemanha havia entre 3,000 e 4,000 veículos (COWAN, HULTEN, 1996).

Em 1997, no ano posterior do lançamento do EV1 da GM, a montadora japonesa Toyota lançou o VEH Prius com baterias NiMH (HOYER, 2008; CHAN, 2002), que obteve um consumo de 4,5litros/100km no percurso urbano, (HOYER, 2008) com uma autonomia por carga de $96 \mathrm{~km}$ pelo valor de US\$18.000,00 (WESTBROOK, 2001). No mesmo ano, a Nissan lançou o VEP Nissan Altra EV que utilizava baterias de íons de lítio com uma autonomia por carga de $192 \mathrm{~km}$ pelo valor de US\$50.999 (CHAN, 2002). 
Após o lançamento do Prius, a GM desenvolveu, em 1998, protótipos híbridos EV1 a diesel e a gás natural com baterias NiMH (BRADLEY, FRANK, 2007). E lançou a segunda geração da tecnologia de propulsão elétrica pura EV1 com baterias NiMH (FLUITTER, 2008), desenvolvidas pela ECD (DOE, 2008). A opção de compra dessa tecnologia de baterias, pelo valor de US\$43,995, viabilizava a disponibilidade de uma autonomia por carga de $220 \mathrm{~km}$ (CHAN, 2002). Em relação à autonomia oferecida pelo Prius, o aumento de autonomia na segunda geração do EV1 representava mais de dois fatores de desempenho entre os veículos. Mas, em 2003, o projeto do EV1 foi descontinuado pela GM (FLUITTER, 2008).

Em seis anos, foram comercializados 1200 veículos da primeira e da segunda geração. De modo que, na primeira geração do EV1, foram produzidas 660 unidades do modelo que foram direcionadas a celebridades e um público previamente selecionado (FLUITTER, 2008).

A estratégia de precificação adotada pela Toyota foi dessemelhante a utilizada pelas firmas americanas. Nesse sentido, foi estabelecida a estratégia de inserção mercadológica no segmento de veículos elétricos híbridos com uma precificação atrativa. Sob outra perspectiva de mercado, as montadoras americanas estavam evitando investir no mercado de veículos elétricos híbridos enquanto as estimativas de vendas estivessem com retorno de investimento negativo. Assim, essa diferença de percepção da estratégia de marketing foi considerada como grande parte da razão que direcionou a Toyota como líder de mercado em veículos elétricos híbridos nos Estados Unidos (DOE, 2008).

\subsection{Análise}

Através do lançamento comercial EV-1 da GM, observamos que esse período representa a fase III do arcabouço teórico do Suarez (2004) de maneira a sugerir que a manobra estratégica no nível da firma é o único fator influenciado dessa fase. Mas, além de observarmos a influência relevante desse fator, verificamos a influência de outros fatores nesse período. Nesse sentido, verificamos que os fatores externos influenciadores do desenvolvimento da tecnologia do veículo elétrico na firma foram o campo tecnológico, a pressão social a favor da mitigação da poluição atmosférica, a política de apoio ao $\mathrm{P} \& \mathrm{D}$ de veículos elétricos e a crise econômica da Califórnia. 
Em relação aos fatores internos, observamos a influência da estratégia mercadológica, a sondagem e aprendizagem tecnológica, a sondagem e aprendizagem mercadológica e análise de marketing.

Em 1981, grupos ambientalistas, tais como a National Clean Air Coalition, iniciaram a protestar fortemente contra a política anti-ambientalista do governo Reagan. Nesse mesmo ano, iniciou-se uma série de audiências públicas para mitigar a questão do aquecimento global. E, em 1985, foi revelada a existência de uma extensiva área de ozônio destruída na região da Antártida. Esse fato elevou o ímpeto ambientalista e a questão do aquecimento global se tornou tão relevante que, na eleição presidencial de 1993, o movimento ambientalista foi representado pelo vice-presidente Al Gore, defensor da mitigação do aquecimento global. Mas, contrastando com o primeiro período direcionado pela poluição atmosférica, o governo se encontrou em um contexto de reestruturação econômica devido ao término da Guerra Fria, que ocorreu em 1990. Os investimentos militares representavam uma elevada proporção da movimentação econômica americana e, ao cessar a necessidade da realização desses investimentos, o governo gerou alternativas para novas fontes de desenvolvimento econômico. Nesse sentido, o incentivo para a criação da indústria de veículos elétricos foi ao encontro desse novo contexto político e econômico americano.

A GM adotou a estratégia de favorecer a aquisição de novas tecnologias para se reposicionar no mercado. Os veículos importados elevaram a sua participação de mercado de forma vertiginosa no período anterior e a firma realizou a automatização e robotização das suas operações para elevar a sua competitividade. Nesse contexto, a GM se beneficiou da capacidade ociosa do setor aeronáutico e, em 1985, convidou a Hughes Aircraft para se unir às suas operações de maneira que o desenvolvimento da tecnologia do veículo elétrico na GM evoluiu vertiginosamente com essa união.

A potencialidade da transferência tecnológica entre o setor aeroespacial e o setor automotivo foi evidenciada tanto nesse período quanto nos períodos anteriores. Mas, ao desenvolver a plataforma do Sunraycer com uma equipe formada exclusivamente por profissionais da AeroVironment, a GM se beneficiou da tecnologia aeroespacial de uma forma mais integrada. 
Assim, através do apoio essencial da AeroVironment no desenvolvimento do Sunraycer, a GM venceu a corrida de veículos elétricos solares World Solar Challenge, em 1987, de maneira que a ampla vantagem obtida em relação ao segundo colocado da corrida elevou a propensão a desenvolver a tecnologia do veículo elétrico comercialmente. E, em 1990, a GM lançou o protótipo Impact no L.A. Auto Show.

Mas, a estratégia corporativa de focar em competitividade em manufatura (produtividade, automação, etc.) implicou um atraso em lançamento de protótipos de veículos elétricos nesse período. Assim, a retomada de veículos elétricos só foi provocada pela participação bem sucedida na corrida de veículos elétricos na Austrália.

E, conforme podemos verificar no quadro 7, a iniciativa do setor privado desencadeou uma série de medidas governamentais technology-forcing (VINSEL, 2011) em relação ao desenvolvimento da tecnológica do veículo elétrico.

Ao identificar a viabilidade tecnológica do desenvolvimento do veículo elétrico na GM, através do lançamento do Impact, os legisladores do California Air Resources Board (CARB) instituíram o ZEV Mandate, em 1990, para mitigar a questão da poluição atmosférica e para transferir a capacidade ociosa do setor militar para o setor civil de maneira que a indústria do veículo elétrico se tornasse uma nova fonte de recursos para o estado.

Durante a década de 80, a tecnologia avançada de baterias para veículos elétricos recebeu um corte abrupto no orçamento americano para P\&D. E, na década de 90, a indústria de baterias avançadas estava significativamente defasada em relação a indústrias estrangeiras como, por exemplo, as japonesas ou coreanas. Dessa forma, para alavancar o desenvolvimento da cadeia de baterias de modo a atingir as metas do ZEV Mandate, os programas de P\&D do DOE foram reestruturados de forma que o departamento promoveu o desenvolvimento de consórcios para compartilhar os custos e os riscos do desenvolvimento da tecnologia com as montadoras. Mas, o apoio do DOE no USABC foi restrito a algumas tecnologias de baterias de forma que verificamos o estabelecimento de consórcio privado independente para suprir a lacuna tecnológica gerada nesse contexto. Essa observação se fundamenta na instituição do ALABC, em 
1992, devido à exclusão da tecnologia de baterias de chumbo-ácido no portfólio de P\&D do USABC. Devido a crença compartilhada do potencial de expansão da tecnologia de baterias de chumbo-ácido para a aplicação em veículos elétricos, a ILZRO articulou o estabelecimento do ALABC para apoiar o desenvolvimento dessa tecnologia.

No período anterior, observamos que a principal política pública foi a centralização do P\&D e da gestão do setor energético americano no DOE. Enquanto que, nesse período, verificamos o envolvimento direto do governo no estabelecimento de consórcios, evidenciando um processo de inovação nas políticas públicas do veículo elétrico.

A tendência em estabelecer uma política technology-forcing se estendeu para a legislação da poluição atmosférica Clean Air Act. Assim, em 1990, o governo federal concedeu autonomia ao EPA para solicitar as tecnologias mais avançadas de dispositivos de controle de emissões atmosféricas através da emenda do Clean Air Act.

Nesse período, verificamos uma coordenação maior de políticas públicas. E, após essa primeira etapa caracterizada pela abordagem technology-forcing, observamos que o governo tentou desenvolver uma abordagem mais sinérgica com o setor privado e realizou a transição para uma abordagem market-driven (LARRUE, 2003) nas ações governamentais.

Para apoiar a regulamentação estabelecida na Califórnia, em 1992, o governo federal instituiu o Energy Policy Act Public Law 102-486, que incentivou o desenvolvimento da tecnologia do veículo elétrico ao oferecer subsídios para a aquisição da tecnologia e para o desenvolvimento de infraestrutura de recarga. Essa política pública se contrasta com o período anterior no sentido de evidenciar a preocupação dos agentes reguladores com a operação comercial do veículo elétrico.

E, em relação aos consórcios, o governo federal instituiu o PNGV, em 1993, para apoiar a tecnologia híbrida e a Califórnia acompanhou essa regulamentação ao instituir, em 1996, o Partial ZEV Credits, que abrangia a tecnologia híbrida, contrastando com a regulamentação original. 
No escopo estadual, em 1993, a Califórnia estabeleceu o CALSTART. Esse consórcio objetivou o apoio à transferência tecnológica do setor aeroespacial para o setor civil de forma que foi composto por empresas do setor aeronáutico como, por exemplo, a Hughes Aircraft.

Quadro 7 - Análise das políticas públicas do driver da poluição atmosférica II

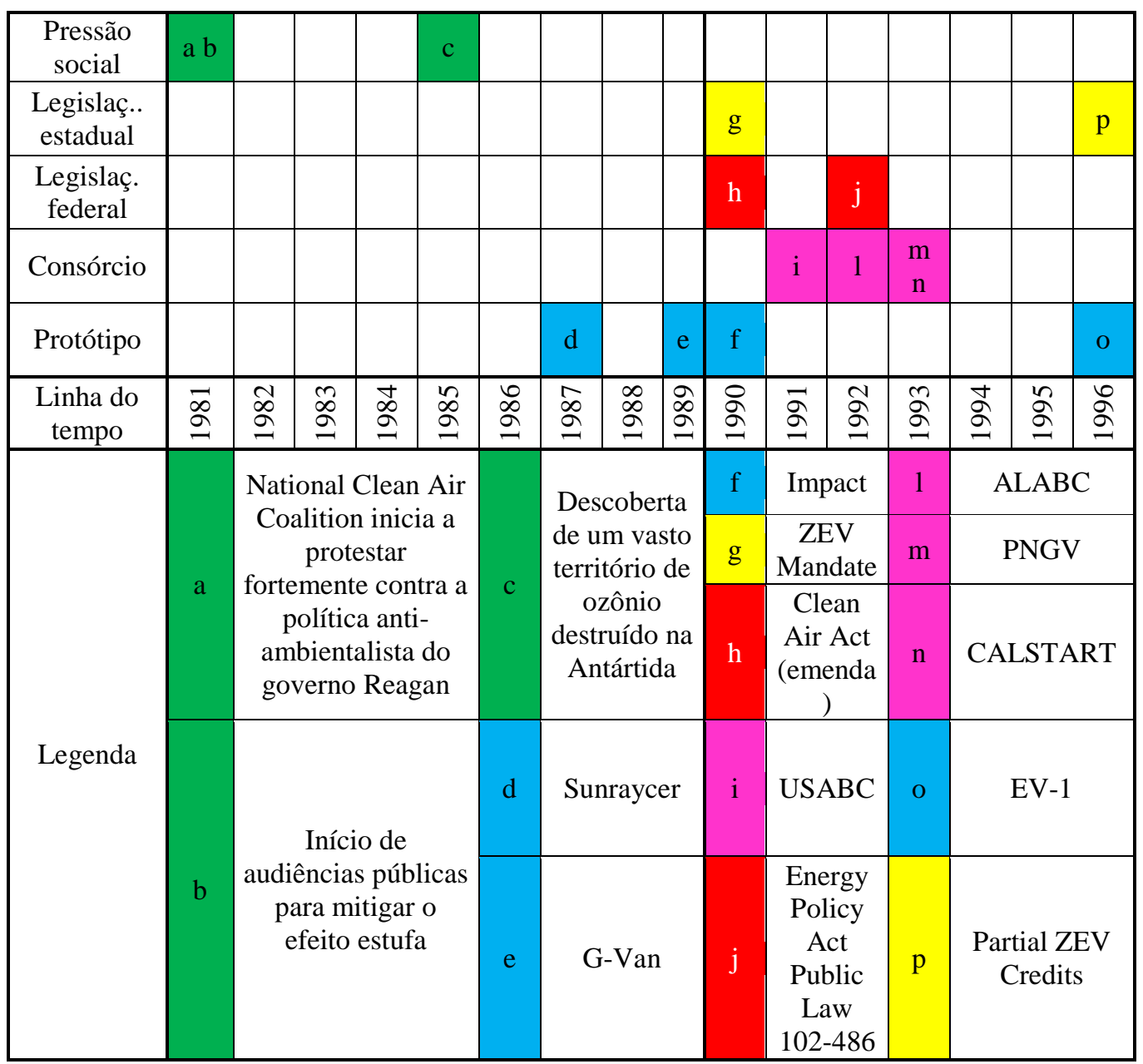

Fonte: elaboração da autora

Em relação ao campo tecnológico, a singularidade apresentada nesse período está no processo de internacionalização do P\&D do veículo elétrico. Por exemplo, nesse período, a tecnologia do sistema de transmissão ac para veículos elétricos foi desenvolvida pelo Professor C.C.Chan e a tecnologia de células fotovoltaicas e de mobilidade solar do setor aeroespacial estavam com capacidade ociosa. Nessa direção, verificamos que o protótipo G-Van e Sunraycer se beneficiaram diretamente dessa convergência tecnológica. Em relação ao lançamento comercial 
EV-1, a tecnologia de baterias de utilizada na primeira geração se beneficiou do consórcio privado ALABC, que estipulou a meta de curto prazo de desenvolver a tecnologia de baterias de chumbo-ácido regulado por válvula para veículos elétricos.

Além desse processo de aumento de recursos através de parcerias para a realização de $\mathrm{P} \& \mathrm{D}$, observamos um elevado estreitamento de inter-relações entre os protótipos da GM, entre o setor aeroespacial e automotivo e entre o setor público-privado evidenciado através da transferência de conhecimento entre Paul MacCready, Kenneth Baker e Jon Bereisa. Após o desenvolvimento do Sunraycer, que se beneficiou da competência em mobilidade solar de Paul MacCready, o protótipo (Impact) e o lançamento comercial (EV-1) desenvolvido a partir dessa plataforma foram beneficiados da experiência prévia de Kenneth Baker e de Jon Bereisa, que participaram do desenvolvimento do Electrovette I e II, desenvolvidos no período anterior. Dessa forma, a convergência de conhecimentos entre Paul MacCready, Kenneth Baker e Jon Bereisa no desenvolvimento do EV-1 beneficiaram tanto a tecnologia do veículo elétrico desenvolvida na GM quanto o consórcio público-privado USABC, que foi representado por Kenneth Baker e Jon Bereisa, respectivamente.

A sondagem e aprendizagem tecnológica desenvolvida nesse período manteve a mesma quantidade de protótipos, mas verificamos o desenvolvimento de duas novas plataformas e a utilização de uma nova tecnologia de baterias, que foi testada na segunda geração do lançamento comercial da GM. Essas observações sugerem que o amadurecimento da tecnologia na GM viabilizou a sondagem e aprendizagem no escopo de sistemas e que a tecnologia de baterias para veículos elétricos estava apta para acompanhar essa evolução.

Nesse período, verificamos o primeiro lançamento comercial da GM de maneira que foi realizado um estudo de marketing precedendo a sondagem e aprendizagem mercadológica. A observação empírica dessa abordagem para a obtenção de informações de mercado para o desenvolvimento de tecnologias radicais sugere que ela se tornou pouco aderente para o estabelecimento do sucesso comercial do EV-1. A estimativa de comercialização de 6265 veículos em dois anos na simulação realizada com consumidores em potencial pelo estudo de marketing se contrastou com a venda real de 1200 unidades em seis anos. Ao realizar a sondagem e aprendizagem 
mercadológica com o modelo desenvolvido a partir do estudo de marketing desenvolvido previamente, a GM se inseriu no mercado com uma tecnologia de propulsão e de baterias inferior ao oferecido por outras montadoras. Mesmo tentando se adaptar ao lançar a segunda geração de baterias com a tecnologia NiMH e oferecer uma autonomia por carga com mais de dois fatores de diferença de competidores como o Prius da Toyota, o mercado não reagiu favoravelmente e o EV-1 foi descontinuado. 


\section{ANÁLISE E CONCLUSÕES}

Ao longo da pesquisa, desenvolvemos uma análise transversal referente a cada período direcionador da tecnologia do veículo elétrico na GM. Nesse capítulo, apresentaremos, conforme definido anteriormente na metodologia, uma análise longitudinal dos eventos iniciais, dos eventos colaborativos ou opositores, das ações do governo, do mercado de carros, do campo tecnológico, da estratégia da GM e dos protótipos desenvolvidos.

Em relação aos eventos iniciais, observamos que houve uma progressão no escopo da influência política. No primeiro período, direcionado pelo surgimento do nevoeiro fotoquímico na região de Los Angeles, a pressão social iniciou com a articulação do escopo político regional de forma a exercer uma influência bottom-up. No próximo período, iniciado pelas crises do petróleo, a articulação política envolveu o escopo ministerial, recebendo a influência exógena do conflito árabe-israelense. E, no terceiro período, a pressão social do movimento ambientalista contra a poluição atmosférica foi exercida na alta hierarquia federal, adotando uma abordagem top-down.

Dessa forma, no segundo e no terceiro período, observamos a influência das mudanças da paisagem, abordada por Geels (2002).

Identificamos uma dinâmica entre a pressão social para favorecer a mitigação da poluição atmosférica e a oposição das montadoras a essa questão. Dessa forma, verificamos que a influência de alguns eventos que foram colaborativos ou opositores ao movimento ambientalista. No primeiro período, a denúncia realizada pelo Ralph Nader gerou um centro gravitacional com diversos segmentos da sociedade que favoreceram ao movimento ambientalista. Mas, no período seguinte, observamos uma pulverização desse esforço devido à questão econômica da crise do petróleo, que direcionou, por exemplo, o abandono do apoio sindical ao movimento ambientalista de forma redirecionar seu esforço para favorecer a postergação dos prazos das legislações. No terceiro período, a questão econômica favoreceu o movimento ambientalista devido à percepção do estabelecimento da indústria de veículos elétricos como uma oportunidade para mitigar as duas questões de forma simultânea. 
Em relação às legislações de controle de poluição atmosférica e de apoio do desenvolvimento da tecnologia do veículo elétrico pelos governos (estadual e federal), verificamos uma alternância entre os dois primeiros períodos de maneira que, no terceiro período, observamos um incentivo ao desenvolvimento tecnológico paralelo. $\mathrm{O}$ início das instituições regulatórias foi caracterizado para o desenvolvimento de tecnologias de controle de emissões de poluentes de forma que, no segundo período, houve uma diminuição na ênfase aos dispositivos de controle enquanto que a tecnologia do veículo elétrico foi legitimada no escopo legislativo, recebendo incentivos para P\&D, por exemplo, apoio aos testes em campo. Essa constatação vai ao encontro da prescrição teórica de Harbone e Hendry (2009), que sugere o compartilhamento de custos e riscos de P\&D de projetos do setor energético entre o governo e o setor privado E, no terceiro período, os governos incentivaram tanto o desenvolvimento do veículo elétrico quanto o investimento em dispositivos de controle de poluentes veiculares. Ao longo desse estudo, verificamos o aumento da sofisticação e integração do processo político público-privado. No primeiro período, iniciou-se o estabelecimento de agências regionais com a finalidade exclusiva para a mitigação da poluição atmosférica. No segundo período, houve a reestruturação da gestão e do P\&D do setor energético, centralizando a sua operação. E, no terceiro período, observamos o desenvolvimento de consórcios público-privados.

No campo tecnológico, observamos que a influência do setor militar e aeroespacial no desenvolvimento da tecnologia do veículo elétrico ao longo dos três períodos. No primeiro período, a GM incorporou conhecimentos adquiridos previamente no setor aeroespacial e militar no desenvolvimento dos seus protótipos. No período seguinte, constatamos que a GM contratou pelo menos um engenheiro da NASA, que participou do desenvolvimento dos protótipos desse período. De forma que, no terceiro período, a GM celebrou parcerias com várias empresas do setor aeroespacial para projetar o Sunraycer.

Outra observação do campo tecnológico foi em relação ao $\mathrm{P} \& \mathrm{D}$, que apresentou um processo gradual de reversão de terceirização de recursos e de internacionalização dos centros de P\&D. No primeiro período, o desenvolvimento do veículo elétrico se beneficiou da competência adquirida nos esforços de P\&D que estavam sendo terceirizados pelo setor aeroespacial e militar desde a Segunda Guerra Mundial. E o P\&D para a comercialização dos veículos da fïrma era 
centralizado. No segundo período, o governo solicitou o apoio do setor aeroespacial para realizar o P\&D de todo o sistema de propulsão da tecnologia do veículo elétrico terrestre. E o processo de P\&D do veículo elétrico na GM começou a receber influência e apoio do governo. Em relação ao terceiro período, a GM solicitou o apoio da AeroVironment para desenvolver e acompanhar o processo de transferência da tecnologia do veículo elétrico desde o Sunraycer até o EV-1. E os desenvolvimentos dos protótipos e do lançamento comercial da GM foram influenciados por tecnologias desenvolvidas, por exemplo, pelo governo americano, pelo ALABC, pelo setor aeroespacial, por centros de P\&D da Ásia e do Canadá.

Assim, ao analisar as pressões que os eventos iniciais (paisagem) causaram nas políticas públicas de $\mathrm{P} \& \mathrm{D}$, legislações e campo tecnológico (regimes) de modo a oportunizar a emergência da tecnologia do veículo elétrico na GM (nicho), verificamos a presença de uma tentativa de processo de transição tecnológica abordada por Geels (2002).

Em relação ao mercado de carros, observamos a mudança de paradigma tecnológico ocorrido ao longo dos três períodos. No primeiro período, a GM exercia a liderança no mercado automotivo mundial. Mas, os modelos compactos e econômicos desenvolvidos em mercados externos iniciaram a conquistar o mercado americano de forma que, no segundo período, a crise do petróleo gerou uma janela de oportunidade para as montadoras que desenvolviam veículos com consumo energético mais eficiente. Assim, no terceiro período, o paradigma tecnológico desenvolvido pela Toyota a direcionou para a liderança do mercado automotivo global, gerando um movimento de adaptação de paradigma tecnológico do mercado a essa nova forma de desenvolver veículos automobilísticos.

A estratégia da GM também se modificou ao longo do estudo. Verificamos a transição de uma estratégia deliberada para uma estratégia emergente de modo que, no primeiro período, a GM desenvolveu uma abordagem de usar o marketing para vender o mesmo tipo de carros. Mas, no segundo período, as importações se elevaram vertiginosamente e a firma reagiu através do desenvolvimento de uma plataforma global. E, as importações continuaram a captar a fatia de mercado da GM. Dessa forma, no terceiro período, a firma se reestruturou completamente para acompanhar as mudanças abruptas ocorridas no mercado automotivo. 
Em relação aos protótipos, observamos um processo de variação, seleção e retenção (GEELS, 2002) dos desenvolvimentos tecnológicos do sistema de propulsão do veículo elétrico ao longo do estudo, contrastando com a tecnologia de baterias, que manteve o processo de variação e seleção. No primeiro período, observamos uma grande quantidade de sondagem e aprendizagem tecnológica em diferentes combinações de sistemas de propulsão, de tipos de baterias, de categorias de veículos e de plataformas. No segundo período, observamos a seleção de categorias de veículos, sistemas de propulsão. Houve a seleção de um sistema de baterias, mas observamos a continuidade do processo de variação nesse período. E, no terceiro período, verificamos o processo de retenção tecnológica em sistemas de propulsão. Mas, acompanhando os períodos anteriores, a tecnologia do sistema de baterias continuou apresentando um processo de variação e seleção.

O processo de sondagem e aprendizagem tecnológica amadureceu ao longo dessa trajetória. No primeiro período, houve uma exploração de diversas combinações tecnológicas enquanto que, no segundo período, observamos o início dos testes de campo com as tecnologias selecionadas. De forma que, no terceiro período, a sondagem e a aprendizagem em tecnologia se realizou no escopo de sistemas e verificamos a realização de análise de marketing e a primeira sondagem e aprendizagem mercadológica. Em termos teóricos, a abordagem da utilização de análises de marketing é divergente à prescrição desenvolvida por Lynn et al. (1996), devido ao pouco entendimento do mercado em relação aos benefícios que a nova tecnologia pode proporcionar. Nesse contexto, Veryzer (1998) sugere que esse processo de obtenção de informação mercadológica ocorra através de inferências de um profissional que tenha um amplo conhecimento tanto da tecnologia quanto do mercado, indo ao encontro da prescrição teórica de Lynn et al., (1996). De forma a utilizar a lógica de síntese como forma de entender as necessidades do mercado inexplorado.

O objetivo dessa pesquisa está fundamentado no entendimento da trajetória de desenvolvimento da tecnologia do veículo elétrico na GM de maneira que a questão de pesquisa que norteou o estudo é: Quais são as ações em tecnologia que a General Motors realizou em relação a batalha tecnológica do veículo elétrico? 
Para responder essa questão de pesquisa, utilizamos o arcabouço teórico desenvolvido por Suarez (2004) que viabiliza o entendimento do processo no estágio de realização de P\&D (fase 1), de lançamento de protótipos (fase 2) e criação de mercado (fase 3). De forma que, essas são as fases que essa pesquisa longitudinal analisou para atender ao objetivo proposto.

A estrutura conceitual desenvolvida por Suarez (2004) analisa a evolução tecnológica do ponto de vista do setor e não do ponto de vista da empresa. Dessa forma, os resultados obtidos no estudo sob o ponto de vista da GM viabilizam a harmonização do arcabouço teórico original com o arcabouço teórico desenvolvido por Lynn et al. (1996) que abordam a metodologia de sondagem e aprendizagem mercadológica sob a perspectiva da firma.

Verificamos que os fatores que influenciaram de forma causal no processo ao longo dos três períodos (totalizando mais de quarenta anos) analisados foram a instituição regulatória (causada pela poluição atmosférica e pela crise do petróleo) e a transferência tecnológica do setor aeronáutico e aeroespacial.

Nos períodos direcionados pela questão da poluição atmosférica, a pressão exercida pela sociedade gerou uma relevante influência para a instituição regulatória. De forma que, no primeiro período, estabeleceu-se uma sinergia intensa entre esses fatores. No segundo período, observamos o estabelecimento do alinhamento da pressão social e da questão regulatória vinculada aos fatores econômicos, políticos de forma que, através dessas confluências, a GM lançou comercialmente o seu primeiro veículo elétrico.

No período direcionado pela primeira e segunda crise do petróleo, observamos a influência da questão econômica atuar de forma relevante no estabelecimento da tecnologia no sentido da pressão social se tornar um fator de menor influência no processo de incentivo ao desenvolvimento da tecnologia.

Nesse período, observamos o incentivo governamental para o desenvolvimento de projetos de demonstração para a realização de testes de campo. Dessa forma, encontramos uma evidência 
empírica que converge com a prescrição teórica de Harbone e Hendry (2009) no sentido de unir o setor público-privado para o desenvolvimento de tecnologias do setor energético.

Ao longo do estudo, verificamos o estabelecimento da sondagem e aprendizagem tecnológica de 14 protótipos no momento anterior a primeira sondagem e aprendizagem mercadológica da GM. Nesse sentido, essa observação vai ao encontro dos resultados obtidos no estudo longitudinal do artigo desenvolvido por Yu et al., em 2011, que argumentou sobre a viabilização da expansão da estrutura conceitual da sondagem e aprendizagem mercadológica desenvolvida por Lynn et al., em 1996, evidenciada na figura 9.

Figura 9 - Integração da sondagem e aprendizagem nas batalhas tecnológicas

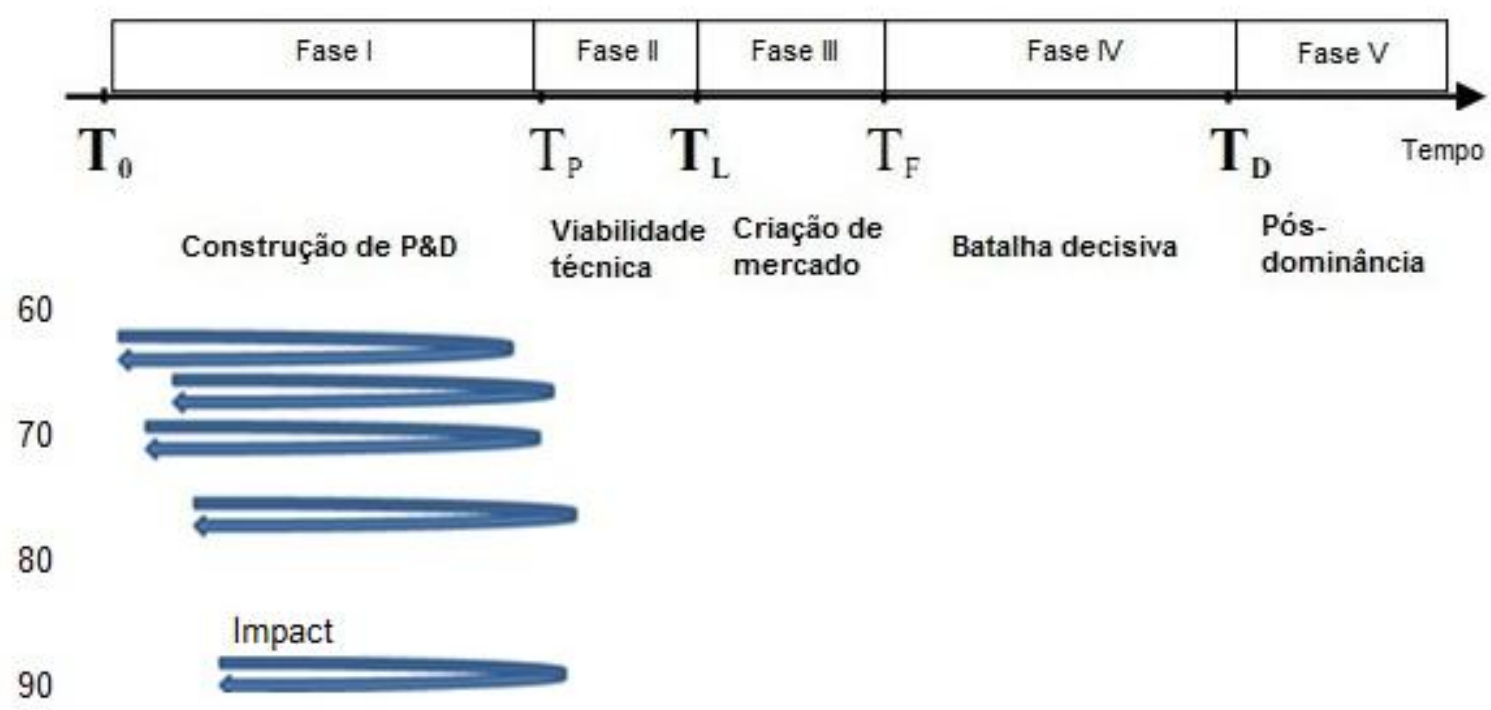

Fonte: adaptado de YU et al., 2011

Em relação à evolução tecnológica dos sistemas de propulsão elétrica e das baterias, observamos o processo de variação, seleção e retenção tecnológica do sistema de propulsão elétrica de forma a conduzir a maturidade dos sistemas para o lançamento comercial EV-1. Mesmo com o sistema de baterias estar em um processo de variação e seleção, sugerindo que o sistema de baterias estava apto para acompanhar essa evolução. Alguns testes caracterizados pelo primeiro e segundo períodos estavam sendo realizados para verificar exclusivamente o desempenho das baterias. Mas, no terceiro período, observamos a sondagem e aprendizagem tecnológica no lançamento 
comercial do EV-1. Essa observação sugere que a evolução do sistema de propulsão elétrica viabilizou a continuação do processo de variação e seleção de baterias de forma endógena ao processo de sondagem e aprendizagem mercadológica. Nesse sentido, observamos que houve uma hierarquia de desenvolvimento tecnológico no sentido da evolução em sistemas de propulsão elétrica preceder a evolução do sistema de baterias, sugerindo uma causalidade tecnológica. Em termos teóricos, verificamos que o processo de sondagem e aprendizagem tecnológica pode ocorrer paralelamente à sondagem e aprendizagem mercadológica.

Em relação ao campo tecnológico, podemos observar no quadro 8, o processo de transferência de conhecimento (nos três períodos) entre os engenheiros que participaram do desenvolvimento da tecnologia do veículo elétrico na firma. No desenvolvimento dos primeiros protótipos (Electrovair I e II, Electrovan, Stir-Lec I), no primeiro período direcionado pelo evento inicial da poluição atmosférica, observamos o envolvimento dos engenheiros Paul Agarwal e Floyd Wyczalek. Em seguida, observamos o envolvimento do engenheiro Jon Bereisa que participou do desenvolvimento dos protótipos desenvolvidos no segundo e no terceiro períodos do estudo (Electrovette I e II, Impact e EV1). Nos desenvolvimentos tecnológicos observados no terceiro período (Sunraycer, Impact e EV1), verificamos o apoio de Jon Bereisa ao Kenneth Baker e Paul MacCready no desenvolvimento dos modelos. Assim, Jon Bereisa atuou como conector entre Paul e Floyd e o pessoal mais jovem. Assim, viabilizamos a verificação do vínculo entre o primeiro protótipo e o primeiro lançamento comercial da GM. 
Quadro 8 - Transferência de conhecimento entre os engenheiros da GM (1964-1996)

\begin{tabular}{|c|c|c|c|c|c|c|c|c|c|c|c|c|}
\hline \multirow{5}{*}{ Engenheiros } & \multicolumn{12}{|c|}{ Protótipos (P) / Lançamento comercial (LC) } \\
\hline & $\begin{array}{l}1964 \\
-66\end{array}$ & 1966 & \multicolumn{3}{|c|}{1968} & 1969 & $\begin{array}{l}1976 \\
-79\end{array}$ & 1979 & 1987 & 1989 & 1990 & 1996 \\
\hline & \multicolumn{6}{|c|}{ Poluição atmosférica I } & \multicolumn{2}{|c|}{$\begin{array}{l}\text { Crises do } \\
\text { petróleo }\end{array}$} & \multicolumn{4}{|c|}{ Poluição atmosférica II } \\
\hline & $\mathrm{P}$ & $P$ & $\mathrm{P}$ & $\mathrm{P}$ & $\mathrm{P}$ & $\mathrm{P}$ & $\mathrm{P}$ & $\mathrm{P}$ & $\mathrm{P}$ & $\mathrm{P}$ & $\mathrm{P}$ & $\mathrm{LC}$ \\
\hline & $\mathrm{a}$ & $\mathrm{b}$ & $\mathrm{c}$ & $\mathrm{d}$ & $\mathrm{e}$ & $\mathrm{f}$ & $\mathrm{g}$ & $\mathrm{h}$ & $\mathrm{i}$ & $\mathrm{j}$ & 1 & $\mathrm{~m}$ \\
\hline Paul Agarwal & $\bullet$ & & & & $\bullet$ & & $\bullet$ & & & & & \\
\hline $\begin{array}{c}\text { Floyd } \\
\text { Wyczalek }\end{array}$ & & , & & & & , & & & & & & \\
\hline Jon Bereisa & & & & & & & - & & & & - & - \\
\hline $\begin{array}{c}\text { Kenneth } \\
\text { Baker }\end{array}$ & & & & & & & - & & & & & - \\
\hline $\begin{array}{c}\text { Paul } \\
\text { MacCready }\end{array}$ & & & & & & & & & $\bullet$ & & $\bullet$ & - \\
\hline \multirow{6}{*}{ Legenda } & $\mathrm{a}$ & \multicolumn{5}{|c|}{ Electrovair I e II } & $\mathrm{g}$ & \multicolumn{5}{|c|}{ Electrovette I e II } \\
\hline & $\mathrm{b}$ & \multicolumn{5}{|c|}{ Electrovan } & $\mathrm{h}$ & \multicolumn{5}{|c|}{ AT\&T van } \\
\hline & $\mathrm{c}$ & \multicolumn{5}{|c|}{ Opel Kadette } & $\mathrm{i}$ & \multicolumn{5}{|c|}{ Sunraycer } \\
\hline & $\mathrm{d}$ & \multicolumn{5}{|c|}{ Military $6 x 6$} & $\mathrm{j}$ & \multicolumn{5}{|c|}{ G-Van } \\
\hline & $\mathrm{e}$ & \multicolumn{5}{|c|}{ Stir-Lec I } & 1 & \multicolumn{5}{|c|}{ Impact } \\
\hline & f & \multicolumn{5}{|c|}{ GM512 VEP e VEH } & $\mathrm{m}$ & \multicolumn{5}{|c|}{ EV-1 } \\
\hline
\end{tabular}

Fonte: elaboração da autora

Em relação ao processo de sondagem e aprendizagem, no quadro 8 observamos as sondagens e aprendizagens tecnológicas no primeiro, no segundo e no terceiro período (1964-1990) de maneira que, no terceiro período, foi estabelecida a primeira sondagem e aprendizagem de mercado (1996).

No quadro 9, podemos observar os fatores que influenciaram o processo de desenvolvimento da tecnologia do veículo elétrico na GM de forma a viabilizar a expansão da estrutura conceitual desenvolvida por Suarez, em 2004. No nível do ambiente, constatamos a possível influência do 
setor industrial aeronáutico e aeroespacial nas três fases da batalha. No primeiro e no terceiro período, a constatação foi realizada através dos artefatos tecnológicos utilizados enquanto que, no segundo período, a observação foi desenvolvida através da verificação da experiência prévia do engenheiro Jon Bereisa no setor aeroespacial, que participou do desenvolvimento do Electrovette I e II.

Em relação ao fator da pressão social, no primeiro período da poluição atmosférica, esse fator exerceu uma influência significativamente relevante. Observamos nesse estudo que, desde 1942, as pressões sociais realizadas através de instituições de pesquisa, de representantes públicos de diferentes escopos do estado da Califórnia e do setor da saúde pública, por exemplo, envolveram esforços conjuntos para encontrar os responsáveis pela poluição atmosférica causada na região. Ao verificar de forma conclusiva que essa responsabilidade pertencia a indústria petroquímica e automotiva, os esforços se tornaram cada vez mais incisivos. Nesse sentido, após quase vinte anos de pressão social, iniciou-se o processo de estabelecimento regulatório. No terceiro período, essa questão se uniu a questão econômica da recessão gerada pela questão da política internacional.

Ao encerrar a Guerra Fria, os recursos econômicos direcionados para a defesa militar diminuíram abruptamente. Assim, a Califórnia, por exemplo, se encontrou em um contexto de propensão de transferência de recursos do setor de defesa militar aeronaútica para o setor civil.

Os fatores da política internacional e questão econômica também influenciaram de forma relevante na segunda fase da batalha. Nesse período, o estabelecimento da primeira e da segunda crise do petróleo gerou um contexto de necessidade de desenvolvimentos de alternativas energéticas de forma que o desenvolvimento do veículo elétrico foi amplamente apoiado nesse período. De modo complementar, a crise do petróleo foi um movimento causado explicitamente por questões de política internacional relacionado a rivalidade existente nos países do oriente médio e nos países envolvidos na Guerra Fria. 
Quadro 9 - Fatores de dominância observados na batalha tecnológica do veículo elétrico na GM (1964-1996)

\begin{tabular}{|c|c|c|c|c|}
\hline Tipo de Fator & Fator de dominância & Fase I & Fase II & Fase III \\
\hline \multirow{5}{*}{ Nível da firma } & Credibilidade/ ativos complementares & $\bullet \bullet \bullet$ & $\bullet \bullet \bullet$ & \\
\hline & Manobra estratégica & $\bullet \bullet \bullet$ & $\bullet \bullet \bullet$ & $\bullet \bullet \bullet$ \\
\hline & Sondagem e aprendizagem tecnológica & $\bullet \bullet \bullet$ & $\bullet \bullet \bullet$ & \\
\hline & Sondagem e aprendizagem mercadológica & & & $\bullet \bullet \bullet$ \\
\hline & Análise de marketing & & & $\bullet \bullet \bullet$ \\
\hline \multirow{7}{*}{$\begin{array}{l}\text { Nível do } \\
\text { ambiente }\end{array}$} & Regulamentação & & $\bullet \bullet \bullet$ & $\bullet \bullet \bullet$ \\
\hline & Caracteristicas do campo tecnológico & $\bullet \bullet \bullet$ & $\bullet \bullet \bullet$ & $\bullet \bullet \bullet$ \\
\hline & Política de apoio ao P\&D & & $\bullet \bullet \bullet$ & $\bullet \bullet \bullet$ \\
\hline & Pressão social & $\bullet \bullet \bullet$ & & $\bullet \bullet \bullet$ \\
\hline & Política internacional & $\bullet \bullet \bullet$ & $\bullet \bullet \bullet$ & \\
\hline & Questão econômica & $\bullet \bullet \bullet$ & $\bullet \bullet \bullet$ & $\bullet \bullet \bullet$ \\
\hline & Comportamento do consumidor & $\bullet \bullet \bullet$ & $\bullet \bullet \bullet$ & \\
\hline \multirow{2}{*}{ Legenda } & \multicolumn{4}{|c|}{ Estrutura conceitual original do Suarez (2004) } \\
\hline & \multicolumn{4}{|c|}{ Fatores de dominância observados na dissertação } \\
\hline
\end{tabular}

Fonte: adaptado de Suarez (2004) 


\subsection{Limitações da pesquisa}

A pesquisa foi baseada na observação empírica de uma firma de modo que a metodologia de construção teórica fundamentada em dados viabilizou a expansão teórica sugerida. Mas, dada a limitação da amostra, a replicação do estudo para outras firmas pode oferecer uma oportunidade de validação dos resultados obtidos e gerar outras possibilidades de expansões teóricas.

Outra limitação do estudo foi referente ao acesso a dados primários no sentido de restringir a granulidade das observações do estudo.

\subsection{Sugestões de pesquisas futuras}

- Observação das fases quatro e cinco da batalha tecnológica do veículo elétrico na GM;

- Ampliação do estudo para a perspectiva de novas entrantes;

- Ampliação do estudo para a perspectiva de outras veteranas;

- Aplicação da estrutura teórica sugerida para outras indústrias;

- Expansão da estrutura teórica a partir dos dados coletados nas sugestões anteriores. 


\section{REFERENCIAS}

ABERNATHY, W., CLARK, K. Innovation: Mapping the winds of creative destruction. Research Policy, vol.14, n.1, p.3-22, 1985.

ABERNATHY, W.J., UTTERBACK, J.M. Patterns of innovation in technology. Technology Review, vol.80, n.7, p. 40-47, 1978.

ADRIANCHERNOFF. General Motors Hy-Wire: Touring Sedan. 2012. Disponível em:< http://www.adrianchernoff.com/pages/HyWire.html>. Acesso em: 04 dez. 2012.

AEROVIRONMENT. 2011. Disponível em:< http://www.avinc.com/>. Acesso em: 05 dez. 2012.

AGARWAL, P. et al. Stir-Lec I: a stirling electric hybrid car. SAE Technical Paper, 1969

AGARWAL, P. The GM high-performance induction motor drive system. IEEE Transactions on Power Apparatus and Systems, vol. PAS-88, n.2, p.86-93, 1969.

AGRUSS, B. Testing batteries for vehicular applications. III. Selection and characterization of a power battery. Journal of Electrochemical Society, vol.117, n.9, p.1207-1210, 1970.

ALABC. ALABC Prospectus 2010-2012. 2012. Disponível em: <http://www.alabc.org/about/prospectus.> Acesso em: 03 dez. 2012.

ALPERT, M. The care \& feeding of engineers. Fortune Magazine, 21 set. 1992. Disponível em: <http://money.cnn.com/magazines/fortune/fortune_archive/1992/09/21/76879/index.htm>. Acesso em: 04 dez. 2012. 
ANDERSON,P. \& TUSHMAN, M. Technological discontinuities and dominant designs: A cyclical model of technological change. Administrative Science Quarterly. vol 35, n.4, p.604-633, 1990.

ARB. Air Resources Board. Key events in the history or Air Quality in California. 2012. Disponível em:<http://www.arb.ca.gov/html/brochure/history.htm>. Acesso em: 04 dez. 2012.

ARENA, J. The little car the did nothing right: The 1972 Lordstown assembly strike, the Chevrolet Veja, and the unravelling of growth economics. 2009. Thesis. History Graduate Program, The Ohio State University, Columbus, 2009.

AUGUSTINE, P. The Clean Air Act: An archetype for dynamic and comprehensive environmental policy. Joint Institute for Energy \& Environment, n. JIEE 2003-05, 2003. Disponível em: < http://isse.utk.edu/pdf/jieepubs/2003_05air.pdf>. Acesso em: 06 dez. 2012.

AUTOCHANNEL. 1997. Disponível em: <http://www.theautochannel.com/ news/press/date/19970429/press002076.html>. Acesso em:04 dez. 2012.

AWM. Air and Waste Management. Honors \& Awards. 2009. Disponível em: < http://events.awma.org/files_original/01-3164-HonorsandAwards-Final09.pdf>. Acesso em: 05 dez. 2012.

BAER, W. et al. Analysis of federally funded demonstration projects. Santa Monica: RAND, 1976. 202p. Final Report. Disponível em: http://www.rand.org/content/dam/rand/pubs/reports/2006/R1926.pdf>. Acesso em: 06 dez. 2012.

BAHBAH, B. The United States and Israel's energy security. Journal of Palestine Studies, vol.11, n.2, p. 113-131, 1982.

BARSNESS, R. The Department of Transportation: Concept and structure. The Western Political Quarterly, vol.23, n.3, p.500-515, 1970. 
BAZERMAN, M. Processo Decisório. 5.ed. Rio de Janeiro: Campus, 2004.

BEARDSLEY, C. Wanted: Superbatteries. IEEE Spectrum, vol.9, n.7, p.42, 1972.

BEKKER, M. G. Accomplishments and future tasks in off-road transportation. Journal of Terramechanics, vol.11, n.2, p.11-30, 1974.

BISH, J. R., TIETMEYER, G. P. Electric vehicle field test experience. IEEE Transactions on Vehicular Technology, vol. 32., n.1, p.81-89, 1983.

BOTSFORD, A., SZCZEPANEK, A. Fast charging vs. slow charging: Pros and cons for the new age of electric vehicles. 2009. Disponível em: <http://www.cars21.com/assets/link/EVS-243960315\%2520Botsford.pdf>. Acesso em: 05 dez. 2012.

BOYD, A. The United States Department of transportation. Proceedings of the IEEE, vol.56, n.4, p.396-401, 1968.

BRADLEY, T. FRANK, A. Design, demonstrations and sustainability impact assessments for plug-in hybrid electric vehicles. Renewable and Sustainable Energy Reviews, vol.13, n.1, p.115-128, 2009.

BRAGA, B. Electric G-Van demonstration and commercial assessment project. Palo Alto: Electric Power Research Institute, 1992. 58p. Final report. Disponível em: <http://www.osti.gov/bridge/purl.cover.jsp?purl=/7037886-6jn1Ly/7037886 .pdf > Acesso em: 05 dez. 2012.

BROOKE, 1. Tip-toeing through the hybrid patents minefield, 14 fev. 2012. SAE International. Disponível em: < http://ev.sae.org/article/10670>. Acesso em: 04 dez. 2012.

BULL, S. Renewable energy today and tomorrow. Proceedings of the IEEE, vol.89, n.8, p.1216-1226, 2001. 
BUNKLEY, N. Robert Stempel, na engineer Who led G.M., dies at 77. The New York Times, New York, 10 maio 2011. Disponível em: <http://www. nytimes.com/2011/05/11/business/11stempel.html?_r=0>. Acesso em: 05 dez. 2012.

BURKE, A., KURANI, K., KEENEY, E. Study of the secondary benefits of the ZEV Mandate. Report for the California Air Resources Board. Institute of Transport Studies, University of California, Davis, 2000.

CABRAL, N. et al. Planejamento e produção de electricidade: Veículo eléctrico e energias renováveis. Relatório. Coimbra: Universidade de Coimbra, 2009. 64p.

CAIRNS, E., ALBERTUS, P. Batteries for electric and hybrid-electric vehicles. Annual Review of Chemical and Biomolecular Engineering, vol.1, p.299-320, 2010.

CALLON, M. The state and technical innovation: a case study of the electrical vehicle in France. Research Policy, vol.9, n.4, p.358-376, 1980.

CALSTART. 2012. Disponível em: < http://www.calstart.org/Homepage.aspx>. Acesso em: 03 dez. 2012.

CCT. Chevrolet Centennial Times. Chevrolet's very own rocket man. 2011. Disponível em: <http://media.gm.com/content/dam/Media/images/Shared/Banner/

Chevrolet/2011/110930_CH_CENT_Newspaper_Schweiz_RZ_low.pdf.> Acesso em: 04 dez. 2012.

CHAN, C. C. The state of the art of electric and hybrid vehicles. Proceedings IEEE, vol 90, n.2, p. 247-275, 2002. Disponível em: http://ieeexplore.ieee.org/xpls/abs_all.jsp?arnumber=989873>. Acesso em: 06 dez. 2012.

CHAN, C., CHAU, K. Modern electric vehicle technology. New York: Oxford University Press Inc., 2001. 
CHANARON, J., TESKE, J. Hybrid vehicles: a temporary step. International Journal of Automotive Technology and Management, vol.7, n.4, p.268-288, 2007.

CHANG, R. New York Auto Show: Da-Da-Daaah...The 'A-Team' Van. The New York Times, New York, 31 mar. 2010. Disponível em: <http://wheels.blogs.nytimes.com/2010/03/31/newyork-auto-show-da-da-daaah-the-a-team-van/> . Acesso em: 05 dez. 2012.

CLARK, K. The interaction of design hierarchies and market concepts in technological evolution. Research Policy, vol.14, n.5, p.235-251, 1985.

COLE, J. The Advanced Lead/Acid Battery Consortium. Journal of Power Sources, vol, 40, n.1-2, p.1-15, 1992.

COLLANTES, G., SPERLING, D. The origin of California's zero emission vehicle mandate. Transportation Research Part A: Policy and Practice, vol.42, n.10, p.1302-1313, 2008.

COOPER, J. E., INGLING, W. Sealed alkaline batteries for space applications. IEEE Transactions on Aerospace, vol.1, n.1, p.34-37, 1963.

COWAN, R., HULTEN, S. Escaping lock-in: The case of the electric vehicle. Technological Forecasting and Social Change, vol.53, n.1, p.61-79, 1996.

DANNEELS, E. The dynamics of product innovation and firm competences. Strategic Management Journal, vol.23, n.12, p.1095-1121, 2002.

DAVIDSON, J. Sloan, Alfred Pritchard, Jr. GM Heritage Center: Generations of GM History, 2007. Disponível em: <http://history.gmheritagecenter.com/wiki /index.php/Sloan,_Alfred_Pritchard,_Jr.>. Acesso em: 04 dez. 2012. 
DDC. Defense Documentation Center. First Quarterly Technical Progress Report on Research and Development of na Advanced Laboratory Liquid Metal Regenerative Fuel Cell for the period 1 March-18 May 1963. 1963. Indianopolis: General Motors CorporationAllison Division 1963b, 112p.

DE GIER, E. Paradise lost revisited: GM and the UAW in historical perspective. Visiting fellow working papers. 2010. Disponível em: <http://digitalcommons.ilr. cornell.edu/intlvf/30/>. Acesso em: 04 dez. 2012.

DEGRASSE, R. Military expansion, economic decline: The impact of military spending on U.S. economic performance. Edição expandida. Armonk: M.E. Sharpe, 1983. Disponível em: < http://www.getcited.org/pub/102291850>. Acesso em: 05 dez. 2012.

DELUCHI, M., WANG, Q., SPERLING, D. Electric vehicles: Performance, life-cycle costs, emissions, and recharging requirements. Transportation Research Part A: General, vol.23, n.3, p.255-278, 1989.

DEWEY, S. The antitrust case of the century: Kenneth F. Hahn and the fight against smog. Southern California Quarterly, vol.81, n.3, p.341-376, 1998 b.

DEWEY, S. Working for the environment: Organized labor and the origins of environmentalism in the United States, 1948-1970. Environmental History, vol.3, n.1, p.45-63, 1998a.

DOE. Department of Energy. A summary history: Department of Energy, 1977-1994, 1994. Disponível em: <http://energy.gov/sites/prod/files/maprod/ documents/Summary_History.pdf>. Acesso em: 04 dez 2012.

DOE. Department of Energy. Electric and hybrid vehicles program. Relatório Washington, 1993. 72p. Disponível em: <http://www.afdc.energy.gov /pdfs/2466.pdf>. Acesso em: 05 dez. 2012. 
DOE. Department of Energy. U.S. Federal investments in energy R\&D:1961-2008. Relatório. Richland Washington: Pacific Northwest National Laboratory, 2008b. 19p.

DOE. Department of Energy. Linkages of DOE's Energy Storage R\&D to batteries and Ultracapacitors for Hybrid, Plug-in Hybrid, and Electric Vehicles: relatório. Albuquerque: Sandia National Laboratories, 2008a, 142p

DOSI, G., NELSON, R. An introduction to evolutionary theories in economics. Journal of Evolutionary Economics, vol.4, n.3, p.153-172, 1994.

DOSI, G., NELSON, R. Technical change and industrial dynamics as evolutionary processes. LEM Working papers. Laboratory of Economics and Management Sant 'Anna School of Advanced Studies, 2009.

DOUGLAS, D., BIRK, J. Secondary batteries for electrical energy storage. Annual reviews, vol.5, p.61-88, 1980 .

DOZ, Y., PRAHALAD, C. Patterns of strategic control within multinational corporations. Journal of International Business Studies, vol.15, n.2, Special Issue on Strategic Planning, Autonomy and Control Processes in Multinational Corporations, p.55-72, 1984.

DRDOGMC. Delco-Remy Division of General Motors Corporation. Feasibility studies of the electrothermally regenerative transducer: Relatório técnico Cincinnati: Army Tank Automotive Center. 1964. p.92. Department of the Army Project n.518-01-001

DRESSELHAUS, M. S., THOMAS, I. L. Alternative energy technologies: Materials for clean energy. Nature, vol. 414, n. 6, p.332-337, 2001.

EISENHARDT, K. M. Building theories from case study research. Academy of Management Review, vol. 14, n.4, p.532-550, 1989. 
EPA. Environmental Protection Agency. EPA History. 2012. Disponível em:< http://www.epa.gov/aboutepa/history/index.html>. Acesso em: 06 dez. 2012.

ESTADOSUNIDOS. Electric vehicle research, development and demonstration act of 1975: Hearings before the subcommittee on energy research, development and demonstration of the committee on Science and Technology U.S. House of representatives. Washington: U.S. Government Printing Office, 1975. 1156p. First session on H.R. 5470, n.27, June 3, 4, 5, 6, 1975.

FIALKA, J. GM's long, hard, bumpy Road to the Chevrolet Volt, 10 jul. 2009. The New York Times. Disponível em: <http://www.nytimes.com /cwire /2009 /07/10/10climatewire-gms-longhard-bumpy-road-to-the-chevrolet-vo-40366. html?pagewanted=all>. Acesso em: 04 dez. 2012.

FINKELSTEIN, S. GM and the great automation solution. Business Strategy Review, vol.14, n.3, p.18-24, 2003.

FLINK, J. Innovation in automotive technology: After a long interval of stagnation, automotive technology may be entering a period of renewed creativity. American Scientist, vol.73, n.2, p.151-161, 1985.

FLUITER, T. Design of lightweight electric vehicles. 2008. Tese - The University of Waikato, Hamilton, 2008. Disponível em: <http://en.scientificcommons.org/56431710>. Acesso em: 05 dez. 2012.

FRANCFORT, J. et al. Site operator program final report for fiscal years 1992 through 1996. Idaho Falls, 1998. 93p. Disponível em: < http://www1.eere.energy.gov/vehiclesandfuels/avta/pdfs/prog_info/final.pdf $>$. Acesso em: 05 dez. 2012.

FREYSSENET, M. The second automobile revolution. Londres: Palgrave Macmillan, 2009. 
GAGNON, S. Strategic challenges in developing electric vehicles: a literature review. International Journal of Vehicle Design, vol.21, n.1, p.89-109, 1999.

GARUD, R., GEHMAN, J. Metatheoretical perspectives on sustainability journeys: Evolutionary, relational and durational. Research Policy, vol.41, n.6, p.980-995, 2012.

GARVEY, C. Electric autos and clean air. 1980. Disponível em: < http://heinonline.org/HOL/Page?handle=hein.journals/epajrnl6\&div=156\&g_sent=1\&collection= journals>. Acesso em: 05 dez. 2012.

GATHRIGHT, A. California recharging electric-car drive. Chicago Tribune, Chicago, 01 Apr .1990. Disponível em:< http://articles. Chicagotribune .com/1990-0401/travel/9001260700_1_ev-development-electric-vehicles-los-angeles-city-power>. Acesso em: 05 dez. 2012.

GEELS, F. Technological transitions as evolutionary reconfiguration processes: a multi-level perspective and a case-study. Research Policy, vol.31, n.8-9, p.1257-1274, 2002.

GEELS, F. The hygienic transition from cesspools to sewer systems (1840-1930): The dynamics of regime transformation, Research Policy, vol.35, n.7, p.1069-1082, 2006.

GEELS, F., SCHOT, J. Typology of sociotechnical transition pathways, Research Policy, vol.36, n.3, p.399-417, 2007.

GEORGE, A., BENNET, A. Case studies and theory development in the social science. Londres: MIT Press, 2005.

GERARD, D., LAVE, L. Implementing technology-forcing policies: The 1970 Clean Air Act Amendments and the introduction of advanced automotive emissions controls in the United States. Technological Forecasting and Social Change, vol.72, n.7, p.761-778, 2005. 
GERSSEN-GONDELACH, S., FAAIJ, A. Performance of batteries for electric vehicles on short and longer term. Journal of Power Sources, vol. 212, p.111-129, 2012.

GILPIN, R. Three models of the future. International Organization, vol.29, n.1, p.37-60, 1975. GMC. General Motors Corporation. 1989. Disponível em:< http://www.gm heritagecenter.com/gm-heritage-archive/docs/G-Van/1990-Chevrolet-G-Van.pdf> Acesso em: 05 dez. 2012.

GMHERITAGECENTER. Stempel, Robert. 2012. Disponível em:< http://history .gmheritagecenter.com/wiki/index.php/Stempel,_Robert_C.>. Acesso em: 05 dez. 2012.

GODIWALlA, Y. Corporate planning and the chief executive. Long Range Planning, vol.12, n.2, p.2-15, 1979.

GOKLANY, I. Clearing the air: the real story of the war on air pollution. Washington: Cato Institute, 1999.

GOMEZ-IBANEZ, J., HARRISON JR., D. Imports and the future of the U.S. automobile industry. The American Economic Review, vol.72, n.2, p.319-323, 1982.

HAAGEN-SMIT. A lesson from the smog capital of the world. Proceedings of the National Academy of Science, vol.67, n.2, 1970.

HAMMES, D., WILLIS, D. Black gold: the end of Bretton Woods and the oil-price shocks of the 1970s. The Independent Review, vol.9, n.4, 2005.

HARBORNE, P., HENDRY, C. Pathways to commercial wind power in the US, Europe and Japan: The role of demonstration projects and field trials in the innovation process. Energy Policy, vol.37, n.9, 2009. 
HEIMANN, H. The air pollution problem in the United States. Proceedings of the Royal Society of Medicine, vol.57, n.10 pt 2, p.1000-1005, 1964.

HENDERSON, R. \& CLARK, K. Architectural innovation: the reconfiguration of existing product technologies and the failure of established firms. Administrative Science Quarterly, vol.35, n.1, p.9-30, 1990.

HEYWOOD, J. et al. The role for Federal R\&D on alternative automotive power systems. Report to the Office of Energy R\&D Policy, National Science Foundation, 1974.

HIETBRINK, E., et al. Dual battery electric powerplant. SAE. Technical Paper, 1971.

HIGGS, R. The Cold War economy: Opportunity costs, ideology, and the politics of crisis. Explorations in Economic History, vol.31, n.3, p.282-312, 1994.

HILL, C., UTTERBACK, J. Technological innovation for a dynamic economy. Pergamon Press, 1979.

HOLZMAN, D. A driving force. Environmental Health Perspectives, vol.105, n.6, p.582-587, 1997. Disponível em: < http://www.ncbi.nlm.nih.gov/pmc /articles/PMC1470067/>. Acesso em: 05 set. 2012.

HOYER, K.G. The history of alternative fuels in transportation: the case of electric and hybrid cars. Utilities Policy, vol.16, n. 2, p.63-71, 2008.

HULTIN, J. "Unions, the environment and corporate social responsibility". Yale Review of Law and Social Action, 1972. Disponível em: http://heinonline.org/HOL/Page?handle=hein.journals/yrlsa3\&div=9\&g_sent=1\&collection=jour nals>. Acesso em: 06 dez. 2012. 
ISSEL, W. "Land values, human values, and the preservation of the city's treasured appearance": Environmentalism, politics, and the San Francisco freeway revolt. Pacific Historical Review, vol.68, n.4, p. 611-646, 1999.

JACKSON, D. The history of Delco Remy Divsion of General Motors: The plants, $2012 \mathrm{~b}$. Disponível em: < http://www.delcoremyhistory. com/theplants. htm>. Acesso em: 04 dez. 2012.

JACKSON, D. The history of the Delco-Remy Divsion of General Motors: The products, 2012a. Disponível em: <http://oai.dtic.mil/oai/oai?verb=getRecord\& metadataPrefix $=$ html\&identifier=ADA313302> . Acesso em: 04 dez. 2012.

JOHN J. Lander 1918-2000. People News - The Electrochemical Society, 2000. Disponível em: $<$ http://www.electrochem.org/dl/interface/wtr/wtr00/IF12-00-Page16.pdf >. Acesso em: 04 dez 2012.

KALHAMMER, F. et al. Status and prospects for zero emissions vehicle technology. Relatório. 2007. 207p. Disponível em: <http://arb.ca.gov/msprog/zevprog/ zevreview/zev_panel_report.pdf>. Acesso em: 05 dez. 2012.

KALM, E. Design of an aerodynamic green car. 2007. Master Thesis - Ergonomic Design \& Production Engineering, Lulea University of Technology, Lulea, 2007.

KEMPTON, W., TOMIC, J. Vehicle-to-grid power implementation: From stabilizing the grid to supporting large-scale renewable energy. Journal of Power Sources, vol. 144, n.1, p.280-294, 2005.

KENNEDY, H. Legislative and regulatory action in air pollution control. Public Health Reports, vol.78, n.9, p.799-806, 1963.

KILliAN, J. Sputnik, Scientists, and Eisenhower - A memoir of the First Special Assistant to the President for Science and Technology. Cambridge: The MIT Press, 1982. 
KLIER, T. From tail fins to hybrids: How Detroit lost its dominance of the U.S. auto market. Economic Perspectives, vol.33, n.2, 2009.

KOERNER, E. Technology planning at General Motors. Long Range Planning, vol.22, n.2, p.9$19,1989$.

KURYLKO, D. Corvair gave Nader a ride to prominence. Disponível em: < http://www.autonews.com/article/20111031/CHEVY100/111029892>. Acesso em: 04 dez. 2012.

KWOKA JR., J. Market power and market change in the U.S. automobile industry. The Journal of Industrial Economics, vol.32, n.4, p.509-522, 1984.

LALL, S. The international automotive industry and the developing world. World Development, vol.8, n.10, p.789-812, 1980.

LANNING, P. Sparkside of the moon with Chevrolet.. The Sun. Londres, 02 nov. 2011. Disponível em: < http://www.thesun.co.uk/solhomepage/motors/phil_lanning/3908382/.html>. Acesso em: 04 dez. 2012.

LARRUE, P. "Lessons learned from the Californian ZEV Mandate: From a 'TechnologyForcing' to a 'Market-Driven' regulation. Bordeaux and Toulouse: Groupement de Recherches Economiques et Sociales, 2003. Disponível em: < http://cahiersdugres.ubordeaux4.fr/2003/2003-07.pdf>. Acesso em: 02 fev. 2012.

LAVRAKAS, P., Encyclopedia of survey research methods. $1^{a}$ Ed.Vol.I. Thousand Oaks: SAGE Publications, 2008.

LEE, J. et al. Forcing technological change: A case of automobile emissions control technology development in the US. Technovation, vol.30, n.4, p.249-264, 2010. 
LICKLIDER, R. The power of oil: The arab oil weapon and the Netherlands, the United Kingdom, Canada, Japan, and the United States. International Studies Quarterly, vol.32, n.2, p.205-226, 1988.

LINDEN, L. et al. Federal support for the development of alternative automotive power systems: The general issue and the stirling, diesel, and electric cases. Cambridge: MIT, 1976. 380p. Report MIT-EL 76-014. Disponível em: < http://www.osti.gov/energycitations/product.biblio. jsp?osti_id=7108041>. Acesso em: 06 dez. 2012.

LINFORD, H. Power systems for electric vehicles. Environmental Science and Technology, vol.1, n.5, p.394-399, 1967.

LOWE, M. et al. Lithium-ion batteries for batteries for electric vehicles: the U.S. value chain. Disponível em: <http://www.cggc.duke.edu/pdfs/Lowe_Lithium-Ion_Batteries_CGGC_10-0510_revised.pdf >. Acesso em: 01-12-2012.

LYNCH, D. The Calstart consortium. IEEE Spectrum, vol.30, n.7, p.54-57, 1993.

LYNN, G. S. et al. Marketing and discontinuos innovation: the probe and learn process. California Management Review. vol 38, n 3, p.8-37, 1996.

MACCREADY, P. Sunraycer odyssey. Engineering \& Science, vol.51, n.2, p.3-15, 1988.

CEEETA. Tecnologias de micro-geração e sistemas periféricos: Motores de êmbolos. Disponível em:< http://www.marioloureiro.net/tecnica/energProdu/ MotoresCEEETA.pdf>. Acesso em: 04 $\operatorname{dez} 2012$.

MARKS, C. et al. A. Electrovan: a fuel cell powered vehicle SAE Technical Paper, 1967. 
MASSEY, D. The foundation of United States security assistance to Egypt: 1969-1979. Master Thesis.. Air Force Institute of Technology. 2005. Disponível em:< http://oai.dtic.mil/oai/oai?verb=getRecord\&metadataPrefix=html\& identifier=ADA300667>. Acesso em: 04 dez. 2012.

MAZUR, A., LEE, J. Sounding the global alarm: environmental issues in the US national news. Social Studies of Science, vol.23, n.4, p.681-720, 1993.

MCGRATH, R. Making na Impact at General Motors. Journal of STEM Education: Innovations and Research, vol.1, n.2, 2000.

MECHTENBERG, A. Understanding the importance of an energy crisis. 2009. Ph.D. Thesis (Applied Physics). University of Michigan, Michigan, 2009. Disponível em:<http://wwwpersonal.umich.edu/ amechten/Abigail. Mechtenberg.Ch3.Thesis.pdf $>$. Acesso em: 05 dez. 2012.

MELOSI., M. Automobile in American life and society: The automobile and the environment in $\begin{array}{llll}\text { american history. } & \text { Disponível } & \text { em:tp://www.autolife. }\end{array}$ umd.umich.edu/Environment/E_Overview/E_Overview.htm>. Acesso em: 04 dez. 2012.

MEYER, D. A brief outline of the first century of GMC Truck history. 2008. Disponível em:< http://history.gmheritagecenter.com/wiki/index.php/A_Brief_

Outline_of_the_First_Century_of_GMC_Truck_History>. Acesso em: 05 dez. 2012.

MILLER, A. S. Energy policy from Nixon to Clinton: From grand provider to market facilitator. 25 Envtl. L. 715, 1995.

MINTZ, M., COHEN, J. America S.A Os donos secretos do poder. Rio de Janeiro: Artenova, 1971 
MORALES, R. et al. Prospects for alternative fuel vehicle use and production in Southern California: Environmental quality and economic development. UCLA Lewis Center for Regional Policy Studies, working paper n.2, 1991. Disponível em:< http://trid.trb.org/view.aspx?id=618625>. Acesso em: 06 dez. 2012.

MOSELEY, P. Research results from the Advanced Lead-Acid Battery Consortium point the way to longer life and higher specific energy for lead/acid electric-vehicle batteries. Journal of Power Sources, vol.73, n.1, p.122-126, 1998.

MURMANN, J., FRENKEN, K. Toward a systematic framework for research on dominant designs, technological innovations, and industrial change. Research Policy, vol. 35, n. 7, p. 925952, 2006.

NAIC. National Air Intelligence Center. Application of Error Compensation Technology of Inertial Instruments in Improvement of Strategic Ballistic Missile Accuracy. Disponível em:< http://oai.dtic.mil/oai/oai?verb=getRecord\& metadataPrefix $=$ html\&identifier=ADA313302> . Acesso em: 04 dez. 2012.

NASA. National Aeronautic and Space Administration. A brief history of the Lunar roving vehicle. Huntsville: Marshall Space Flight Center. 2002. 27p. Disponível em:< http://history.nasa.gov/alsj/MSFC-LRV.pdf>. Acesso em 04 dez. 2012.

NASA. National Aeronautic and Space Administration. Development of a brushless dc motor for satellite application. Relatório técnico. Washington: Goddard Space Flight Center. 1964. $15 \mathrm{p}$. Disponível em:< http://ntrs.nasa.gov/archive/nasa/casi.ntrs.nasa.gov/19640005994_1964005994.pdf>. Acesso em: 05 dez. 2012.

NASA. National Aeronautic and Space Administration. Electric vehicle battery research and development. Relatório técnico. Cleveland: Lewis Research Center. 1973b. 18p. Disponível em:< http://ntrs.nasa.gov/archive/nasa/casi.ntrs.nasa.gov/19740002833_1974002833.pdf>. Acesso em: 05 dez. 2012. 
NASA. National Aeronautic and Space Administration. Historical review of stirling engine development in the United States from 1960 to 1970. Relatório técnico. Rochester: NASA Scientific and Technical Information Facility, 1974. 130p. Report n. NASA CR-121097.

NASA. National Aeronautic and Space Administration. New batteries and their impact on electric vehicles. Relatório técnico. Cleveland: Lewis Research Center. 1977. 16p. Disponível em:< http://ntrs.nasa.gov/archive/nasa/casi. ntrs.nasa.gov/19770019670_1977019670.pdf>. Acesso em: 05 dez. 2012.

NASA. National Aeronautics and Space Administration. Progress on advanced dc and ac induction drives for electric vehicles. Relatório técnico. Cleveland: Lewis Research Center, 1982. 18p. Disponível em:< http://www.osti.gov/ energycitations/product.biblio.jsp?osti_id=5042530>. Acesso em: 05 dez. 2012.

NASA. National Aeronautics and Space Administration. Space Power Tools. Relatório técnico. Huntsville: George C. Marshall Space Flight Center. 1968. 24p. Disponível em:< http://ntrs.nasa.gov/archive/nasa/casi.ntrs.nasa.gov/19680026294_1968026294.pdf>. Acesso em: 04 dez. 2012.

NASA. National Aeronautics and Space Administration. Traction drive system design considerations for a lunar roving vehicle. Relatório técnico. Hunstsville: George C. Marshall Space Flight $\quad$ Center. $1969 . \quad 35 \mathrm{p} . \quad$ Disponível em:< http://ntrs.larc.nasa.gov/search.jsp?R=19700009492\&qs=N\%3D4294957355\%26Nn\%3D429472 4807\%257CSubject\%2BCategory\%257CLAUNCH\%2BVEHICLES\%2BAND\%2BSPACE\%2B VEHICLES>. Acesso em: 06 dez. 2012.

NELSON, R., WINTER, S. An evolutionary theory of economic change. Cambridge: Harvard University Press, 1982. 
NELSON, R., WINTER, S. In search of useful theory of innovation. Research Policy, vol.6, n.1, p.36-76, 1977.

NELSON, R., WINTER, S. Neoclassical vs. evolutionary theories of economic growth: Critique and prospectus. The Economic Journal, vol.84, n.226, p.886-905, 1974.

NOTH, A. Design of solar powered airplanes for continuous flight. 2008. Dissertation Ecole Polytechnique Fedérale de Lausanne, Zurich, 2008.

NRC. NATIONAL RESEARCH COUNCIL. Review of the Research and Development Plan for the Office of Advanced Automotive Technologies. relatório. Washington: National Academy Press, 1998, 71p.

ORHAN, M. et al., Integrated hydrogen production options based on renewable and nuclear energy sources. Renewable and Sustainable Energy Reviews, vol.16, n.8, p.6059-6082, 2012.

PATIL, P. Prospects for electric vehicles. IEEE Aerospace and Electronic Systems Magazine, vol.5, n.12, p.15-19, 1990.

PAULSEN, R. The role of US Nuclear Weapons in the Post-Cold War Era. Air Force Historical Foundation, $1994 . \quad$ Disponível em:< http://oai.dtic.mil/oai/oai?verb=getRecord\&metadataPrefix=html\&identifier=ADA288446> . Acesso em: 06 dez. 2012.

PENNA, C., GEELS, F. Multi-dimensional struggles in the greening of industry: A dialectic issue lifecycle model and case study. Technological Forecasting and Social Change, vol. 79, n.6, p.999-1020, 2012.

PERRY, O. Before the EV-1 came the Impact. Eastern Electric Vehicle Club, vol.30, n2., 2010. 
PILKINGTON, A., DYERSON, R. Extending simultaneous engineering: electric vehicle supply chains and new product development. International Journal of Technology Management, vol.23, n.1-3, p.74-88, 2002.

PINKSE, J., BOHNSACK, R., KOLK, A. Can incumbents be disruptive innovators? The automotive industry and the emergence of low-emission vehicles. $2^{\text {nd }}$ International Conference on Sustainability Transitions, Lund, Sweeden, 2011.

PRNEWSWIRE. Disponível em:< http://www.prnewswire.com/news-releases/kenneth-r-bakerjoins-ecd-as-vice-chairman-and-coo-73520832.html>. Acesso em: 05 dez. 2012.

RAHM, D. US public policy and emerging technologies: The case of solar energy. Energy Policy, vol.21, n.4, p.374-384, 1993.

RAJASHEKARA, K. History of electric vehicles in General Motors, IEEE Transactions on Industry Applications, vol. 30, n.4, p.897-904, 1994.

RAND, D. Battery systems for electric vehicles - a state of-the-art review. Journal of Power Sources, vol.4, n.2, p.101-143, 1979.

RAUGEI, M. et al. The energy return on energy investment (EROI) of photovoltaics:

Methodology and comparisons with fossil fuel life cycles. Energy Policy, vol.45, n.C, p. 576$582,2012$.

REEVES, R. President Nixon: Alone in the White House. New York: Simon \& Schuster, 2001.

RISHAVY, E.; et al. Electrovair: a battery electric car. SAE Technical Paper, 1967

SALIHI, J. et al. Induction Motor Control Scheme for Battery-Powered Electric Car (GMElectrovair I). IEEE Transactions on Industry and General Applications, vol.IGA-3, n.5, p.463-369, 1967. 
SANDALOW, D. Plug-in electric vehicles: what role for Washington? Washington: The Brookings Institution, 2009.

SARAVANAN, K. et al. Recent trends in renewable energy resources hydrogen fuel cell. International Conference on Advances in Engineering, Science and Management (ICAESM), p.586-589, 2012.

SCHOT, J. et al. Strategies for shifting technological systems: The case of the automobile system. Futures, vol.26, n.10, p.1060-1076, 1994.

SCHOT, J., GEELS, F. Strategic niche management and sustainable innovation journeys: theory, findings, research agenda, and policy. Technology Analysis and Strategic Management, vol.20, n.5, p.537-554, 2008.

SHABECOFF, P. Reagan order on cost-benefit analysis stirs economic and political debate. New York Times. New York, 07 Nov. 1981. Disponível em:< http://www.nytimes.com/1981/11/07/us/reagan-order-on-cost-benefit-analysis-stirs-economicand-political-debate.html?pagewanted=all>. Acesso em: 01-12-2012.

SHNAYERSON, M. The car that could: the inside story of GM's revolutionary electric vehicle. $1^{\text {a }}$ Ed. New York: Random House, 1996.

SLABIAK, W., LAWSON, L. Precise control of a three-phase squirrel-cage induction motor using a practical cycloconverter. IEEE Transactions on Industry and General Applications, vol.IGA-2, n.4, p.274-280, 1966.

SLABIAK, W.; COLLINS, G. Brushless synchronous propulsion motor. SAE Technical Paper, 1968.

SLANGEN, L., LOUCKS, L., SLANGEN, A. Institutional economics and economic organization theory. Wageningen Academic Publishers, 2008. 
SPERLING, D., CANNON, J. The hydrogen energy transition: Cutting carbon from transportation. Burlington: Elsevier Academic Press, 2004.

STEMPEL, R. et al. Nickel metal hydride: ready to serve. IEEE Spectrum, vol.35, n.11, p.2934, 1998.

STINE, D. The Manhattan Project, the Apollo Program and Federal Energy Technology R\&D Programs: A comparative analysis. Congressional Research Service, 2009.

STORPER, M. SCOTT, A. The wealth of regions: Market forces and policy imperatives in local and global context. Futures, vol.27, n.5, p.505-526, 1995.

STROBBE, C. Potentially destabilizing effects of islamic fundamentalism on U.S. aid to Jordan. 1985. Tese. Air Force Institute of Technology, Air University, Dayton, 1985.

SUAREZ, F. F. Battles for technological dominance: na integrative framework, Research Policy, vol. 33, n.2, p. 271-286, 2004.

SUAREZ, F.F., UTTERBACK, J. Dominant designs and the survival firms. Strategic Management Journal, vol. 16, n.6, p. 415-430, 1995.

SYMONS, P., BUTLER, P. Advanced batteries for electric vehicles and emerging applications - introduction. In. D. Linden, T.B. Reddy Eds. Handbook of Batteries, 3. Ed. New York: McGraw-Hill, 2002, Chapter 37, p.37.1-37.25.

TARTAKOVSKY, L. et al. Energy analysis of ethanol steam reforming for hybrid electric vehicle. International Journal of Energy Research, 2011. Disponível em:< http://onlinelibrary.wiley.com/doi/10.1002/er.1908/full>. Acesso em: 06 dez. 2012. 
THE ELECTRIC VEHICLE: the evolution of GM's electric vehicles. Bedfordshire: Vauxhall Education Service, n.5, 2001. Disponível em:<http://www.docstoc.com/docs/11535306/EV1Electric-Car>. Acesso em: 18 fev. 2011.

TUOHK. The University of Hong Kong. 2010. Disponível em:< http://engg.hku.hk/home/people/ccchan/ccchan.htm>. Acesso em: 05 dez. 2012.

UNOOSA. United Nations Office for Outer Space Affairs. Seminars of The United Nations Programme on Space Applications, 2004, n.26E. Disponível em:< http://www.unoosa.org/pdf/publications/st_space_26E.pdf>. Acesso em: 04 dez. 2012

UOM. University of Michigan. 2012b. Disponível em: $<$ http://www.mgoblue.com/sports/mclub/mtt/mader_jerry00.html>. Acesso em: 05 dez. 2012.

UOM. University of Michigan. Kenneth R. Bakker, 2012. Disponível em:< http://www.engin.umich.edu/ead/blos/baker_k.html>. Acesso em:04 dez. 2012.

UOMSC. University of Michigan Solar Car. 2005. Disponível em:< http://solarcar.engin.umich.edu/pastteams/momentum/races/wsc.html>. Acesso em: 05 dez. 2012.

URBAN, G., WEINBERG, B.; HAUSER, J. Premarket forecasting of really-new products. Journal of Marketing, vol.60, n.1, p.47-60, 1996.

USDEW. U.S. Department of Health, Education, and Welfare. Public Health Reports. Disponível em:< http://www.ncbi.nlm.nih.gov/pmc/articles/ PMC1914654/pdf/pubhealthreporig000870003.pdf>. Acesso em: 04 dez. 2012.

USDOT. U.S. Department of Transportation. A chronology of dates significant in the background, history and development of the Department of Transportation. Disponível em:< http://ntl.bts.gov/historian/chronology.htm>. Acesso em: 04 dez. 2012 
UTTERBACK, J. \& ABERNATHY, W. A dynamic model of process and product innovation . Omega, vol 3, n. 6, p.639-656, 1975.

UTTERBACK, J. Mastering the dynamics of innovation: How companies can seize opportunities in the face of technological change. $1^{\mathrm{a} E d}$. Boston: Harvard Business School Press, 1996.

VALES-DAPENA, P. GM's long road back to electric cars. CNNMoney, 7 de Abril de 2009. Disponível em:< http://money.cnn.com/galleries/2008/autos/0809/gallery.gm_electric_cars/index.html>. Acesso em: 04 dez. 2012.

VERYZER JR. R.W. Discountinuous innovation and the new product development process. Journal of Product Innovation Management, vol.15, n.4, p.304-321, 1998.

VINSEL, L. Federal regulatory management of the automobile in the United States, 19661988. Ph. D. Tese - Faculty of the College of Humanities and Social Sciences, Carnegie Mellon University, $\quad$ Pittsburgh, $2011 . \quad$ Disponível em:< http://www.thecre.com/pdf/20111222_Vinsel_Dissertation.pdf>. Acesso em: 04 dez. 2012.

VOLLENBROEK, F. Sustainable development and the challenge of innovation. Journal of Cleaner Production, vol.10, n.3, p.215-223, 2002.

WARDSAUTO. U.S. Vehicle Sales Market Share by Company, 1961-2011. 2012. Disponível em <http://wardsauto.com/keydata/historical/UsaSa28summary>. Acesso em 30 maio 2012.

WEBSTER, W., YAO, N. Progress and forecast in electric vehicle batteries. IEEE Vehicular Technology Conference, vol.30, p.221-227, 1980. 
WEINSTOCK, I. Recent advances in the US Department of Energy's energy storage technology research and development programs for hybrid electric and electric vehicles. Journal of Power Sources, vol.110, n.2, p.471-474, 2002.

WESTBROOK, M. The electric and hybrid electric car. Londres: SAE International and Institution of Electrical Engineers, 2001.

WETMORE, J. Driving the dream: The history and motivations behind 60 years of Automated Highway Systems in America. Automotive History Review, p.4-19, 2003. Disponível em:< http://cspo.org/documents/article_Wetmore-DrivingTheDream.pdf. Acesso em: 06 dez. 2012.

WINTER, M., BRODD, R. What are batteries, fuel cells, and supercapacitors? Chemical Reviews, vol.104, n.10, p.4245-4269, 2004.

WITHERSPOON, R. A mechanically rechargeable 1-KW Zinc-Air Battery. SAE Technical Paper, 1969. Disponível em:< http://papers.sae.org/690204/>. Acesso em: 05 dez. de 2012. WOUK, V. Hybrid electric vehicles, Scientific American, vol.277, n.4, p.70-74, 1997.

WYCZALEK, F. A. Heating and cooling battery electric vehicles-the final barrier. IEEE Aerospace and Electronic Systems Magazine, vol.8, n.11, p.9-14, 1993.

YIN, R. Estudo de caso: planejamento e métodos. 3ª . Ed. Rio de Janeiro: Bookman, 2005.

YU, A. et al. Electric vehicles: Struggles in creating a market. Proceedings of PICMET 2011. Disponível em: $<$ http://ieeexplore.ieee.org/xpls/abs_all.jsp?arnumber=6017911\&tag=1>. Acesso em 07 jul. 2012. 